Rev. 0

\title{
CLOSURE OF HLW TANKS - PHASE 2 FULL SCALE COOLING COILS GROUT FILL DEMONSTRATIONS
}

\author{
E. K. Hansen and A. D. Cozzi \\ Savannah River National Laboratory \\ And \\ J. M. Harden, \\ Clemson Engineering Technologies Laboratory
}

June 2008

Process Science and Engineering

Savannah River National Laboratory

Aiken, SC 29808

Prepared for the U.S. Department of Energy Under Contract Number 


\section{DISCLAIMER}

This report was prepared by Washington Savannah River Company (WSRC) for the United States Department of Energy under Contract No. DE-AC09-96SR18500 and is an account of work performed under that contract. Neither the United States Department of Energy, nor WSRC, nor any of their employees makes any warranty, expressed or implied, or assumes any legal liability or responsibility for the accuracy, completeness, or usefulness, of any information, apparatus, or product or process disclosed herein or represents that its use will not infringe privately owned rights. Reference herein to any specific commercial product, process, or service by trademark, name, manufacturer or otherwise does not necessarily constitute or imply endorsement, recommendation, or favoring of same by WSRC or by the United States Government or any agency thereof. The views and opinions of the authors expressed herein do not necessarily state or reflect those of the United States Government or any agency thereof.

\section{Printed in the United States of America}

Prepared For

U.S. Department of Energy 
Key Words: Tank Closure Full Scale Test Grout Fill Cooling Coils

Retention: Permanent

\title{
CLOSURE OF HLW TANKS - PHASE 2 FULL SCALE COOLING COILS GROUT FILL DEMONSTRATIONS
}

\author{
E. K. Hansen and A. D. Cozzi \\ Savannah River National Laboratory \\ And \\ J. M. Harden, \\ Clemson Engineering Technologies Laboratory
}

June 2008

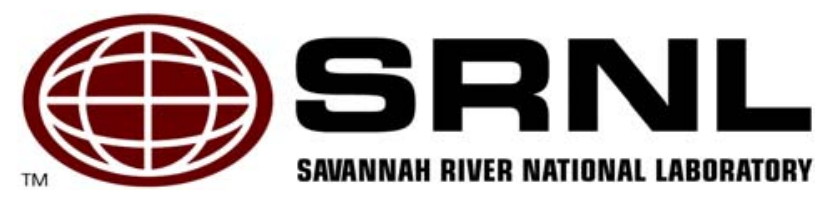




\section{REVIEWS AND APPROVALS}

\section{AUTHORS:}

E. K. Hansen, SRNL, Engineering Process Development

Date

A. D. Cozzi, SRNL, Stabilization Science Research

Date

J. M. Harden, Clemson Engineering Technologies Laboratory

Date

TECHNICAL REVIEWERS:

J. R. Harbour, SRNL, Stabilization Science Research

Date

\section{APPROVERS}

D. A. Crowley, SRNL, Manager, Stabilization Science Research

Date

J. C. Griffin SRNL, Manager, E \& CPT Research Programs

Date

B. J. Adkins, Liquid Waste Technology Development Engineering

Date

M. J. Mahoney, Manager, Liquid Waste Technology Development Engineering Date 


\section{EXECUTIVE SUMMARY}

The Tank Closure and Technology Development group is developing a strategy for closing the high level liquid waste tanks at the Savannah River Site (SRS). The current concept for closing tanks equipped with cooling coils is to fill the cooling coil assemblies with grout to prevent pathways for infiltrating water into the tank after tank closure.

This report provides the documentation for the second of two phases of testing performed by the Savannah River National Laboratory (SRNL). In the first phase, SRNL developed a grout formulation that fulfills the processing and performance assessment (PA) requirements for filling the cooling coil assemblies [5]. The composition of the dry components of the recommended grout by mass is 10\% grade 100 blast furnace slag and 90\% Masterflow (MF) 816 cable grout. The combination of the dry components is typically called the premix. SRNL recommended that the premix be blended into water at a water to premix mass ratio of 0.33 .

In the second phase of testing, documented in this report, SRNL was asked to meet two main objectives. The objectives were to perform a demonstration test to assess cooling coil grout performance in simulated field conditions and to measure relevant properties of samples prepared under simulated field conditions. SRNL successfully met both of these objectives by performing full-scale tests using the recommended grout formulation.

To conduct this second phase of testing, SRNL designed, fabricated, assembled, and tested both vertical cooling coil and horizontal cooling coil configurations. In both cases, the cooling coil assemblies were completely filled with water prior to filling them with grout. Based on the visual observations made during the filling of the cooling coil assemblies with water, SRNL recommends that the cooling coil assemblies for the actual HLW tanks also be filled with water prior to introducing the grout. The equipment used to prepare and transport the grout was commercially available. The operating conditions for the two different assemblies were different, because the experience gained after successfully filling the vertical cooling coil assembly was used to improve the operation for filling the horizontal cooling coil assembly. The vertical cooling coil assembly was filled using individual batches of grout to fill the assembly. The equipment used to mix and transport the grout had many paths for air entrainment. The air predominately ended up in the horizontal sections of the filled vertical cooling coil assembly. To reduce air entrainment for the horizontal cooling coil assembly test, multiple grout batches were placed into a single mixing tank to make a single large batch and the suction to the pump was enclosed. The horizontal cooling coil assembly was successfully filled, with much less observable air voids. Visually, there was much less than four volume percent void space in all of the process lines for both the vertical and horizontal cooling coil assemblies, with the exception of the horizontal supply line for the vertical cooling coil assembly. The process changes made between the vertical and horizontal cooling coil assembly tests reduced air entrainment in the horizontal cooling coil assembly test.

Process flow and pressure measurements were obtained during the filling of both cooling coil assemblies. In the vertical assembly, in-situ temperature measurements were also electronically recorded for un-insulated and insulated piping. Field flow cone measurements were performed to verify that the grout was flowable, prior to processing. Samples from both the vertical and 
horizontal cooling coil assemblies were obtained and analyzed for weight percent water content and density. Process and sample data showed that approximately 35 gallons of excess grout was required to flush out the grout/water mixing zone such that the assembly was completely filled with the batched grout.

Based on the temperature measurements, there is a significant temperature rise in the curing grout for the insulated piping as compared to the un-insulated piping. In the test facility, there was active air flow, constantly removing the heat generated during the curing process. For the actual filling of SRS waste tanks, the methodology for placement of grout into the cooling coil assemblies and into the tank will need to take into consideration the heat transfer requirements such that the grout does not exceed its boiling temperature.

Prior to pumping the recommended grout into the horizontal cooling coil assembly, the grout was mixed for up to 1.25 hours without any visually observable changes in rheological properties, thus confirming an excellent working time. The working time of this grout is most likely greater than 1.25 hours, based on the observation that air bubbles had risen through the grout after the grout had been placed. This observation indicates that there would be some time available to fix a potential equipment failure that might occur during the filling of the cooling coils. Additional testing would be required to determine the amount of time that is available before flushing of the cooling coil piping would be required.

Additional observations and recommendations from the filling of the vertical and horizontal cooling coil assemblies can be found in the Conclusion and Recommendation sections in this report. This report fulfills the award fee requirements of Contract Milestone M2, "Grouting Demonstration Test Report Complete” of the Baseline Change Proposal (BCP) CR07011. 


\section{TABLE OF CONTENTS}

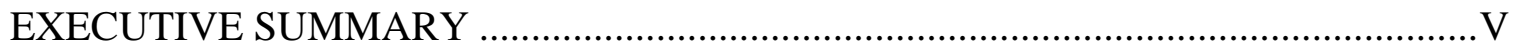

LIST OF FIGURES ……………………………….......................................... VIII

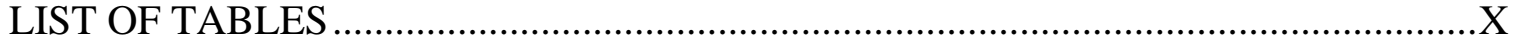

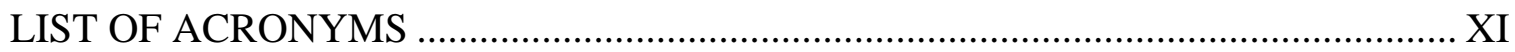

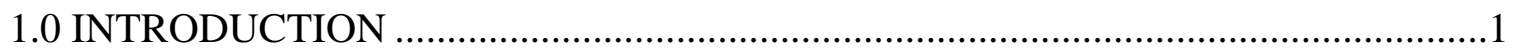

2.0 EXPERIMENTAL

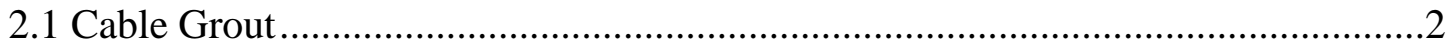

2.2 Design, Assembly, and Full Scale Testing …………….........................................2

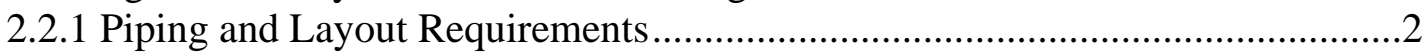

2.2.1.1 Vertical Cooling Coil Assembly ............................................................2

2.2.1.2 Horizontal Cooling Coil Assembly..............................................................6

2.2.2 Materials used and Construction of the Cooling Coils Assemblies......................9

2.2.3 Batching, Grout Mixing and Pumping...........................................................18

2.2.4 Instrumentation and Setup .............................................................................21

2.2.5 Grout Characterization................................................................................22

2.2.6 Operating Conditions - Run Plans...................................................................24

2.2.7 Visual Aid for Void Fraction in Piping.................................................................25

2.2.8 Sectioning of Vertical Cooling Coil Assembly ..................................................25

2.2.9 Sectioning of Horizontal Cooling Coil Assembly ..............................................27

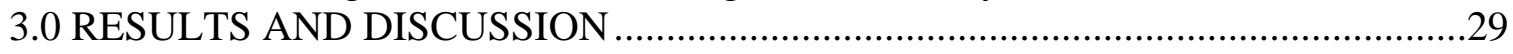

3.1 Pre-Operational ...........................................................................................29

3.2 Vertical Cooling Coil Assembly ............................................................................30

3.3 Horizontal Cooling Coil Assembly ..........................................................................43

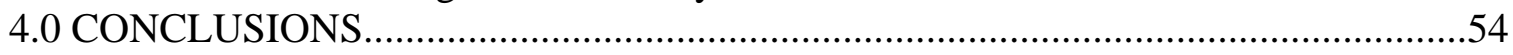

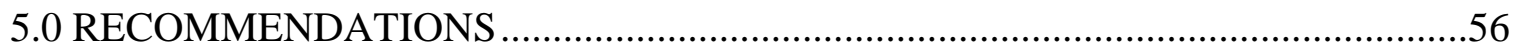

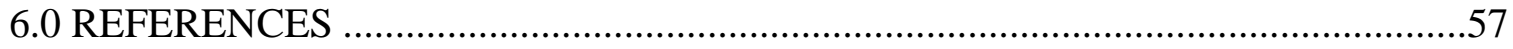




\section{LIST OF FIGURES}

Figure 2-1 Piping and Instrumentation Configuration for the Vertical Cooling Coil Assembly... 5 Figure 2-2 Horizontal Piping Run for the Vertical Cooling Coil Assembly on the $3^{\text {rd }}$ floor ......... 6 Figure 2-3 Vertical/Horizontal Piping Runs for the Horizontal Cooling Coil Assembly............... 8

Figure 2-4 Horizontal Cooling Coil Assembly Located Outside on Ground Level ....................... 9

Figure 2-5 180 degree 2-foot radius bends ............................................................................ 10

Figure 2-6 Layout of Vertical Cooling Coil Assembly in Support Frame ................................... 10

Figure 2-7 Vertical Cooling Coil Assembly - First Floor.............................................................. 11

Figure 2-8 Vertical Cooling Coil Assembly, - Second Floor ......................................................... 12

Figure 2-9 Vertical/Horizontal Cooling Coil Assembly - Third Floor ........................................... 13

Figure 2-10 Horizontal Cooling Coil Assembly - Outside - Side View..................................... 14

Figure 2-11 Horizontal Cooling Coil Assembly - Outside - Top View ..................................... 15

Figure 2-12 Horizontal Cooling Coil Assembly - Outside and First Floor.................................... 16

Figure 2-13 Horizontal Cooling Coil Assembly - Second Floor ............................................. 17

Figure 2-14 ChemGrout GC-500-DH and Supersack.......................................................... 19

Figure 2-15 System Modifications to Reduce Air Entrainment ................................................... 20

Figure 2-16 Thermocouple Layout and Pipe Insulation - Vertical Cooling Coil Lines............... 22

Figure 2-17 ASTM C939 Flow Cone Measurement............................................................ 24

Figure 2-18 Four Volume Percent Void in 2 inch Piping............................................................. 25

Figure 2-19 Vertical Cooling Coil Assembly - Section Marks....................................................... 26

Figure 2-20 Horizontal Piping Run for the Vertical Cooling Coil Assembly on the $3^{\text {rd }}$ floor -

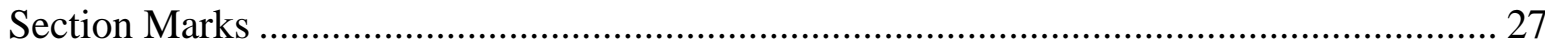

Figure 2-21 Horizontal Cooling Coil Assembly Located Outside - Section Marks .................... 28

Figure 2-22 Vertical Piping Run for the Horizontal Cooling Coil Assembly - Section Marks .. 29

Figure 3-1 Water to Grout Transition in Vertical Cooling Coil Assembly .................................. 31

Figure 3-2 Vertical Cooling Coil Process Parameters .................................................................. 32

Figure 3-3 Typical Grout Discharging the Vertical Cooling Coil Assembly - Sampling ............ 33

Figure 3-4 Physical Properties of Discharged Grout for the Vertical Cooling Coil Assembly ... 34

Figure 3-5 Temperature Measurements of Insulated Pipe 2U ..................................................... 35

Figure 3-6 Temperature Measurements of Insulated Pipe 9U ...................................................... 35

Figure 3-7 Temperature Measurements of Un-insulated Pipe 6U ............................................. 36

Figure 3-8 Sectioned Vertical Piping 1D and 3U from the Vertical Cooling Coil Assembly..... 37

Figure 3-9 Sectioned Vertical Piping 5U and 10U from the Vertical Cooling Coil Assembly... 38

Figure 3-10 Voids in the Upper Loops in the Vertical Cooling Coil Assembly............................ 40

Figure 3-11 Voids in Horizontal Piping VSH1 in the Vertical Cooling Coil Assembly.............. 41

Figure 3-12 Process Locations that Lead to Air Entrainment...................................................... 42

Figure 3-13 Horizontal Cooling Coil Assembly Process Parameters ............................................. 44

Figure 3-14 Typical Grout Discharging the Horizontal Cooling Coil Assembly ......................... 45

Figure 3-15 Physical Properties of Discharged Grout for the Horizontal Cooling Coil Assembly

Figure 3-16 Sectioned Vertical Supply Piping - Horizontal Cooling Coil Assembly .................. 48

Figure 3-17 Sectioned Vertical Return Piping - Horizontal Cooling Coil Assembly .................. 49

Figure 3-18 Sectioned 4A and 8B Horizontal Piping - Horizontal Cooling Coil Assembly ...... 50

Figure 3-19 Sectioned 12C and 16B Horizontal Piping - Horizontal Cooling Coil Assembly .. 51

Figure 3-20 Horizontal Section 8B - Horizontal Cooling Coil Assembly .................................... 52 
WSRC-STI-2008-00298

Rev. 0

Figure 3-21 Sectioned 5A Horizontal Piping - Horizontal Cooling Coil Assembly.................. 53 


\section{LIST OF TABLES}

Table 2-1 Cooling Coil Cable Grout Composition and Physical Properties ............................... 2

Table 2-2 180 Degree 2-foot Radius Bends in the Vertical Cooling Coil Assemblies in Type I

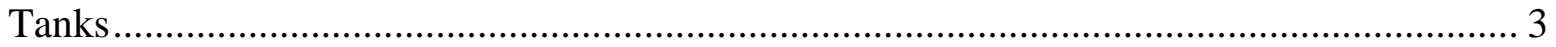

Table 2-3 2-foot Radius Bends and Linear Piping Run for Horizontal Cooling Coil Assemblies

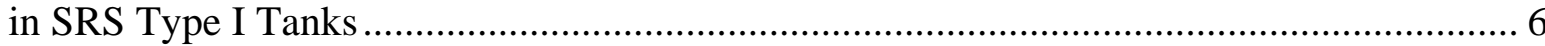

Table 2-4 Instrumentation used in Vertical and Horizontal Cooling Coil Test......................... 21 


\section{LIST OF ACRONYMS}

\begin{tabular}{|c|l|}
\hline ACTL & Aiken County Technology Laboratory \\
\hline ASTM & American Standard for Testing Materials \\
\hline CETL & Clemson Engineering Technologies Laboratory \\
\hline gpm & gallons per minute \\
\hline HLW & High Level Radioactive Waste \\
\hline LW & Liquid Waste \\
\hline MF & Masterflow \\
\hline NIST & National Institute of Standards and Technology \\
\hline psi & pounds per square inch \\
\hline SCUREF & South Carolina University Research and Education Foundation \\
\hline SOW & Statement of Work \\
\hline SRNL & Savannah River National Laboratory \\
\hline SRS & Savannah River Site \\
\hline TCTD & Tank Closure and Technology Development \\
\hline TTQAP & Task Technical and Quality Assurance Plan \\
\hline T/C & Thermocouple \\
\hline W/CM & Water to Cementitious Material Mass Ratio \\
\hline wt\% WC & Weight Percent Water Content \\
\hline
\end{tabular}




\subsection{INTRODUCTION}

This report documents the Savannah River National Laboratory (SRNL) support for the Tank Closure and Technology Development (TCTD) group's strategy for closing high level radioactive waste (HLW) tanks at the Savannah River Site (SRS). Specifically, this task addresses the ability to successfully fill intact cooling coils, presently within the HLW tanks, with grout that satisfies the fresh and cured grout requirements [1] under simulated field conditions. The overall task was divided into two phases. The first phase was the development of a grout formulation that satisfies the processing requirements for filling the HLW tank cooling coils [5]. The second phase of the task, which is documented in this report, was the filling of full scale cooling coils under simulated field conditions using the grout formulation developed in the first phase. SRS Type I tank cooling coil assembly design drawings and pressure drop calculations were provided by the Liquid Waste (LW) customer to be used as the basis for configuring the test assemblies.

The current concept for closing tanks equipped with internal cooling coils is to pump grout into the coils to inhibit pathways for infiltrating water. Access to the cooling coil assemblies is through the existing supply/return manifold headers located on top of the Type I tanks.

The objectives for the second phase of the testing, as stated in the Task Technical and Quality Assurance plan (TTQAP) [2], were to:

o Perform a demonstration test to assess cooling coil grout performance in simulated field conditions, and

o Measure relevant properties of samples prepared under simulated field conditions.

SRNL led the actual work of designing, fabricating and filling two full-scale cooling coil assemblies which were performed at Clemson Engineering Technologies Laboratory (CETL) using the South Carolina University Research and Education Foundation (SCUREF) program. A statement of work (SOW) was issued to CETL [6] to perform this work. 


\subsection{EXPERIMENTAL}

\subsection{Cable Grout}

The cooling coil grout composition and physical properties are provided in Table 2-1 [5]. This grout satisfies the processing requirements [1-3]. The Masterflow (MF) 816 cable grout was obtained from BASF, Inc. and the grade 100 blast furnace slag from Holcim, Inc. Both the MF 816 and slag are cementitious materials. A unique characteristic of this grout is that it has a fairly long working time such that its physical properties change little over an extended period of time. The rheological properties, both yield stress and plastic viscosity, over a period of 90 minutes of continuous mixing, were essentially constant [5]. This grout also satisfied the piping pressure limit of 150 psig established by B. J. Adkins [4] during grout fill, for 1200 linear feet of 2" schedule 40 piping. The condition of flow for this grout is laminar for flow rates up to 200 gallons per minute (gpm), but the actual flow rate will be lower due to the piping pressure limit.

Table 2-1 Cooling Coil Cable Grout Composition and Physical Properties

\begin{tabular}{|c|c|}
\hline Component & Mass fraction \\
\hline Masterflow 816 cable grout & 0.6767 \\
\hline Blast Furnace Grade 100 Slag & 0.0752 \\
\hline Water & 0.2481 \\
\hline \hline Density using pycnometer (g/ml) & 2.07 \\
\hline Water to Cementitious mass ratio (W/CM) & 0.33 \\
\hline Flow Cone (seconds) at $23^{\circ} \mathrm{C}$ & 20 to 30 \\
\hline
\end{tabular}

\subsection{Design, Assembly, and Full Scale Testing}

The design, assembly and full scale testing of the cooling coils, construction materials, grout mixing/transport system, installed instrumentation, and analytical measurements used in this phase of testing are described below.

\subsubsection{Piping and Layout Requirements}

References 13 and 14 are the SRS drawings for the Type I storage tanks that were used to guide the fabrication of the full scale cooling coils. Reference 1 was also used to develop the proposed cooling coil grouting test set-up. These references were provided by the customer.

\subsubsection{Vertical Cooling Coil Assembly}

The piping and instrumentation for the vertical cooling coil assembly are provided in Figure 2-1 and Figure 2-2. 
There are a total of 34 vertical cooling coil assemblies, in the Type I tanks, half of the assemblies are primary and the other half auxiliary [13]. As shown in Table 2-2, the majority of assemblies have either fifteen or seventeen $180^{\circ}$, 2-foot radius bends per assembly. From a hydraulic standpoint, the largest quantity of $180^{\circ}$ 2-foot radius bends would yield the largest pressure drop; hence, nineteen $180^{\circ}$ 2-foot radius bends were used in the full-scale mock-up. The vertical distance between the top and bottom of the $180^{\circ}$ 2-foot radius bends is 22.5 feet [4].

Table 2-2 180 Degree 2-foot Radius Bends in the Vertical Cooling Coil Assemblies in Type I Tanks

\begin{tabular}{|c|c|}
\hline Number of Cooling Coil Assemblies & Number of $\mathbf{1 8 0}$ degree 2-foot radius bends per assembly \\
\hline 12 & 15 \\
\hline 14 & 17 \\
\hline 8 & 19 \\
\hline
\end{tabular}

The horizontal supply/return piping length between the supply/return manifold to the vertical cooling coil ranges between 4 and 51 feet. The horizontal supply/return piping used in the full scale mockup is 54 feet. The drawings indicate that the supply/return lines are located near the top of the tank ("top leads"), above or level with the top of the $180^{\circ} 2$-foot radius bends in the vertical cooling coils, or along the bottom of the tank adjacent to the horizontal cooling coil ("bottom leads"). The horizontal runs were located above the vertical coil assembly and were installed on the $3^{\text {rd }}$ floor in the full scale mockup, which simulated the "top leads" in a Type I waste tank.

The distance between the top of the tank to the top of the $180^{\circ} 2$-foot radius bend is 19.5 inches [13]. The distance from the top of the tank to the bottom of the valve house is 12.7 feet [4]. The distance from the bottom of the valve house to the initial flange connection is 2.75 feet [13]. Hence, the total distance between the top of the $180^{\circ} 2$-foot radius bend to the initial flange connection in the valve house is approximately 17 feet. The distance between the top of the $180^{\circ}$ 2 -foot radius bend to the inlet/outlet connections in the full scale mockup was 12 feet. This five foot height difference was required so that the inlet and outlet could be easily managed on the $3^{\text {rd }}$ floor at CETL. This five foot difference would have added additional hydrostatic head and pressure drop (during flow) to the assembly, but these differences are small compared to overall hydraulic behavior of the assembly. An additional five feet of piping head would yield an additional 4.5 psi to the lowest sections on the $180^{\circ}$ 2-foot radius bend. Based on the rheological properties of the grout being used, this additional pressure, when added to the hydraulic pressure drop of the assembly, is below the design pressure of 150 psig [4] for flows between 0 to 20 gpm.

There are other pipe bends shown in Reference 13 that were common to all of the vertical cooling coil assemblies; four $90^{\circ} 2$-foot radius bends connecting the horizontal/vertical lines per assembly, and four $90^{\circ} 10$-inch radius bends for the piping between the pump house and tank per assembly. One of the vertical cooling coil assemblies had two $90^{\circ} 6$-inch radius bends for a single cooling coil assembly, but this assembly did not have the longest horizontal run of 
supply/return piping. The vertical cooling coil assembly in the full scale mockup used a total of sixteen, $90^{\circ} 10$-inch radius bends.

A single ball valve was installed on the horizontal return line located on the $3^{\text {rd }}$ floor of CETL to assist in the filling of the cooling coil assembly with water. A 0.5 inch vent line, with a 0.5 inch isolation ball valve was also installed at the highest point of the supply line on the $3^{\text {rd }}$ floor to vent the air in the hose used to transport the grout from the grout mixer/pump unit to the inlet to the supply line.

The discharge was located on the $3^{\text {rd }}$ floor, next to the supply line. There was a physical break between the 2 inch discharge and the 3 inch water/grout collection line. The actual discharge location at SRS will most likely be at a lower elevation. The discharge location in the full scale mockup was selected to allow immediate sampling of the grout after exiting the pipe on the $3^{\text {rd }}$ floor. The water/grout that was discharged from the assembly was collected in drums located at the ground level.

In summary, the vertical cooling coil assembly fabricated in the full scale mockup bounds the hydraulic losses in the actual vertical cooling coil assemblies in the SRS Type I waste tanks. This is due to the excess number of $90^{\circ} 10$-inch bends and the extra length of horizontal piping runs used in the full scale mock up. The vertical cooling coil assembly at CETL was located indoors, in an enclosed environment with continuous air movement. 


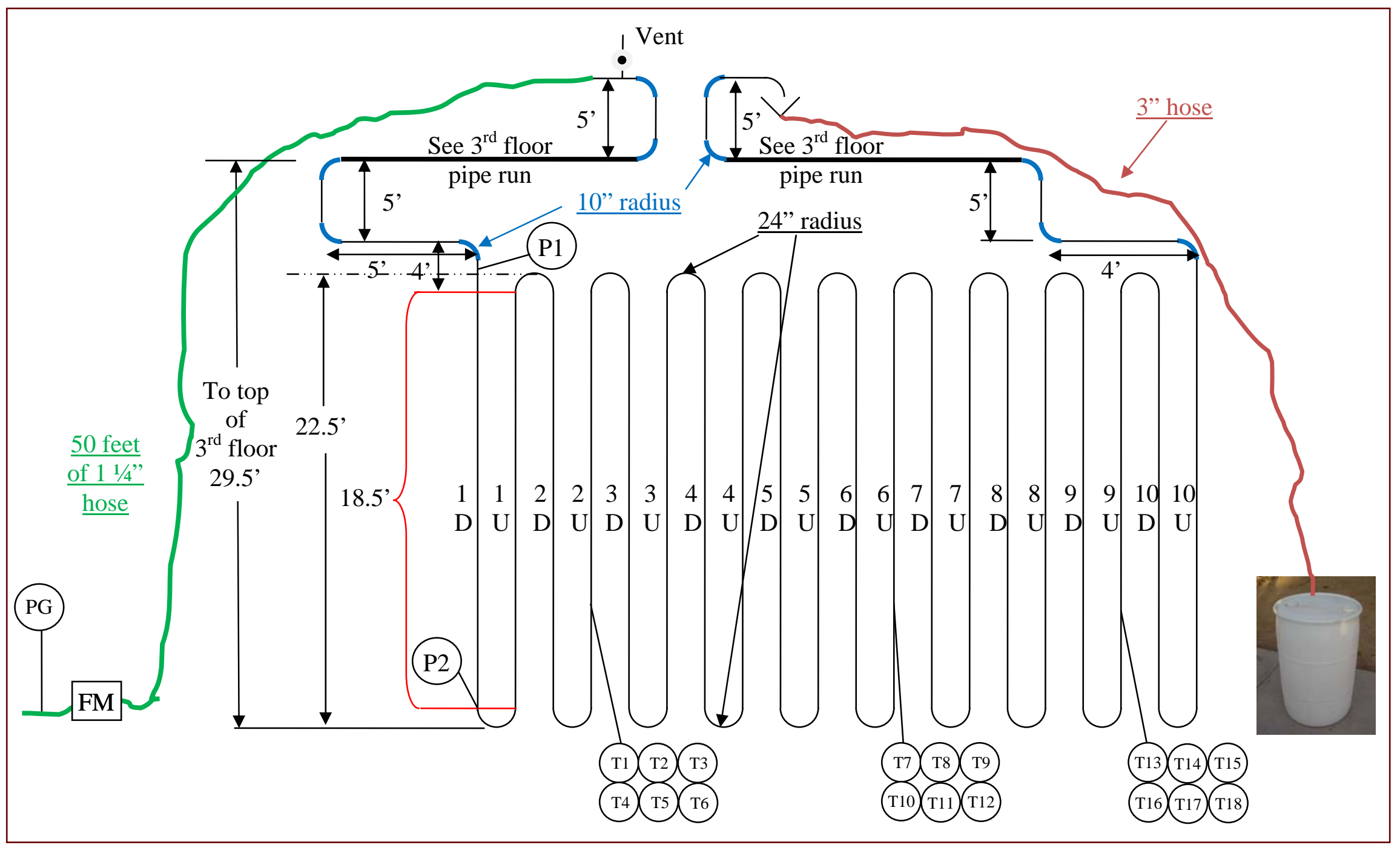

Figure 2-1 Piping and Instrumentation Configuration for the Vertical Cooling Coil Assembly 


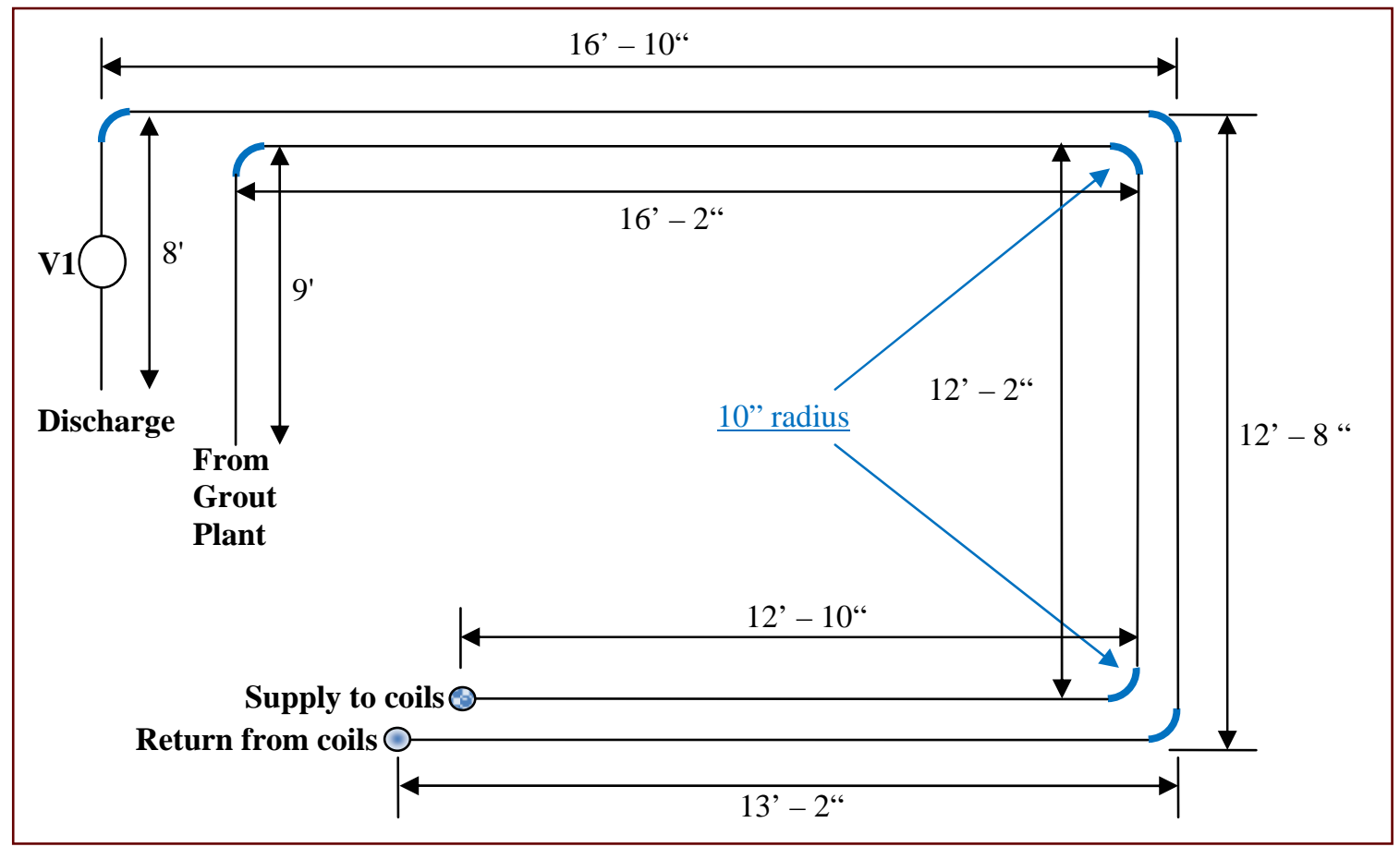

Figure 2-2 Horizontal Piping Run for the Vertical Cooling Coil Assembly on the $3^{\text {rd }}$ floor

\subsubsection{Horizontal Cooling Coil Assembly}

The piping and instrumentation for the horizontal cooling coil assembly fabricated and set up for the full scale mockup are provided in Figure 2-3 and Figure 2-4.

There are two horizontal cooling coil assemblies in Type I tanks, one is the primary and the other the auxiliary [14]. Table 2-3 shows the number of $90^{\circ}$ and $180^{\circ} 2$-foot radius bends in the SRS Type I horizontal assemblies and the total length of the piping runs for the primary and auxiliary coil assemblies. The $90^{\circ}$ bends were used to get around the support columns in the tank and two $90^{\circ}$ bends are connected with 2.75 feet of piping. In the full-scale mockup, a total of fifteen $180^{\circ}$ 2 -foot radius bends were used, which is equivalent to the total length of 2-foot radius bends of the auxiliary coil assembly. No $90^{\circ}$ 2-foot radius bends were used in the full scale mockup for simplicity in setting up the horizontal test facility.

Table 2-3 2-foot Radius Bends and Linear Piping Run for Horizontal Cooling Coil Assemblies in SRS Type I Tanks

\begin{tabular}{|c|c|c|c|}
\hline \multirow{2}{*}{ Coil Assembly } & \multicolumn{2}{|c|}{ Number of 2-foot radius bends } & $\begin{array}{c}\text { Total Linear Piping Run } \\
\text { (ft) }\end{array}$ \\
\cline { 2 - 3 } & $\mathbf{9 0}$ degree & $\mathbf{1 8 0}$ degree & 700 \\
\hline Primary & 6 & 9 & 775 \\
\hline Auxiliary & 10 & 10 & \\
\hline
\end{tabular}


The SRS Type I tank linear piping runs vary between 2.75 to 65 feet between bends. In the full scale mockup, the linear piping runs between the $180^{\circ} 2$-foot radius bends were 51 feet because it was not practical to mockup the actual footprint of the horizontal cooling coil pipe runs in the Type I tanks. Hence, the total linear piping run in the horizontal cooling coil assembly (Figure 2-4), located outdoors at CETL was 816 feet as compared to the maximum 775 feet of linear piping in the actual auxiliary cooling coil assembly. The cooling coils were arranged in a rack. Three sets of coils were placed on each of five levels of the rack. The horizontal cooling coil assembly was located outdoors due to the length of the piping runs.

The supply/return piping runs were located indoors and were in the same area used by the vertical cooling coil assembly supply/return piping. The full scale mockup was approximately five feet shorter in height than that of the SRS Type I horizontal cooling coil assemblies, as previously discussed in section 2.2.1.1. There was an additional 113 feet of horizontal piping required in the mockup to connect the supply/return connection on the $3^{\text {rd }}$ floor to the horizontal cooling coil assembly located outdoors. Sixteen $90^{\circ} 10$-inch radius bends were used in the supply/return connection to the horizontal assembly. The Type I tanks have two $90^{\circ} 2$-foot radius bends to connect the vertical supply/return lines to the horizontal runs and four $90^{\circ} 10$ inch radius bends for the piping between the pump house and tank per assembly. A 0.5 inch vent line was also installed at the high point in the system. The horizontal cooling coil assembly used the same sampling location as that of the vertical cooling coil assembly.

The maximum total piping run (including the 2-foot bends) in the SRS Type I tanks is 870 feet, using the auxiliary cooling coil. The total piping run in the horizontal full scale mockup was 1185 feet, which is hydraulically more conservative than any of the cooling coil assemblies in the SRS Type I tanks. 


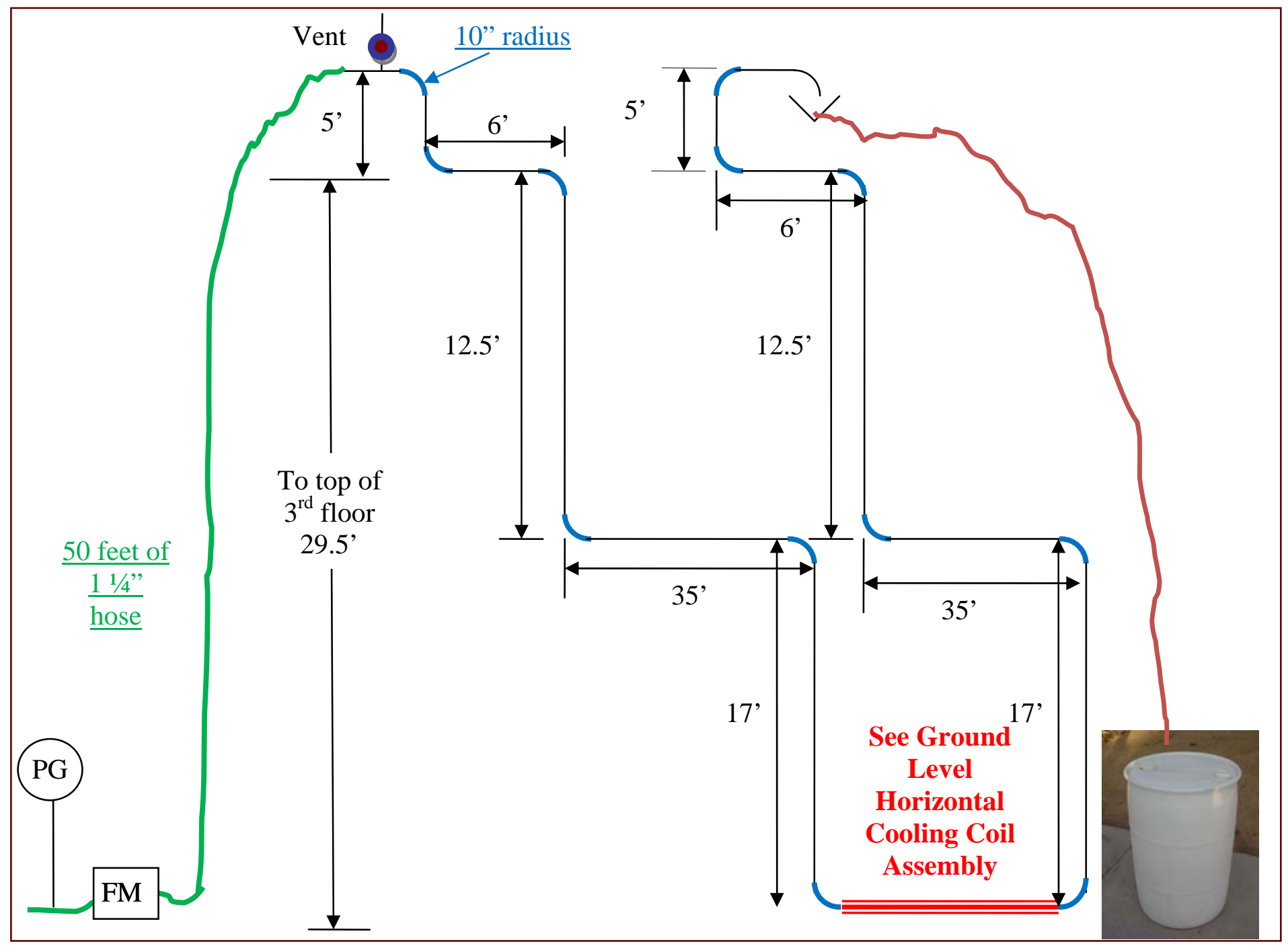

Figure 2-3 Vertical/Horizontal Piping Runs for the Horizontal Cooling Coil Assembly 


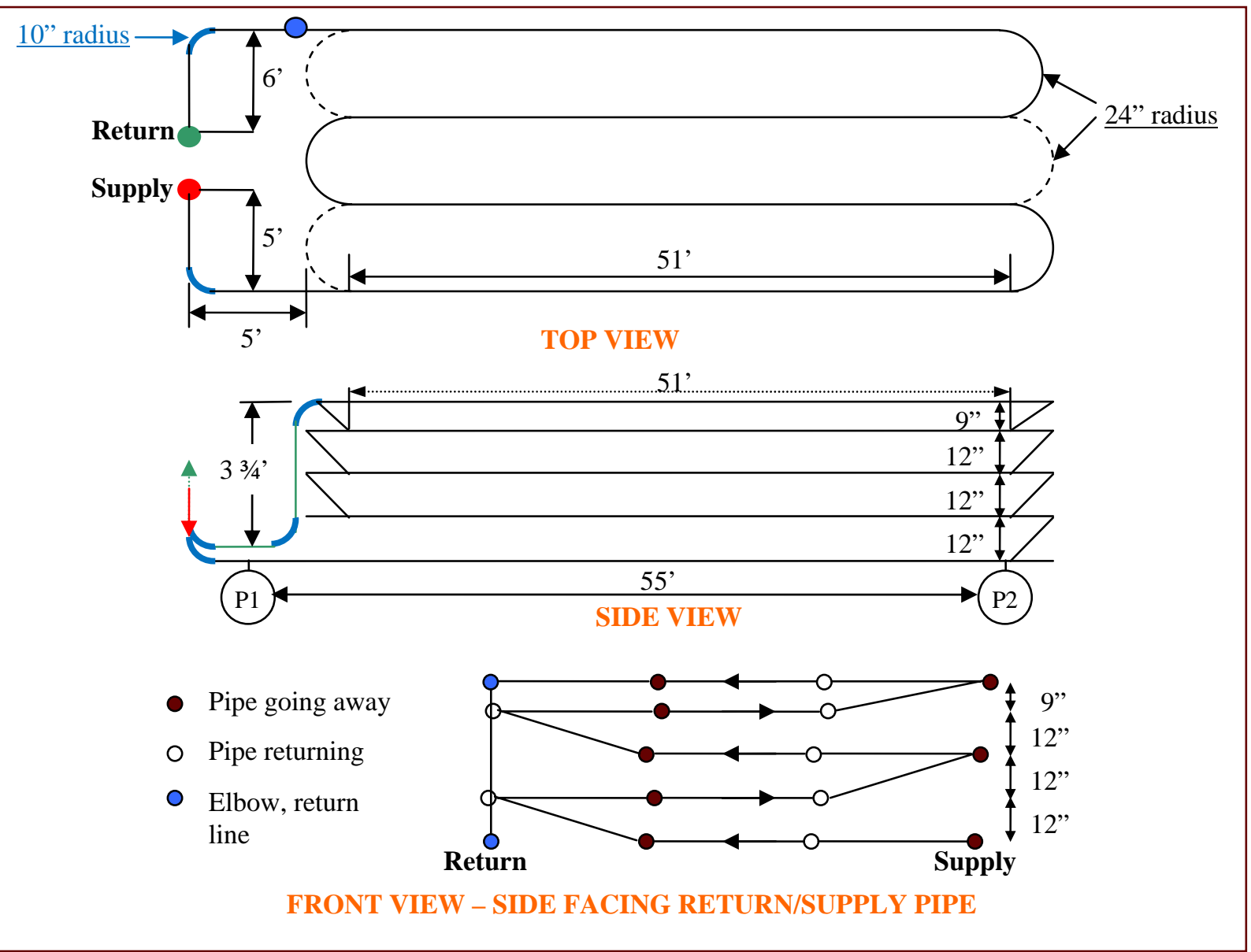

Figure 2-4 Horizontal Cooling Coil Assembly Located Outside on Ground Level

\subsubsection{Materials used and Construction of the Cooling Coils Assemblies}

All of the piping materials used in both the horizontal and vertical cooling coil assemblies were schedule 40, 2" piping or hose. Both the vertical and horizontal cooling coil assemblies used transparent and white PVC hard piping. The transparent piping provided a visual perspective of the grout flowing and mixing in the pipeline during flow and after curing. The vertical cooling coil assembly also contained ASTM A-53 black iron piping. The $180^{\circ}$ 2-foot radius bends for the vertical cooling coil assembly were made from Vardex ${ }^{\circledR}$ clear steel wire reinforced PVC suction hose and were supported in a frame (Figure 2-5). The $180^{\circ} 2$-foot radius bends for the horizontal sections were fabricated using the white PVC pipe by cold bending the pipe using a Pipe Viper ${ }^{\mathrm{TM}}$ and pipe bender (Figure 2-5). A $180^{\circ}$ 2-foot radius bend was fabricated by setting the pipe bender for $33^{\circ}$ bends and then making 24 bends that were three inches apart (the $33^{\circ}$ bend was determined via testing because the PVC piping relaxed after bending). Based on the rheological properties of the grout [6] and a 2-inch schedule 40 piping, the flow will be laminar up to $200 \mathrm{gpm}$. The maximum flow rate provided by the grout pump is approximately $30 \mathrm{gpm}$, hence the flow will be laminar for any condition of pumping, and the selection of piping material used in the full scale testing is deemed hydraulically representative of the piping material used in the Type I tanks, assuming no wall slip. If the flow were to have been turbulent, wall roughness 
would make a difference in the pressure drop and the selection of piping material would have been different.

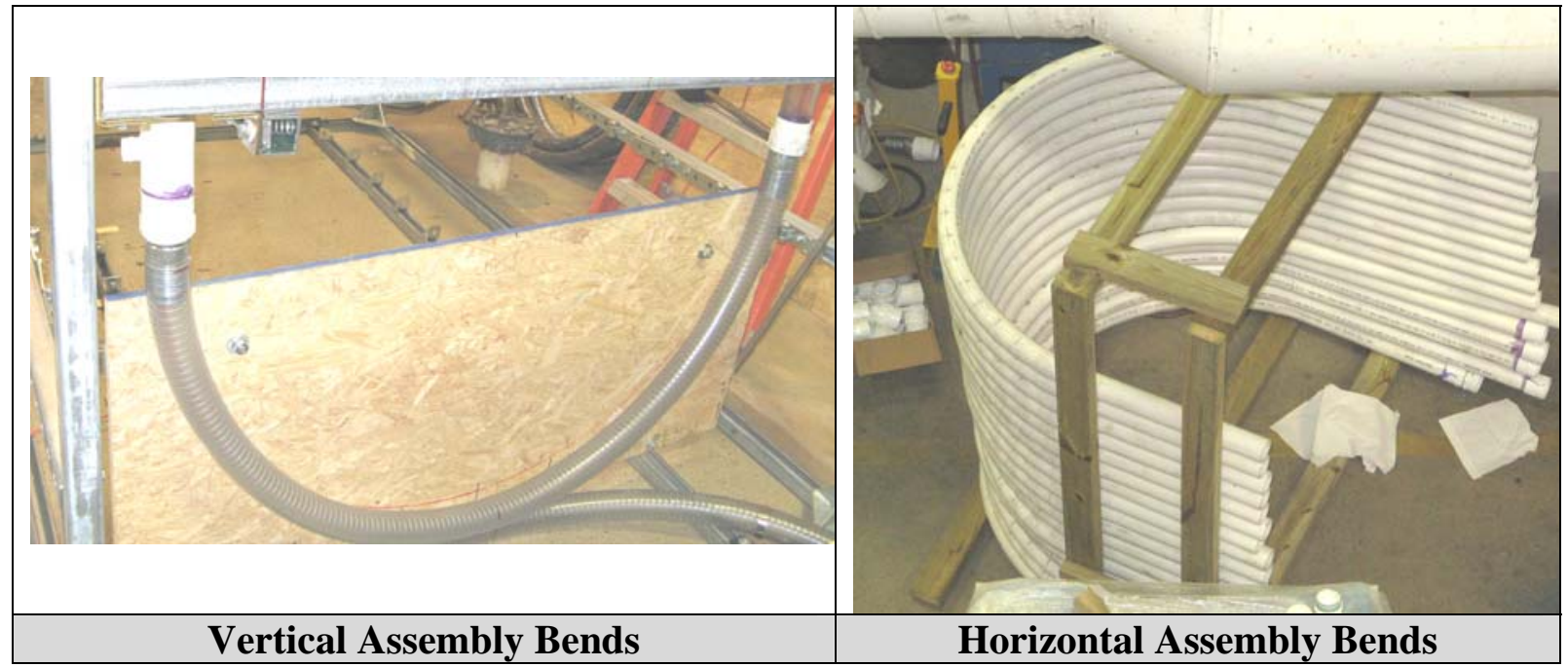

Figure 2-5 180 degree 2-foot radius bends

The vertical cooling coil assembly was supported using Unistrut ${ }^{\mathrm{TM}}$ materials. A top view of how the nineteen $180^{\circ}$ 2-foot radius bends and piping run were installed is shown in Figure 2-6. The support assemblies between the first and second floors were set using a plumb bob. The vertical cooling coil assembly is shown in Figure 2-7, Figure 2-8 and Figure 2-9. Figure 2-9 partially shows the piping on the third level, which also includes the horizontal cooling coil connections. The horizontal cooling coil assembly is shown in Figure 2-10, Figure 2-11, Figure 2-12, and Figure 2-13. The horizontal pipe support frames for the cooling coil assembly located outside are shown Figure 2-10 and Figure 2-11 and the support frames were leveled prior to installing the piping. Figure 2-12 and Figure 2-13 show the piping connecting the horizontal cooling coil assembly on the first floor and the run of horizontal piping on the second floor, respectively.

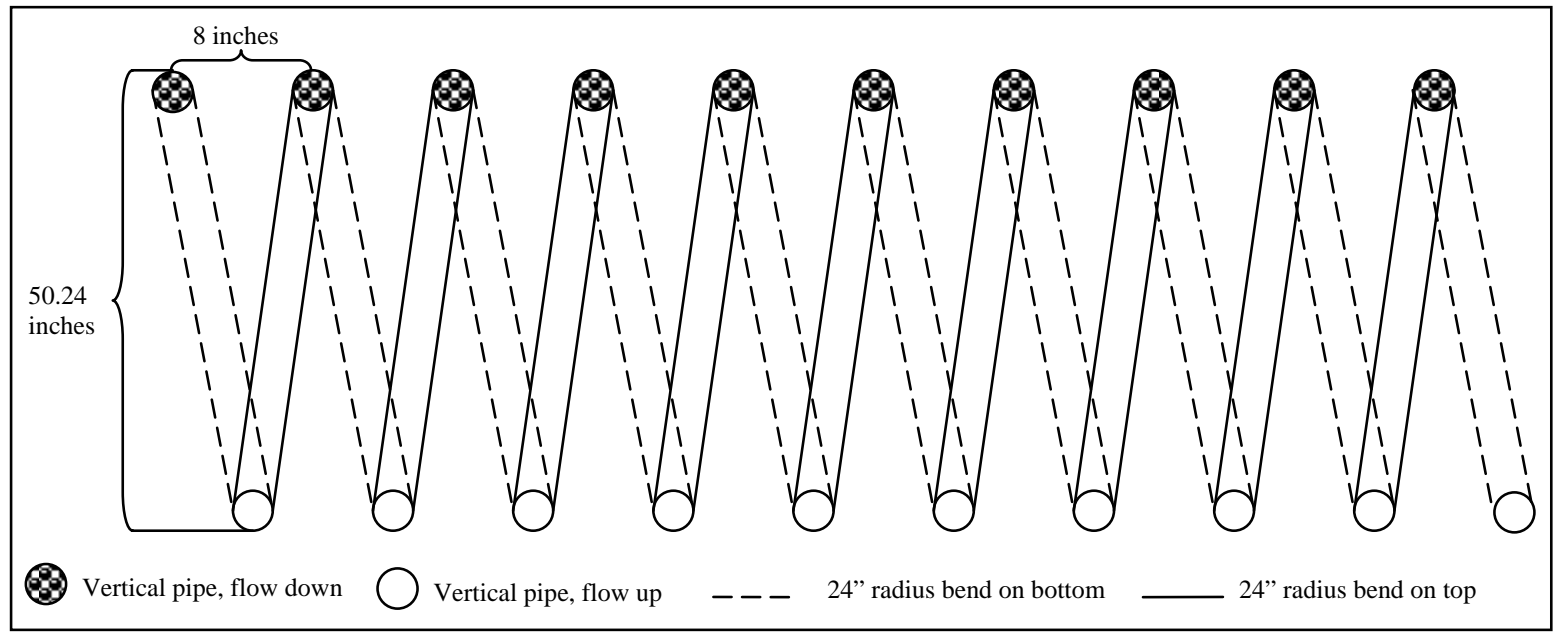

Figure 2-6 Layout of Vertical Cooling Coil Assembly in Support Frame 
WSRC-STI-2008-00298

Rev. 0

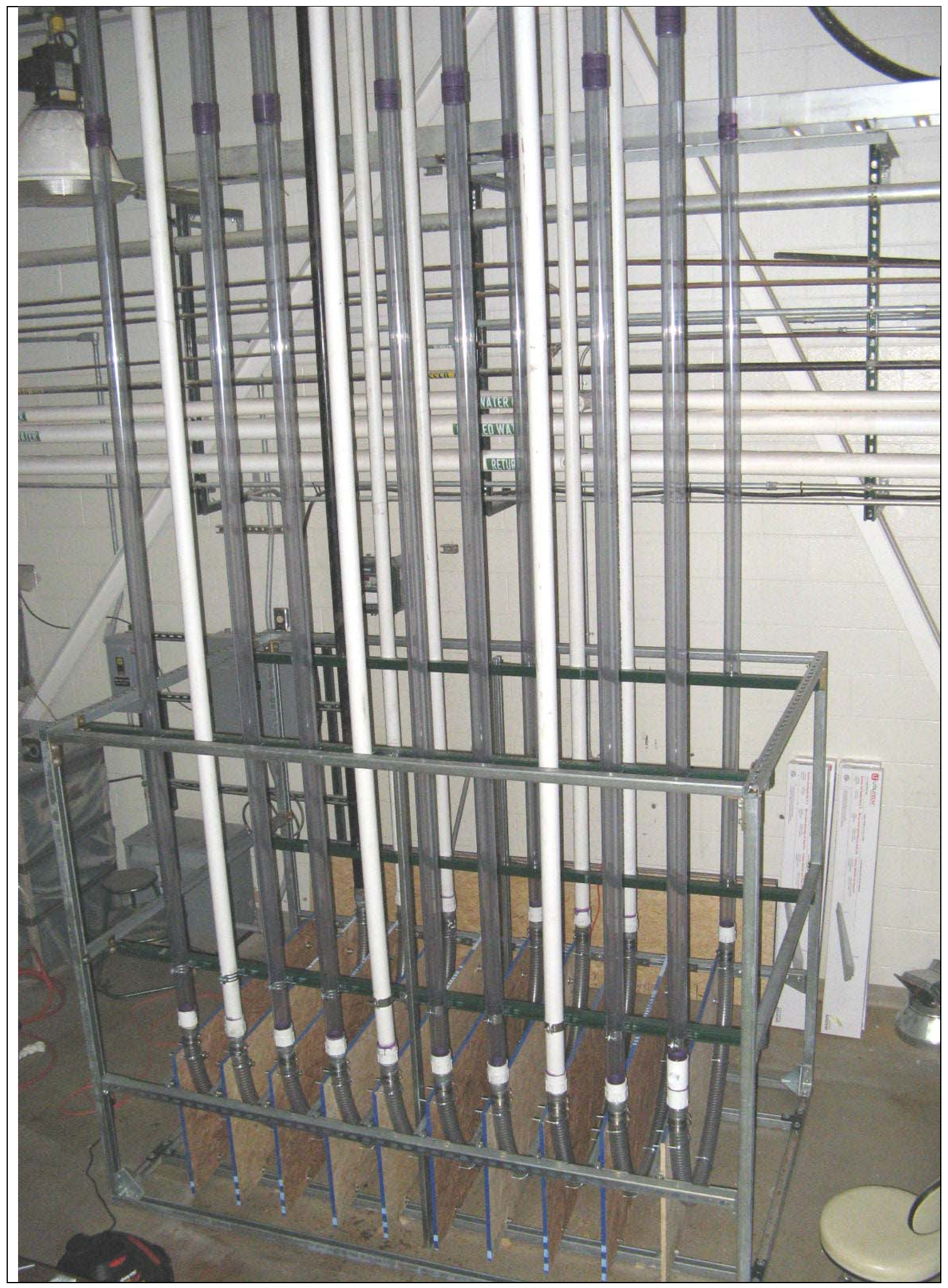

Figure 2-7 Vertical Cooling Coil Assembly - First Floor 


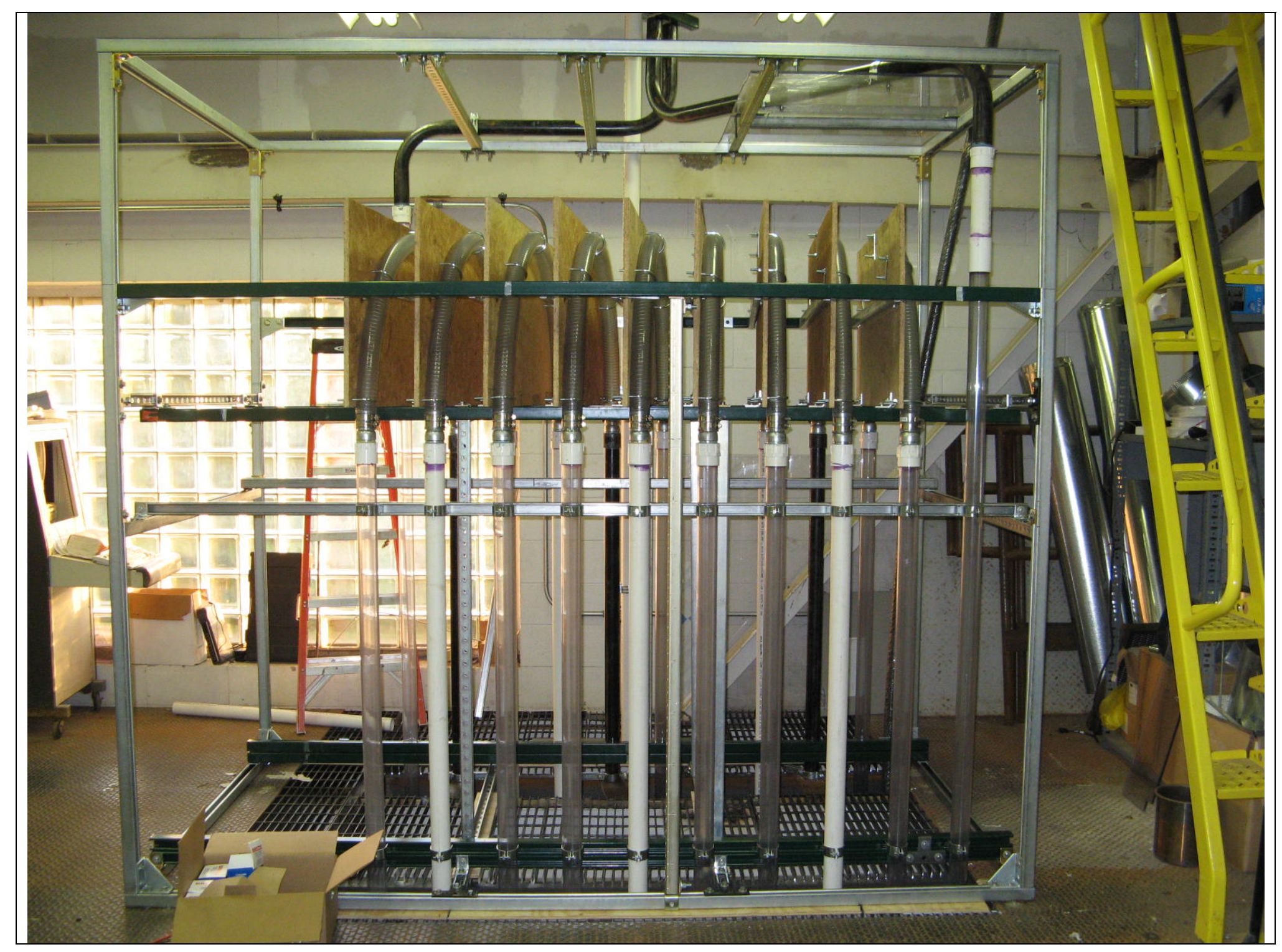

Figure 2-8 Vertical Cooling Coil Assembly, - Second Floor 


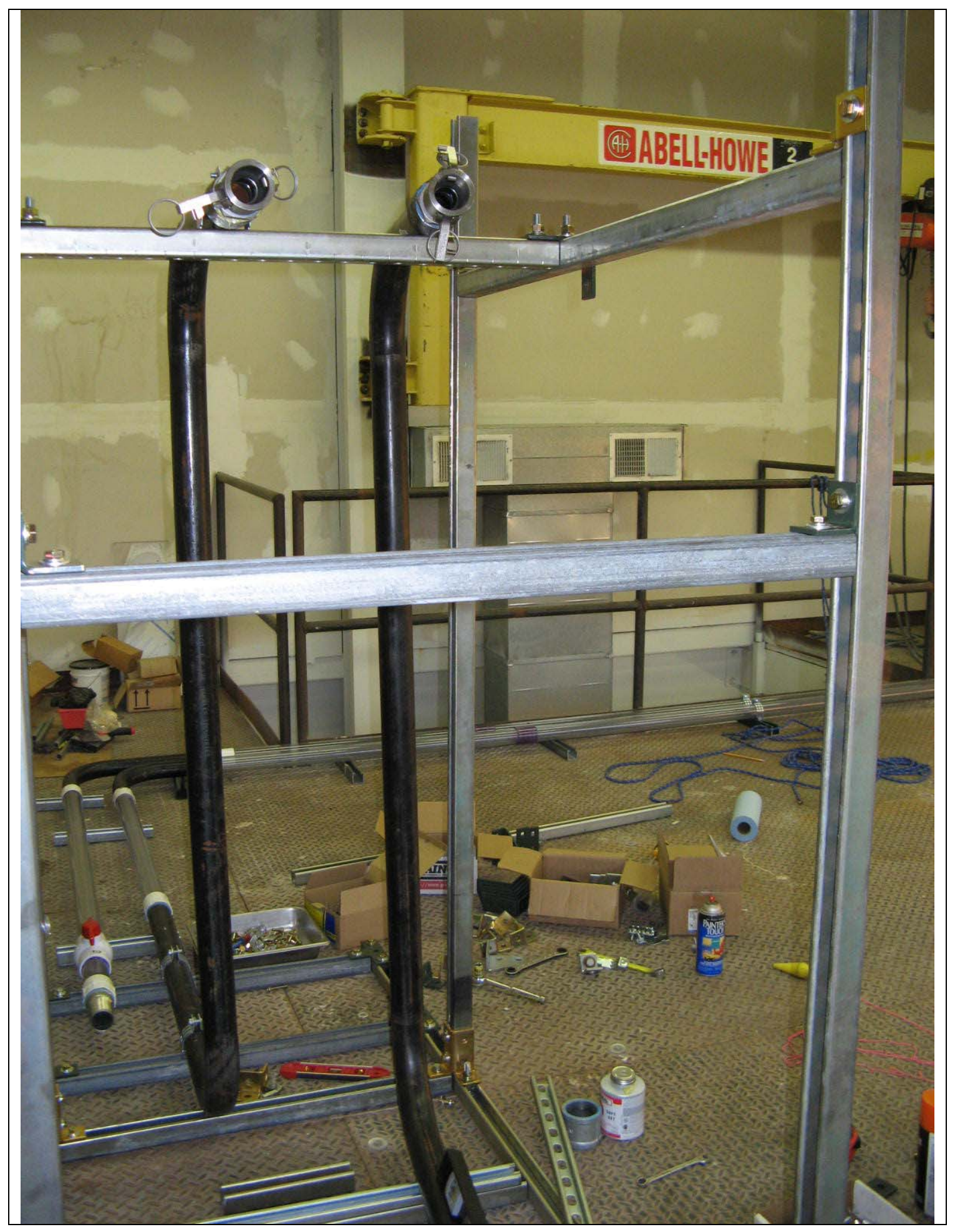

Figure 2-9 Vertical/Horizontal Cooling Coil Assembly - Third Floor 


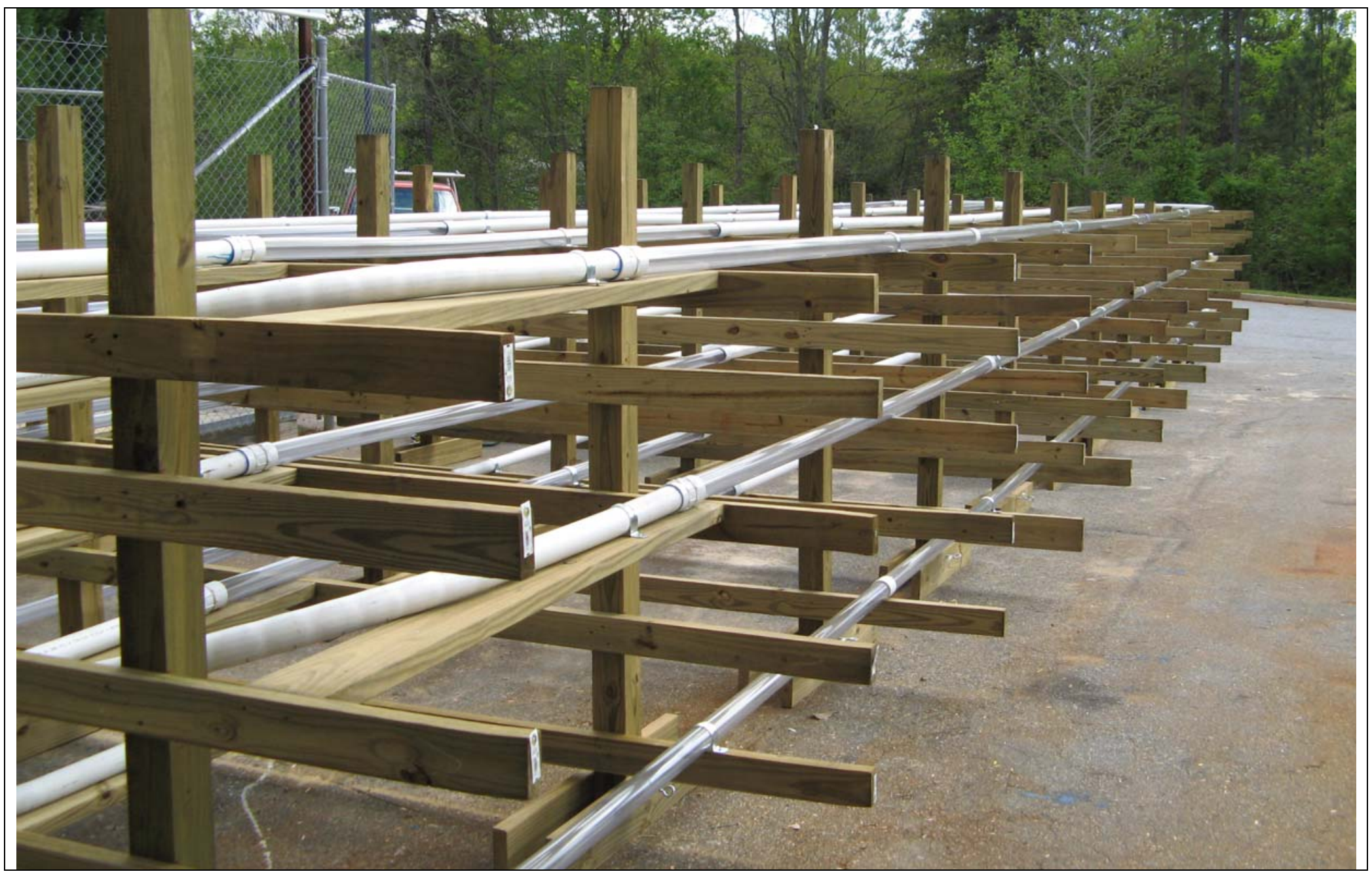

Figure 2-10 Horizontal Cooling Coil Assembly - Outside - Side View 
WSRC-STI-2008-00298

Rev. 0

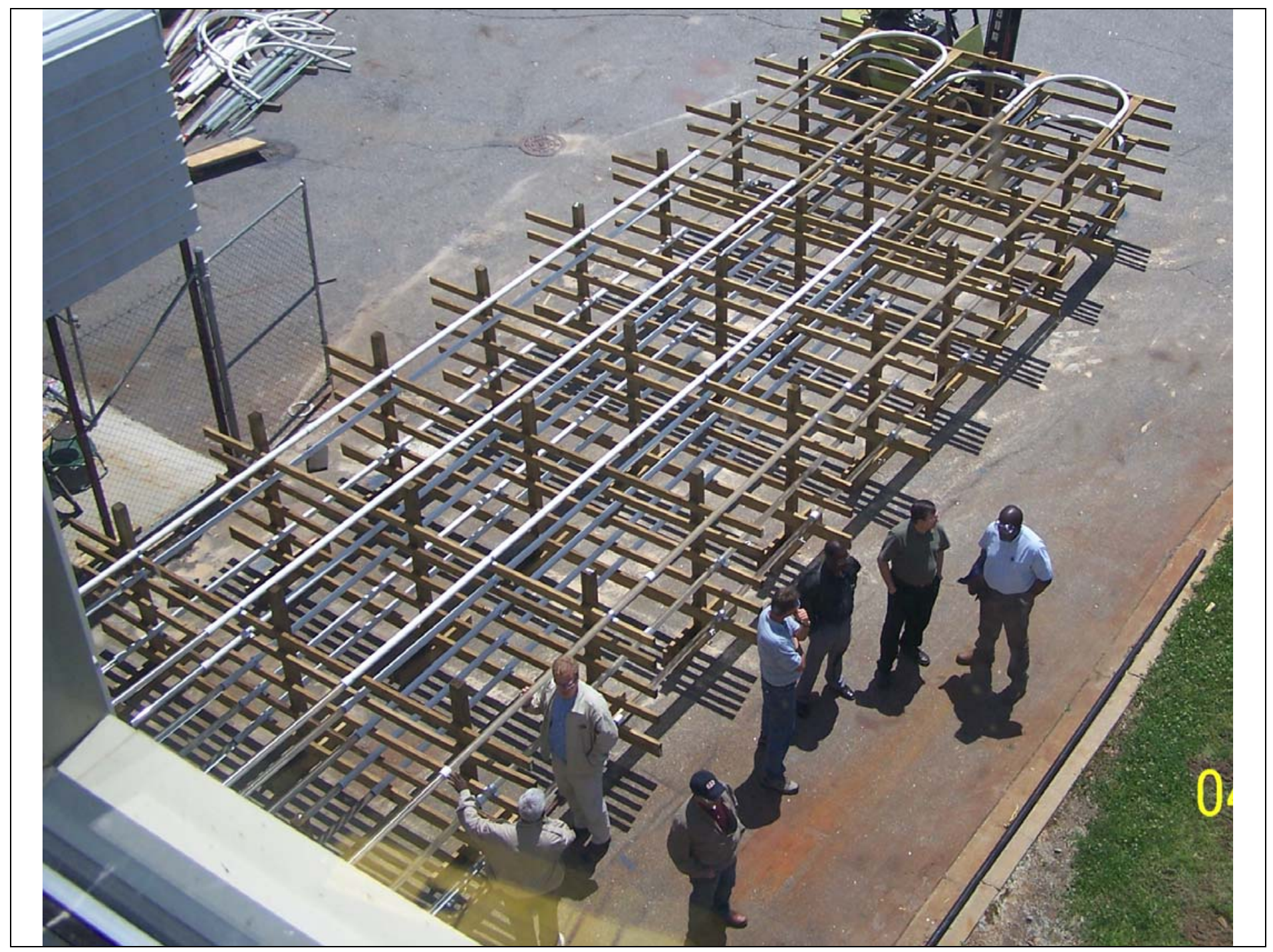

Figure 2-11 Horizontal Cooling Coil Assembly - Outside - Top View 


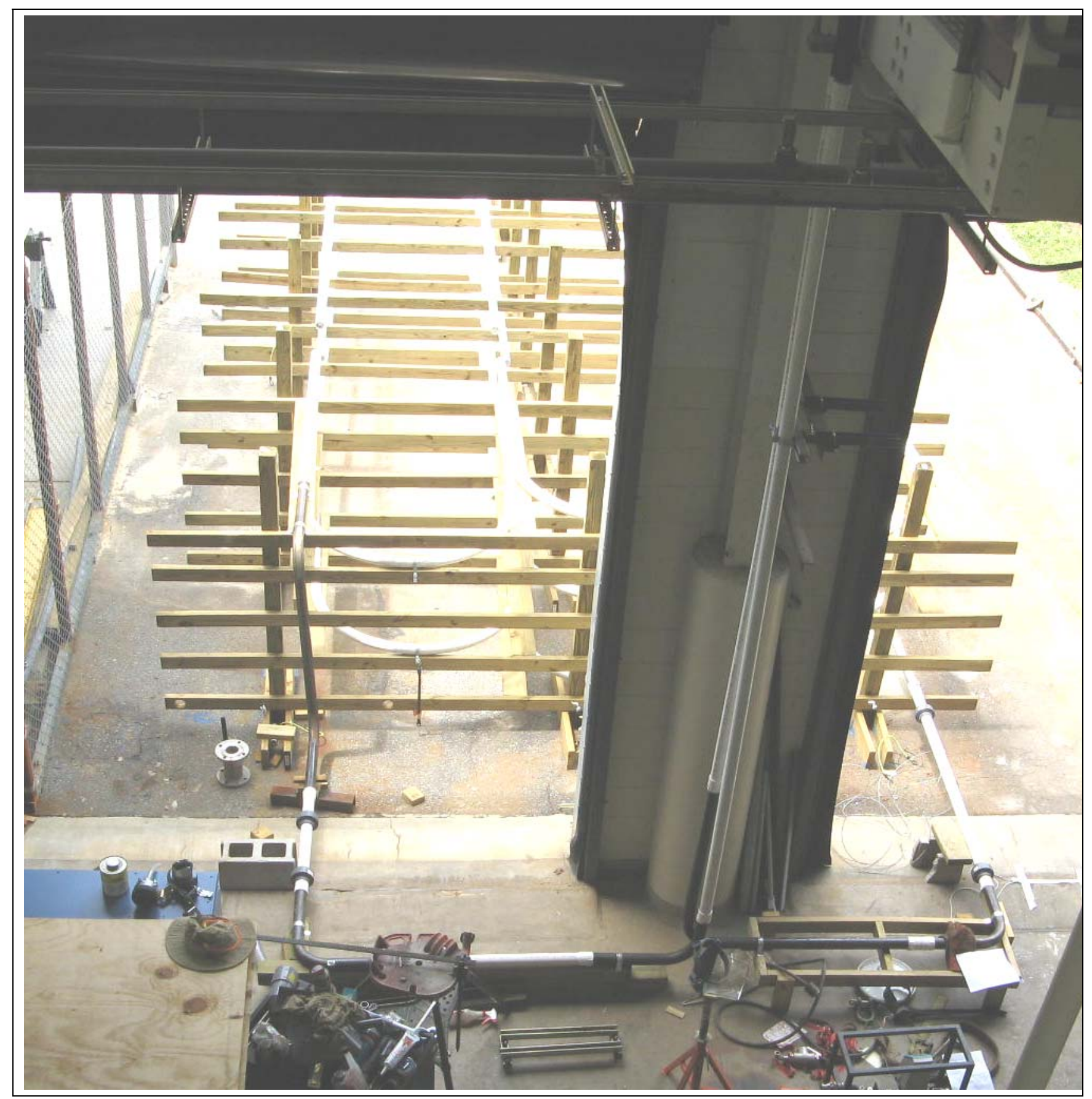

Figure 2-12 Horizontal Cooling Coil Assembly - Outside and First Floor 
Rev. 0

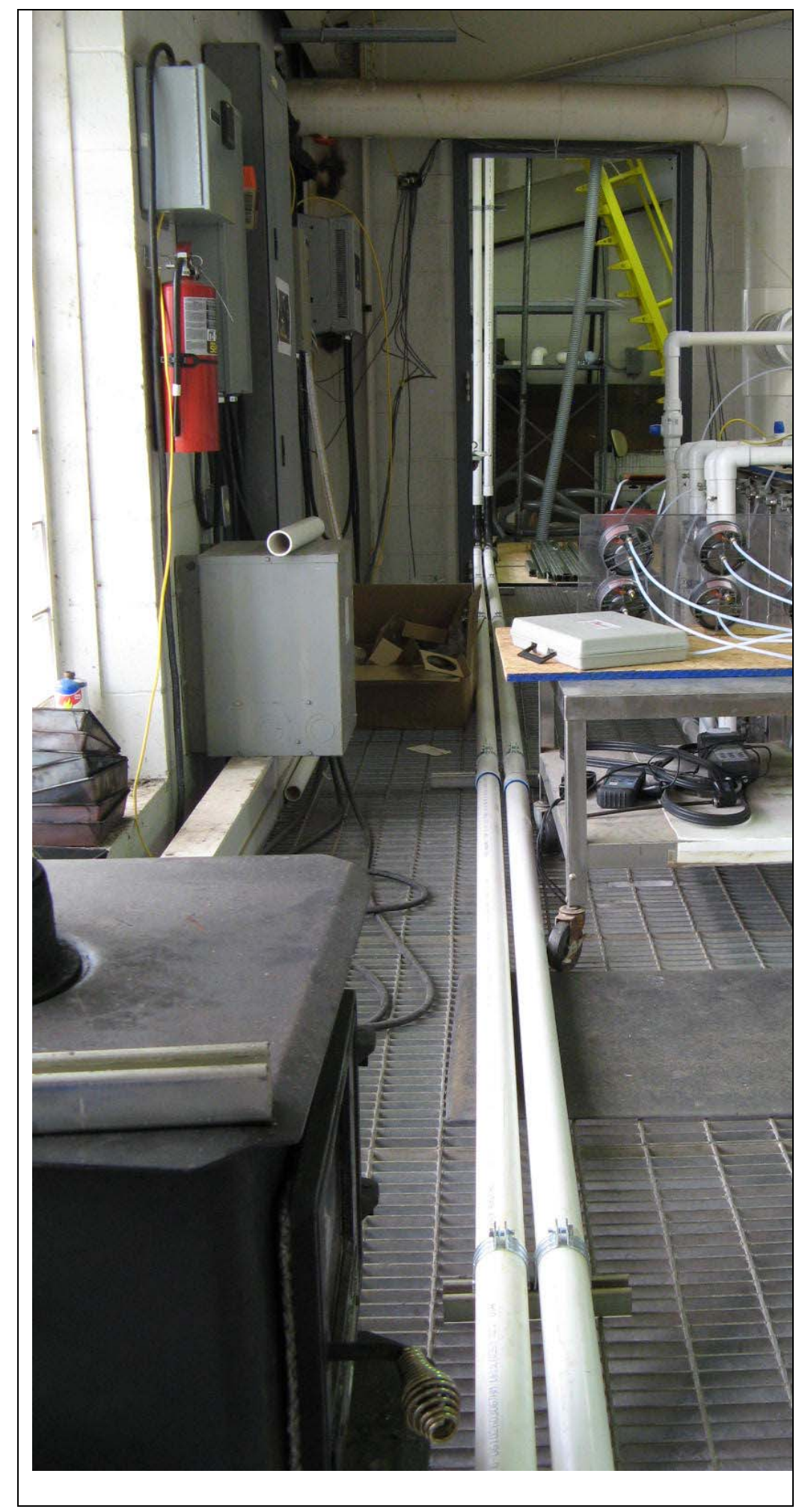

Figure 2-13 Horizontal Cooling Coil Assembly - Second Floor 


\subsubsection{Batching, Grout Mixing and Pumping}

A ChemGrout ${ }^{\mathrm{TM}}$ GC500-DH grout mixer/pumping unit was used for mixing and transporting the grout. The GC500-DH features (Figure 2-14) two 70-gallon mixing tanks, a 15-gallon holding hopper, and an open throat progressive cavity grout pump. The unique double mix tank design permits continuous pumping as each mix tank alternates feeding the pump. Each mixer is equipped with baffles, bag breakers, and variable speed high-efficiency paddles that provide rapid mixing. Two sets of paddles are provided: the bottom paddle is a flat blade that scrapes the bottom, and the top impeller is a $45^{\circ}$ pitch blade that assists in entraining the dry solids into the fluid. The maximum recommended working volume for each mixing tank is approximately 40 gallons. The tank outlet valves are large slide gates that allow the thickest materials to fall easily into the pump hopper. The holding hopper has an auger in it to keep the material thoroughly mixed while constantly supplying the grout pump with material for continuous pumping operation. The grout pump is a variable speed, positive displacement, progressive cavity, rotorstator pump. The pump is rated for 20 gpm. Hydraulic fluid is used to move the impeller and pump, and the flow/pressure of the hydraulic fluid is controlled via a diesel motor. The vendor also provided a magnetic flow meter and a pressure gauge. These items are discussed in more detail in section 2.2.4.

To simplify water addition to the mixers, a water hold tank was installed by the vendor that can dump a specified volume of water into either mixing tank within 30 seconds. Once this tank is emptied, it can be immediately filled by opening a water supply valve. This hold tank can contain any specific volume of water up to approximately 40 gallons, and this volume is controlled via an adjustable overflow weir. The overflow weir was calibrated by weighing out the water (161.33 pounds of water) for a grout batch of 38 gallons and then secured.

To assist in the addition of dry solids (MF 816 and slag) into the mixing tanks, the solids were pre-batched into supersacks that contained enough solids to make a 38 gallon batch of grout. Each supersack contained eight 55 pound bags of MF 816 and 48.89 pounds of Slag. Figure 2-14 shows a supersack being transported to the mixer. 
WSRC-STI-2008-00298

Rev. 0

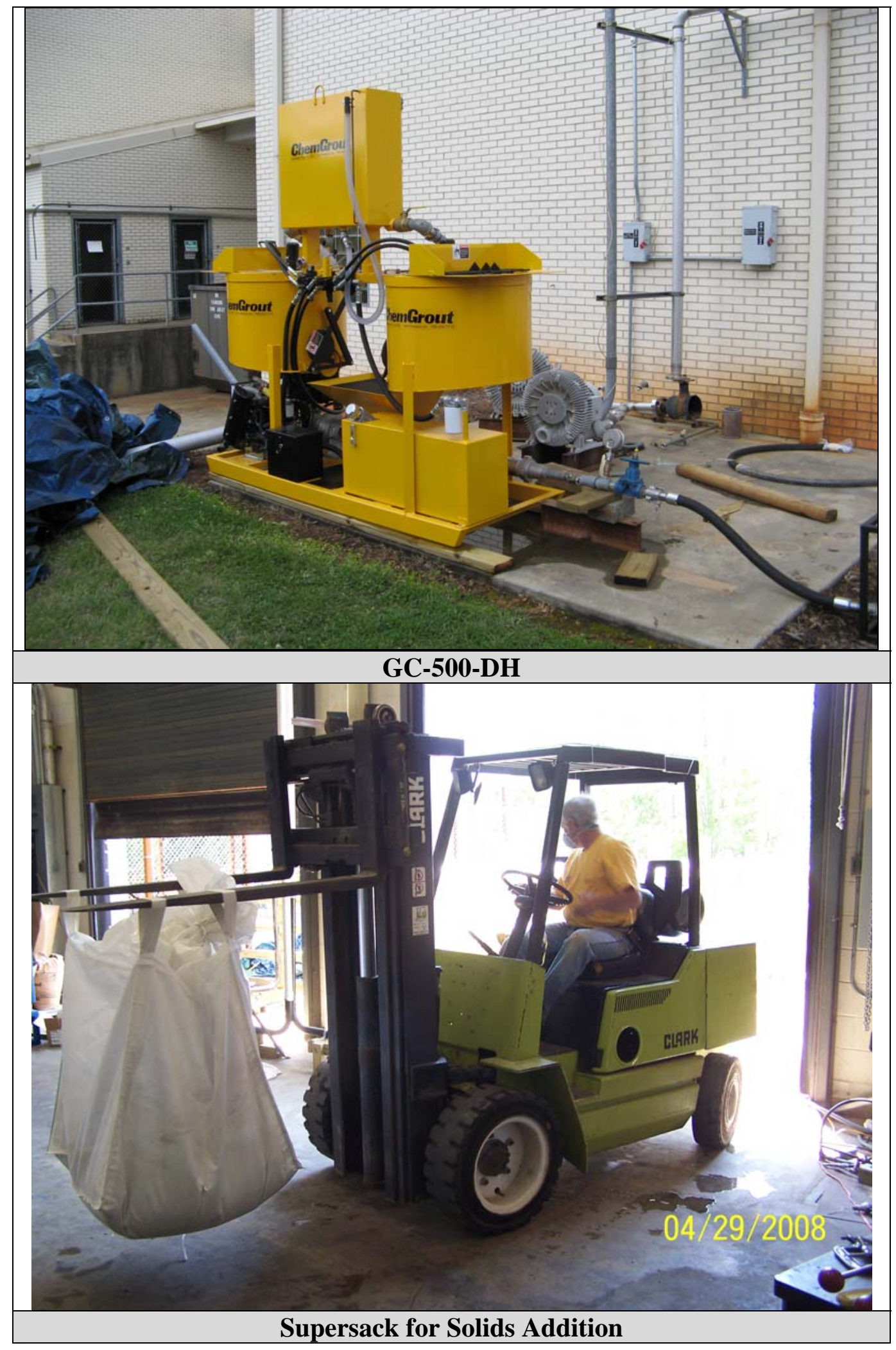

Figure 2-14 ChemGrout GC-500-DH and Supersack 
Once the grout has been made in the mixing tank, it is discharged onto the top of the hopper. A pump was attached to a grout recirculation system such that part of the flow would go to the cooling coil assemblies and part of the flow would be returned to the top of the hopper.

Based on the results from the vertical cooling coil test (see section 3.2), SRNL determined that a different processing method should be undertaken to minimize air entrainment for the horizontal cooling coil test. A mixing tank that could hold all of the batched grout was set up with an agitator designed to remove air. The selected mixing tank could hold up to 500 gallons, had an inside diameter of 47 inches, and a bottom impeller. The impeller was located four inches from the bottom of the tank and contained four flat blades that were four inches wide and thirteen inches long. The mixing assisted in the removal of entrained air by moving the material to the surface and by entraining air on the back side of the blades. During the mixing process using flat blades, air is trapped on the back side of the blades, due to a low pressure region generated during agitation. Prior to pumping out the tank contents, agitation would have been stopped for the whole duration of pumping out the contents in the 500 gallon tank, to release the entrain air from behind the impeller and to prevent the formation of a vortex that would entrain air. Unfortunately, the day before the horizontal run, during functional checkout of the 500 gallon mixing tank using water, the agitator shaft failed. A backup plan was initiated, the agitator was removed, and a 10-inch marine impeller was installed through a tank top port (see Figure 2-15). The marine impeller was located above and near the tank outlet. The agitation provide by this type of impeller is not optimal for air removal. During pump down operations, the speed of this agitator was monitored and reduced to prevent the formation of a vortex which would entrain air into the mix.

To further reduce air entrainment, the suction to the grout pump was enclosed and a pump suction line was installed between the tank and grout pump. This can be seen in Figure 2-15. This modification also resulted in the recirculation line being re-routed to the 500 gallon mixing tank.

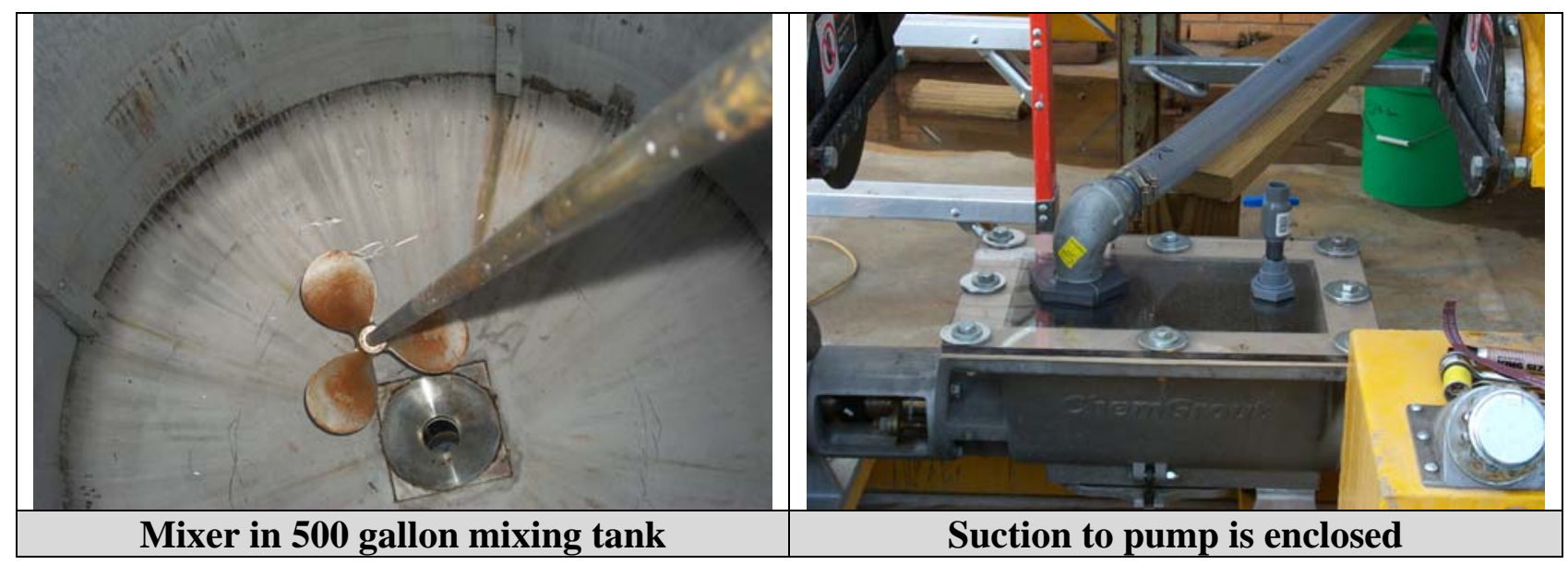

Figure 2-15 System Modifications to Reduce Air Entrainment 


\subsubsection{Instrumentation and Setup}

The instrumentation used to measure the pressures and flow in both the vertical and horizontal cooling coil assemblies is shown in Table 2-4. The P1/P2 pressure transducers were calibrated and are traceable to National Institute of Standards and Technology (NIST). The transducer sensors were flush mounted to the inside of the piping. The pressure gauge supplied by the grout mixing/pumping vendor had a diaphragm oil filled connection. This pressure gauge was not calibrated due to the time limitation placed on the vendor. The magnetic flow meter was calibrated by the Fisher using NIST traceable scales and flow tests at the Fisher's test facility. This magnetic flow meter was also functionally verified using both water and grout at five and ten gpm, via a bucket test.

Table 2-4 Instrumentation used in Vertical and Horizontal Cooling Coil Test

\begin{tabular}{|c|c|c|c|}
\hline $\begin{array}{c}\text { Instrumentation } \\
\text { pressure transducer }\end{array}$ & Location & Range & Accuracy \\
\hline Winters, 4” Stainless Steel & $\begin{array}{c}\text { Grout } \\
\text { Mixer/Pump }\end{array}$ & $0-200 \mathrm{psig}$ & $\pm 2.8 \mathrm{psig}$ \\
\hline $\begin{array}{c}\text { Siemens, sensor FM } \\
\text { Magflo 5100W, DIN 25, } \\
\text { meter FM Magflow } \\
\text { 5000W }\end{array}$ & $\begin{array}{c}\text { Grout } \\
\text { Mixer/Pump }\end{array}$ & $0-80.8 \mathrm{gpm}$ & $\begin{array}{c}0.5 \% \text { of reading above } \\
1.5 \mathrm{ft} / \mathrm{sec} \text { pipe flow }\end{array}$ \\
\hline
\end{tabular}

The vertical cooling coil assembly contained three 18.5 foot lengths that were made from black iron piping. Each of these pipes was instrumented with two sets of three T-type thermocouples (T/C). The two sets of T/Cs were placed one foot apart. In each set, a single pipe centerline and two external pipe wall measurements were made as shown in Figure 2-16. Rigid fiberglass insulation (McMaster Carr, item\# 5556K76), two inches thick and three feet long was centrally placed over the two set of measurements as shown in Figure 2-16. The pipe insulation was placed on two of the vertical pipelines. The K-factor for this insulation is $0.46 \frac{\mathrm{Btu} \cdot \mathrm{in}}{\mathrm{hr} \cdot \mathrm{ft}^{2}}$ at $75^{\circ} \mathrm{F}$. Two additional T-type T/Cs were used to measure the ambient temperature. All of the T/Cs were functionally loop (from the T/C to the computer) verified using both an ice bath and boiling water. A NIST traceable T/C was used in the ice bath and boiling water. The horizontal cooling coil assembly was not instrumented with T/Cs because it was located outside, where the environmental effects, such as sun or rain would had made these results difficult to interpret the results during the curing process. 


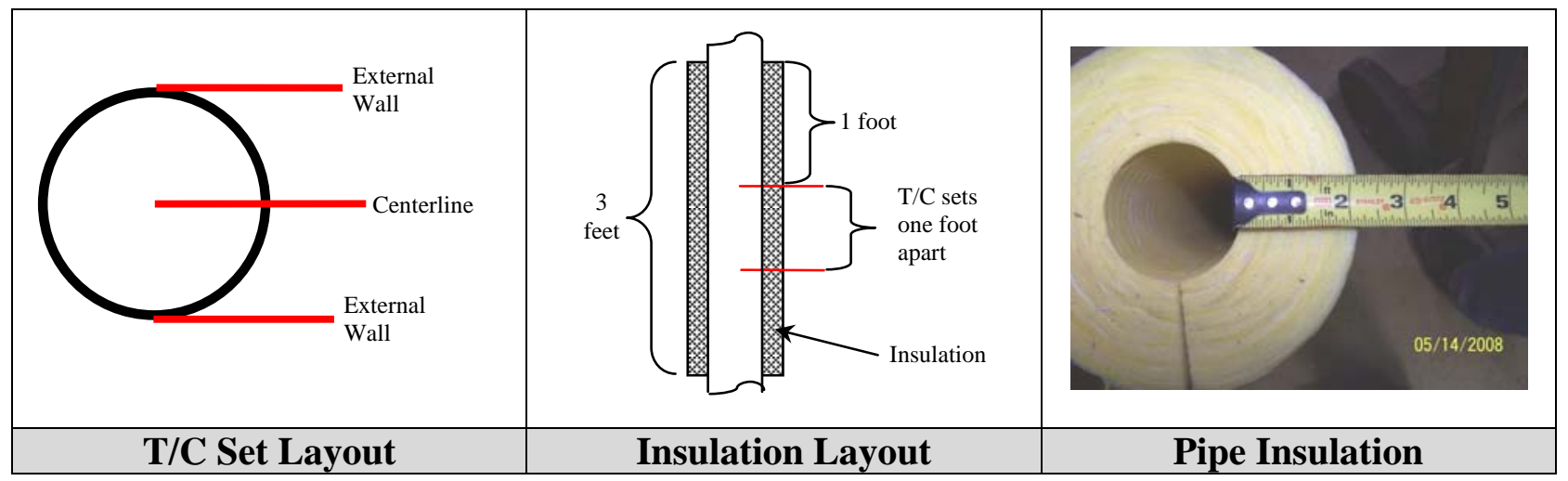

Figure 2-16 Thermocouple Layout and Pipe Insulation - Vertical Cooling Coil Lines

\subsubsection{Grout Characterization}

Grout samples were obtained from processed batches at the mixer and from the discharge of the pipe on the $3^{\text {rd }}$ level, and they were delivered to SRNL for analysis. These grout samples were analyzed for weight percent water content (wt\% WC) and density. The wt\% WC was used to provide information on the grout contents in the cooling coils relative to the batched grout at the mixer and on the length of the mixing zone between the grout and the water that was initially in the cooling coils. The density measurements were performed to compare the bench scale [5] result to the process results.

The wt\% WC was measured using a Mettler Toledo HR83 Halogen Moisture analyzer. This moisture analyzer uses a load cell that continuously measures the mass of the sample during the measurement. Moisture is driven off using a halogen heat lamp which is controlled by an infrared thermometer. The mass of a sample pan is first measured and the weight tarred. Approximately a 1 to 3 gram sub-sample of the crushed cured grout is placed onto the sample pan and this mass $\left(\mathrm{m}_{\text {initial }}\right)$ is recorded by the analyzer. The temperature of the sample is then ramped to $105^{\circ} \mathrm{C}$ and maintained at $105^{\circ} \mathrm{C}$ throughout the measurement. The measurement stops when the weight of the sample does not change more than one milligram over a period of 20 seconds and this final mass $\left(\mathrm{m}_{\text {final }}\right)$ is recorded by the analyzer. The wt\% $\mathrm{WC}$ is then determined using equation (1). Duplicate samples are run and averaged. The analyzer load cell is checked on a daily basis (when used) using a 2.0 gram weight and functionally checked using a $7.0 \mathrm{wt} \% \mathrm{NaOH}$ solution.

$$
w t \% W C=\frac{m_{\text {initial }}-m_{\text {final }}}{m_{\text {initial }}} \times 100 \%
$$

The density of the cured grout was measured using a Quantachrome Stereopycnometer. The pycnometer is functionally checked using a shape with a defined volume on a daily basis to verify that the volume constants $\left(\mathrm{V}_{\mathrm{A}}\right.$ and $\left.\mathrm{V}_{\mathrm{S}}\right)$ are still accurate. Approximately 40 to 80 grams of the cured grout $\left(\mathrm{m}_{\mathrm{p}}\right)$ are placed in the sample cell. Nitrogen was introduced into the sample cell at between 15 to 20 psig, with the pressure $\left(\mathrm{P}_{\mathrm{A}}\right)$ allowed to equalized. A reference cell was then 
opened and the pressure $\left(\mathrm{P}_{\mathrm{B}}\right)$ is allowed to equalize and is recorded. The volume of the sample was determined using equation (2). Triplicate measurements were performed and the average volume determined. The density of the cured grout was determined using equation (3). This method was used to measure the density of the bench scale cured grout and is not typically the method used for determining the bulk density of a grout. Parameters that impact the density measurement include: grout sampling technique, curing time of the grout (bubbles can move from one region to another in the sample), transportation/vibration of the samples prior to curing, and the preparation of the samples for analysis.

$$
\begin{aligned}
& V_{P}=V_{C}+\frac{V_{A}}{1-\frac{P_{A}}{P_{B}}} \\
& \rho_{P}=\frac{m_{p}}{\bar{V}_{p}}
\end{aligned}
$$

During actual operations, flow cone (see Figure 2-17) measurements were performed to determine the flowability of the grout during pumping operations. The flow cone measurement was performed based on ASTM C939 [7]. The flow cone was leveled, a predetermined volume of water was placed in the cone, allowed to stabilize, and the level indicators were set. The water was then allowed to discharge the cone and the time measured until the first break in the continuous flow was observed. The water must flow out of the cone within $8 \pm 0.2$ seconds. Prior to the grout flow measurements, water was added to the predetermined level to wet the internal surfaces of the cone. The grout was added, allowed to equalize (within a minute), the discharge was opened and the time $\left(\mathrm{T}_{\text {flow }}\right)$ was recorded when the first break in the continuous flow was observed. When a batch was measured for flow, only one measurement was performed. The allowable flow time for this grout is provided in Table 2-1. 


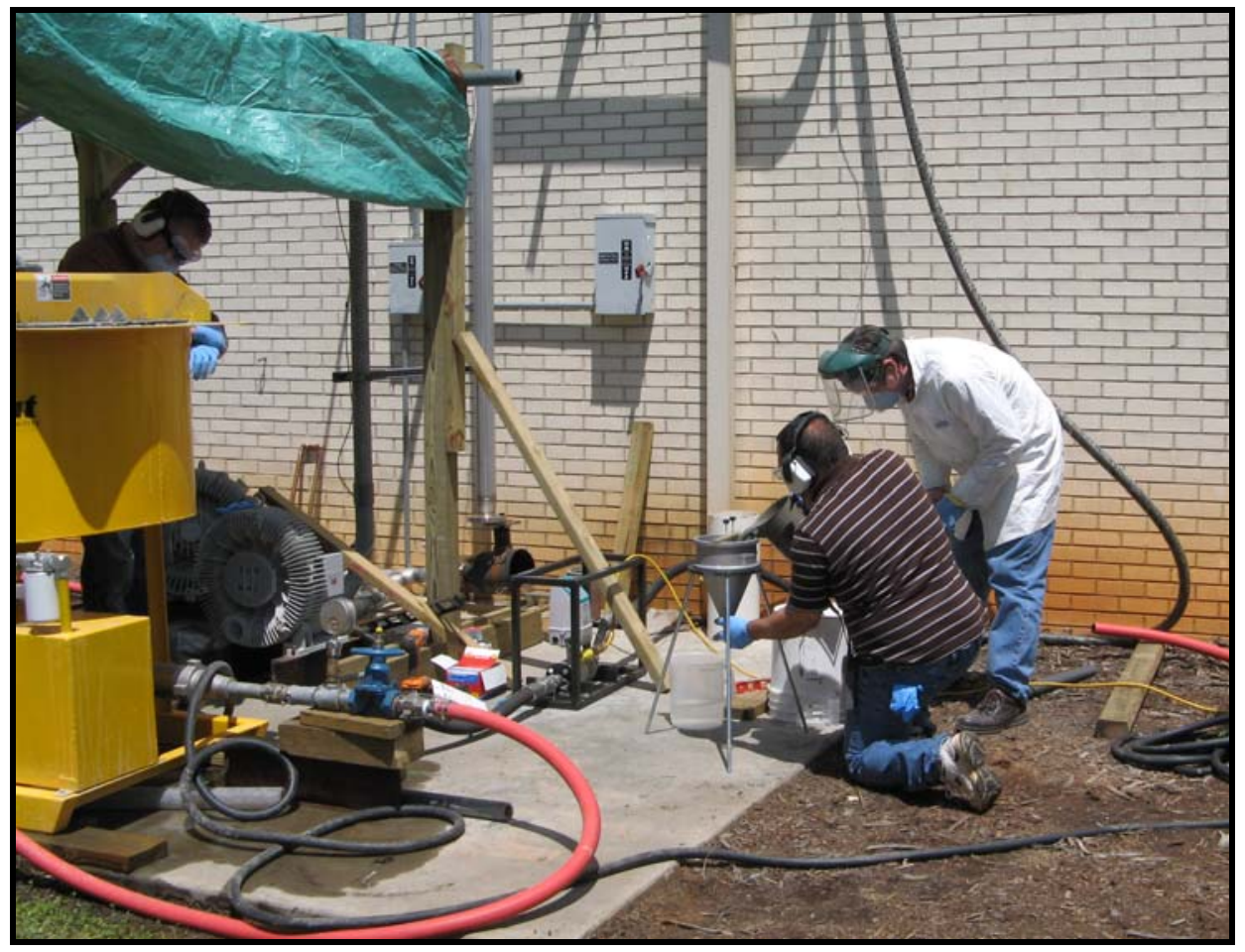

Figure 2-17 ASTM C939 Flow Cone Measurement

After the grout had cured in the piping, sections of piping were cut and pictures were taken of the sectioned piping. These pictures provide a visual indication of how well the grout filled the piping.

A few subsections from the vertical piping run were analyzed using $x$-ray tomography. This provides a gross indication of homogeneity or voids. There was no x-ray tomography performed on the bench scale samples.

\subsubsection{Operating Conditions - Run Plans}

There were two run plans, one for the vertical cooling coil assembly [8] and one for the horizontal cooling coil assembly [9]. The run plans are summarized below.

For the vertical cooling coil assembly, a total of five 38 gallon batches were made. Targeted flow rate was between five and eight gpm. Samples were pulled from the second and fifth batches in the grout mixing equipment and analyzed for water content, density, and flow. Samples were pulled from the discharge on the $3^{\text {rd }}$ floor every minute once solids were first noticed leaving the discharge pipe. These samples were analyzed for water content and density.

For the horizontal cooling coil assembly, a total of nine 38 gallon batches were made and pumped to the 500 gallon mixing tank prior to processing. Each batch was mixed in the GC$500-\mathrm{DH}$ for at least six minutes after all the solids had been added prior to pumping the slurry 
directly to the 500 gallon mixing tank. During filling, the agitator speed was increased to maintain motion, without creating a vortex. The targeted flow rate leaving the mixing tank was between 15 and 28 gpm and this flow was controlled using the diesel motor, because the recirculation line was not active during this fill. A sample was pulled from the 500 gallon mixing tank after seven minutes of pumping and analyzed for water content, density and flow. Samples were pulled from the discharge every 30 seconds once solids were first noticed leaving the discharge. These samples were analyzed for water content and density.

\subsubsection{Visual Aid for Void Fraction in Piping}

A criterion in the TT\&QAP [2] states that the void fraction should be less than four volume percent. Figure 2-18 shows a cross-section of what four volume percent would look like, assuming that the voids can be treated as infinite cylinders. One circle contains a single void and the other circle contains 100 voids that equate to four volume percent. This figure provides a reference to which the cured grout from the sectioned piping can be compared.

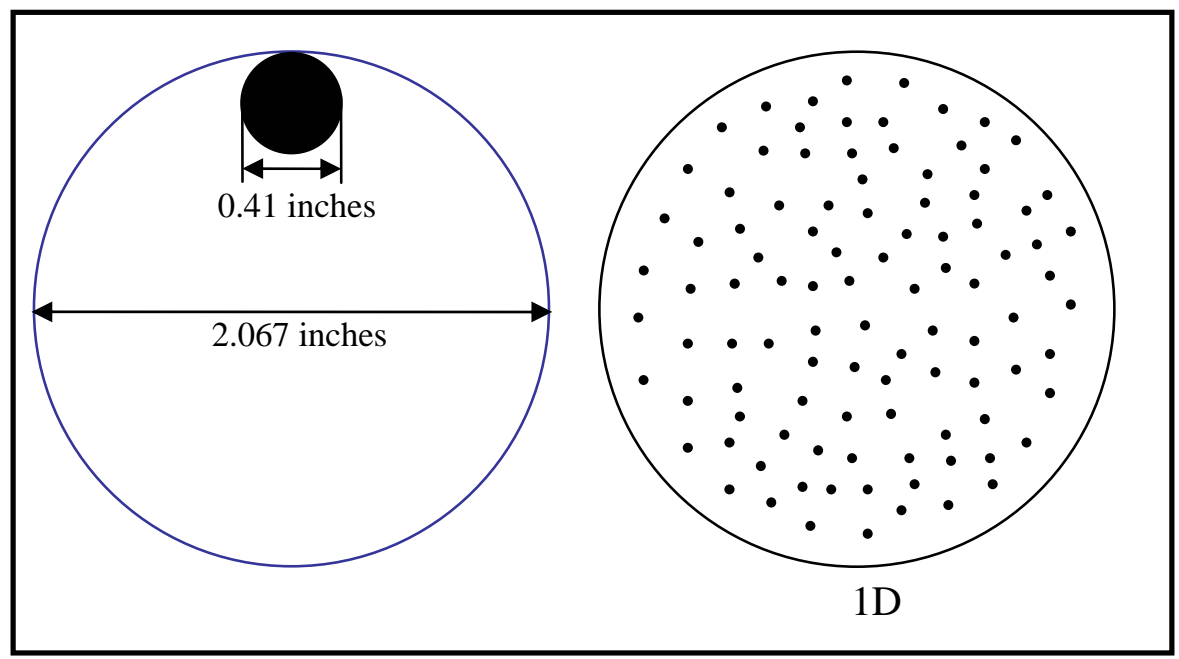

Figure 2-18 Four Volume Percent Void in 2 inch Piping

\subsubsection{Sectioning of Vertical Cooling Coil Assembly}

The sectioning of the vertical cooling coil assembly after the grout has cured is shown in Figure 2-19 and Figure 2-20. These figures show where the cuts in the vertical and horizontal piping were made. A majority of the sections of piping were photographed after the sections were cut flush using a chop saw. Sections of piping between the cuts were also photographed. 


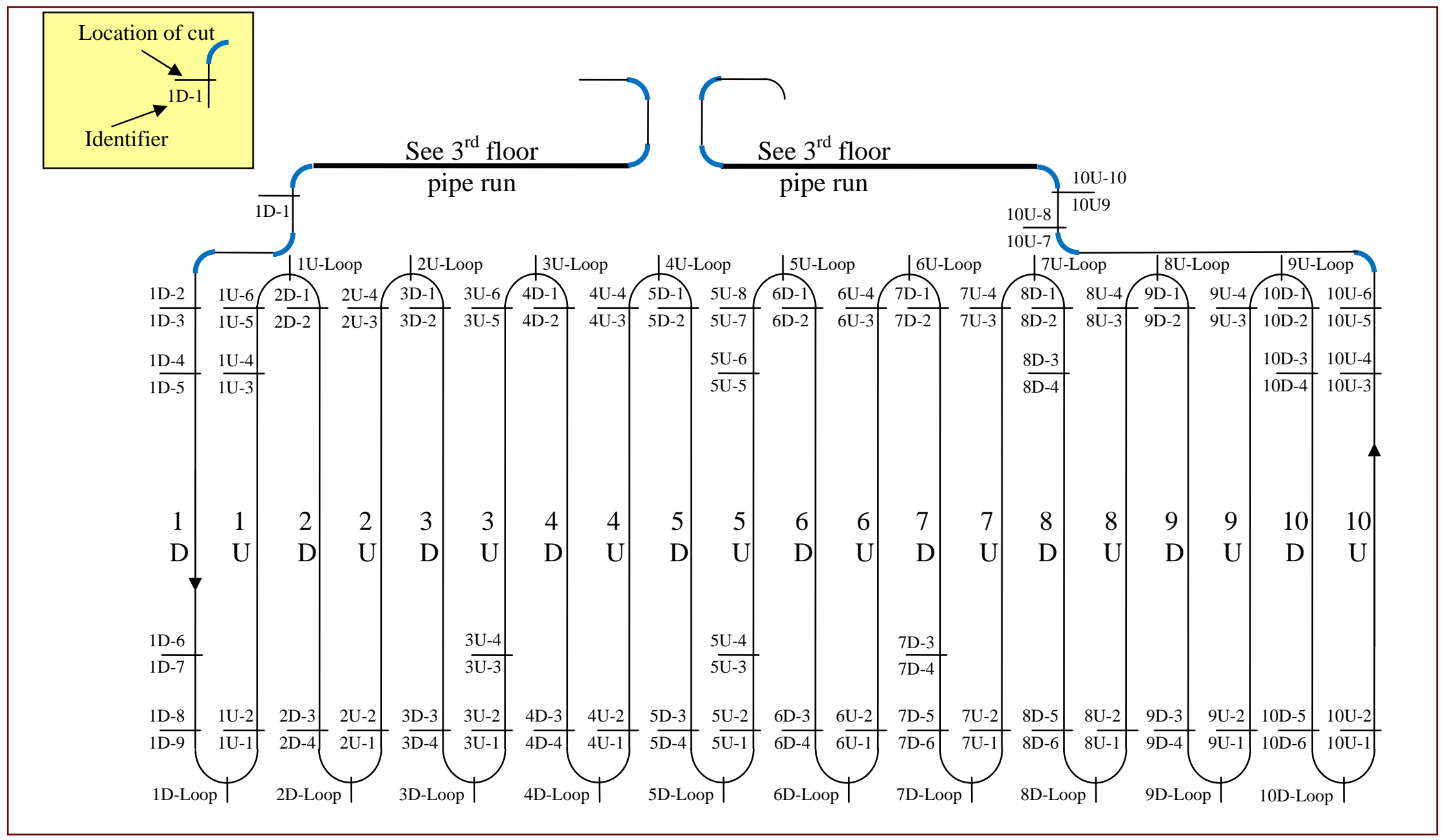

Figure 2-19 Vertical Cooling Coil Assembly - Section Marks 
WSRC-STI-2008-00298

Rev. 0

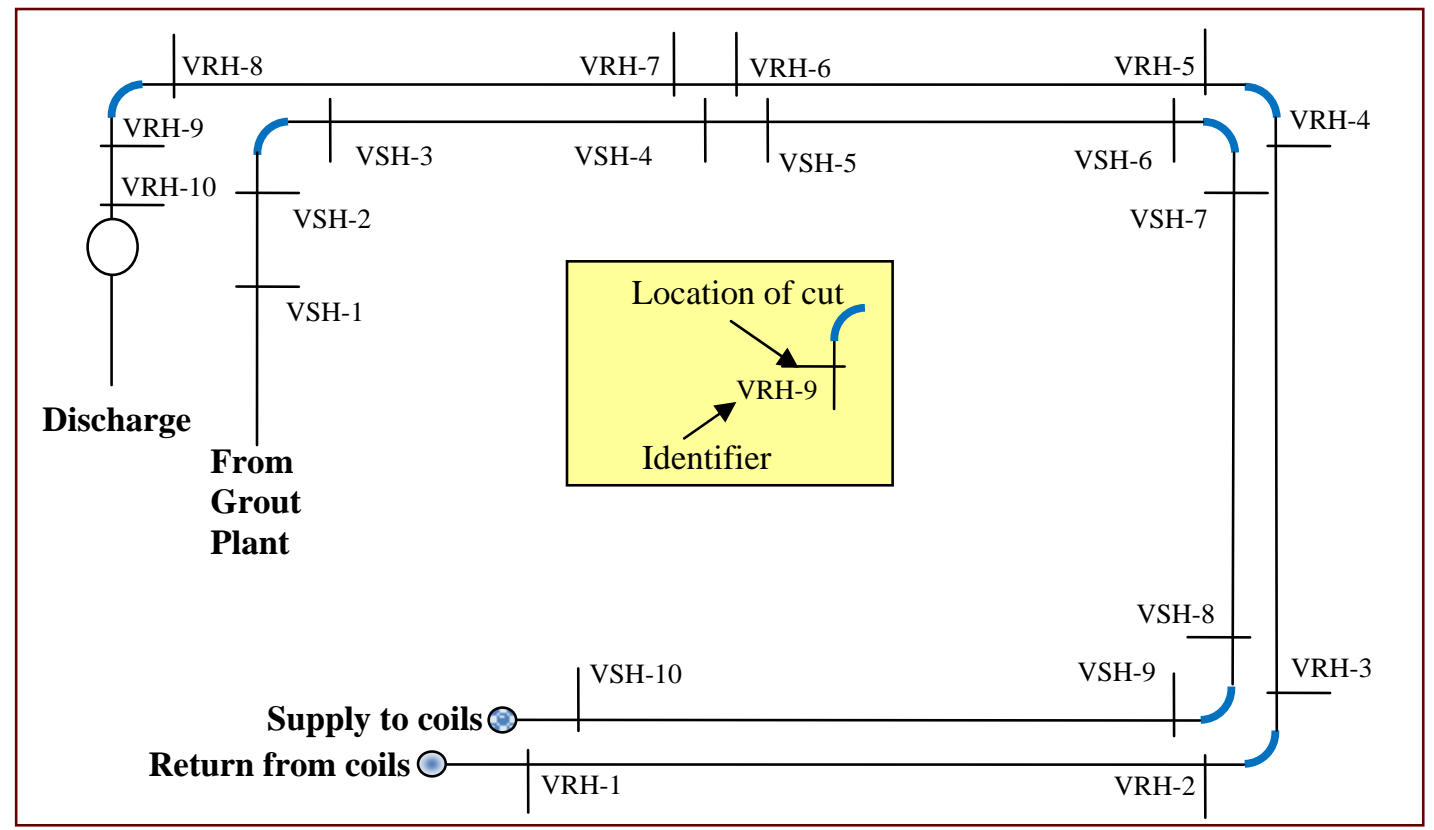

Figure 2-20 Horizontal Piping Run for the Vertical Cooling Coil Assembly on the $3^{\text {rd }}$ floor - Section Marks

\subsubsection{Sectioning of Horizontal Cooling Coil Assembly}

The sectioning locations of the horizontal cooling coil assembly after the grout has cured are shown in Figure 2-21 and Figure 2-22. These figures show where the cuts in the vertical and horizontal piping were made. A majority of the sectioned piping were photographed after the sections were cut flush using a chop saw. Sections of piping between the cuts were also photographed. 
Rev. 0

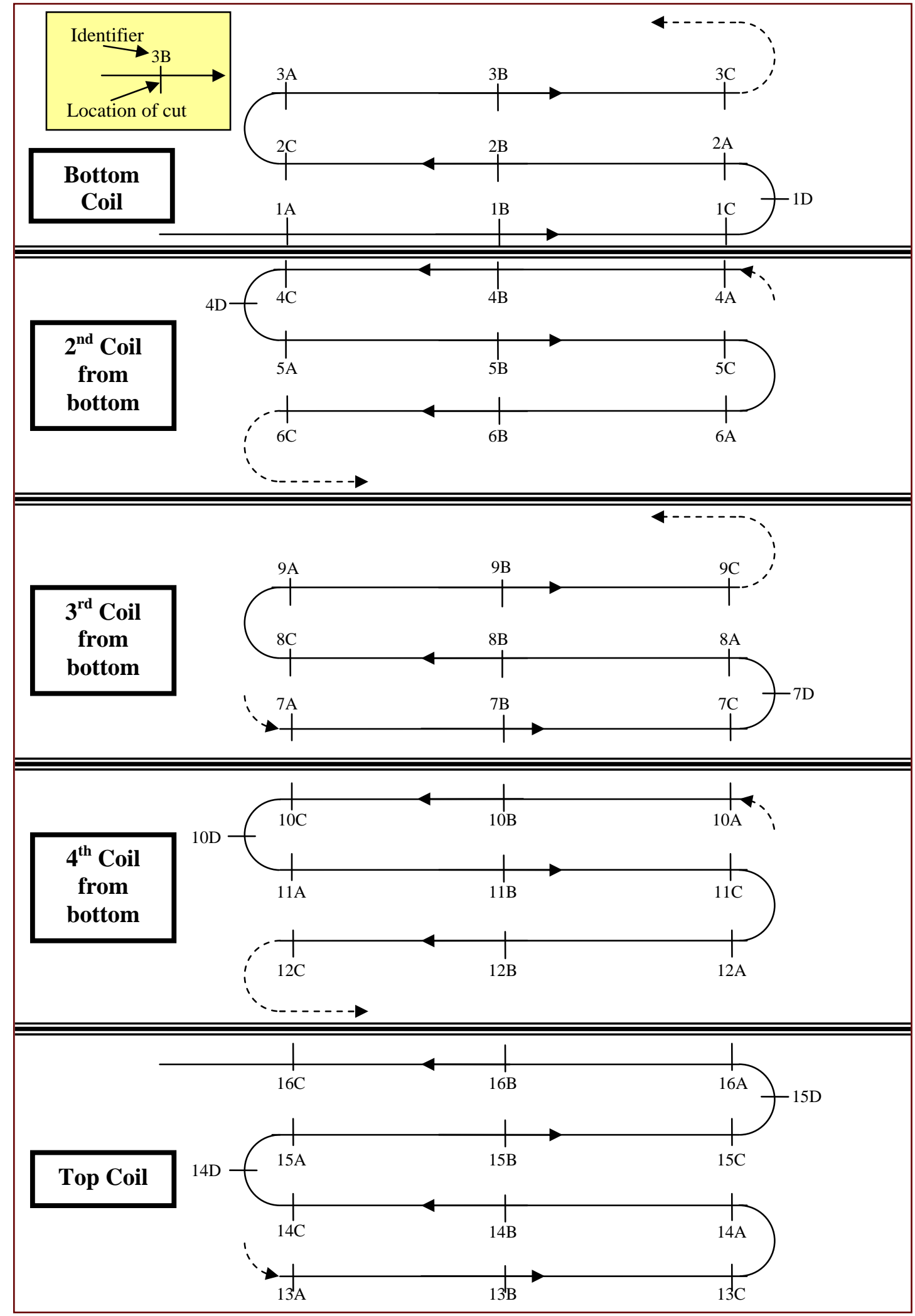

Figure 2-21 Horizontal Cooling Coil Assembly Located Outside - Section Marks 


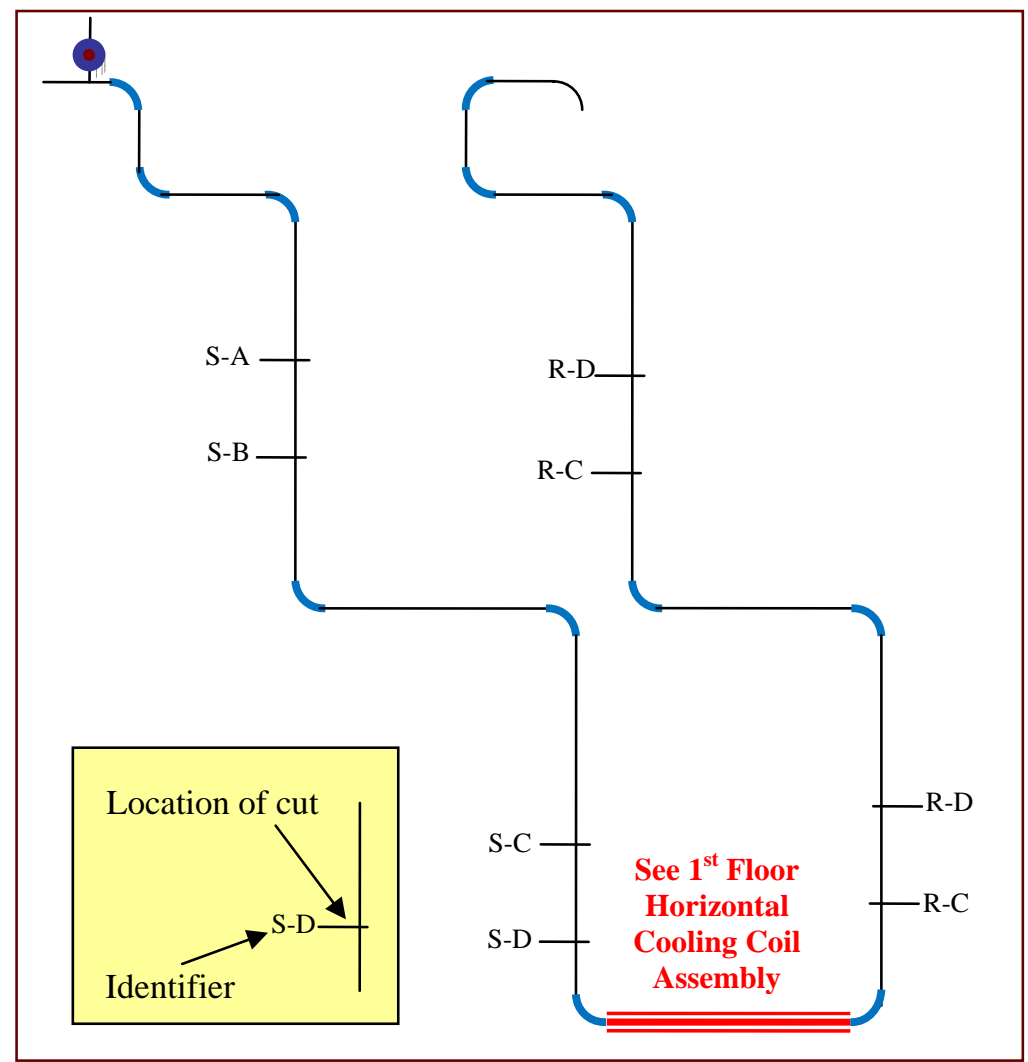

Figure 2-22 Vertical Piping Run for the Horizontal Cooling Coil Assembly - Section Marks

\subsection{RESULTS AND DISCUSSION}

\subsection{Pre-Operational}

The filling of the cooling coil assemblies with water (prior to filling the assemblies with grout) provided useful operational insight (in addition to leak testing the system). The vertical cooling coil assembly was initially loaded with water at a flow rate of five to eight gpm. During this evolution, the flow of water was not fast enough to entrain the air and push it out, nor did it provide enough turbulence to create small bubbles that could be transported in the downward vertical direction. Large quantities of air were trapped in the upper sections of the vertical piping and the majority of it gathered in the upper $180^{\circ} 2$-foot radius bends. Air voids were also present in the horizontal piping supply/return lines. To correct for these problems, the maximum flow rate of $28 \mathrm{gpm}$ provided by the GC-500-DH and using approximately two times the volume of the vertical cooling coil were used to remove the air from the vertical cooling coil assembly.

For the horizontal cooling coil assembly, flow rates of five to eight gpm were also tested, that resulted in the water traveling on the lower cross-sectional area of the piping, leaving an air gap on top of the horizontal sections of piping. During the horizontal fill, 25 gpm and approximately two times the volume of the horizontal cooling coil were used to remove the air from the assembly. 
Based on experience in filling the cooling coils with water, the decision was made to fill the cooling coil assemblies with grout after the cooling coils were completely filled with water. The opaque nature of the grout would have caused problems in identifying the flow issues observed when trying to fill the cooling coils with water. To further minimize air entrainment, air in the supply grout hose was also vented when the line was being filled with grout. A vent line was located as close to the maximum liquid level in the cooling coils and was closed when grout exited the vent line.

\subsection{Vertical Cooling Coil Assembly}

The water in the coils was displaced with the grout as shown in Figure 3-1 and the transition between the water to the grout took less than ten seconds, at which point there was no visual difference of the grout that followed. The pressure and flow data taken during the filling of the assembly are shown in Figure 3-2. The flow rate was initially targeted for five gpm during the run, but due to the initial visual observations of the grout entering the cooling coil supply header on the third floor, the flow was quickly increased to eight gpm and remained above six gpm for the remainder of the test. The decrease from eight to just above six gpm is due to the power demands for mixing and transporting the grout. The diesel motor, for a specified diesel speed, supplies a given quantity of power, which is shared by the two agitators and pump. As conditions change, such as mixing speed and hydraulic resistance due to filling the cooling coils, the flow rate will change. The flow rate was initially increased due to the grout undercutting the water at five gpm. This decision did cause some operational stress on the batching of the material in the GC-500-DH given that the batching time decreased from approximately 7.6 to 5.5 minutes. A reduction in mixing time yields a more viscous grout. The maximum flow rate was limited to two variables, the manual batching time and the required time for all of the grout to mix and become fluid. Miscellaneous pictures taken before, during and after the vertical cooling coil assembly run are provided in Reference 17.

Review of the pressure data indicates that the pressure started to stabilize at around 19 minutes into the run, indicating that the cooling coils were filled with the batched grout. Flow cone measurements were made from the first and fifth batch. For the first batch, the sample was pulled after six minutes of mixing and the flow time was 26 seconds, which was within the acceptable range. The fifth batch had a flow time of 42 seconds, which was outside of the acceptable range; however, this sample was pulled too early from the batch (i.e., after only 1.5 minutes of mixing). Because this sample was pulled only 1.5 minutes after the solids were added to the mixing tank rather than after five minutes of mixing, clumps had not had sufficient time to break apart, which impacted the flow measurement. The contents in the tank were allowed to mix for approximately five minutes prior to being pumped to the assembly. The temperature of the grout being pumped into the assembly was $35^{\circ} \mathrm{C}$. 


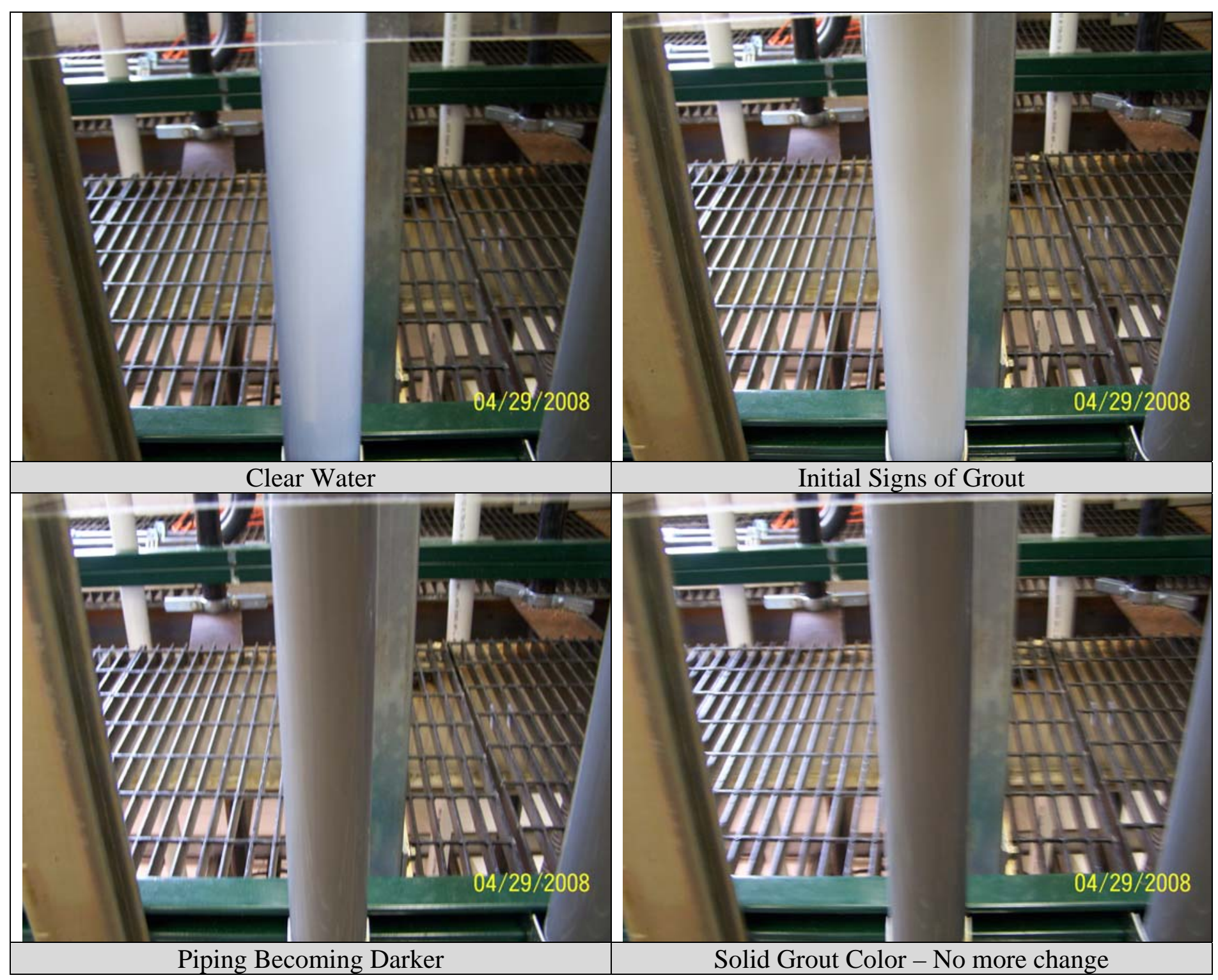

Figure 3-1 Water to Grout Transition in Vertical Cooling Coil Assembly 


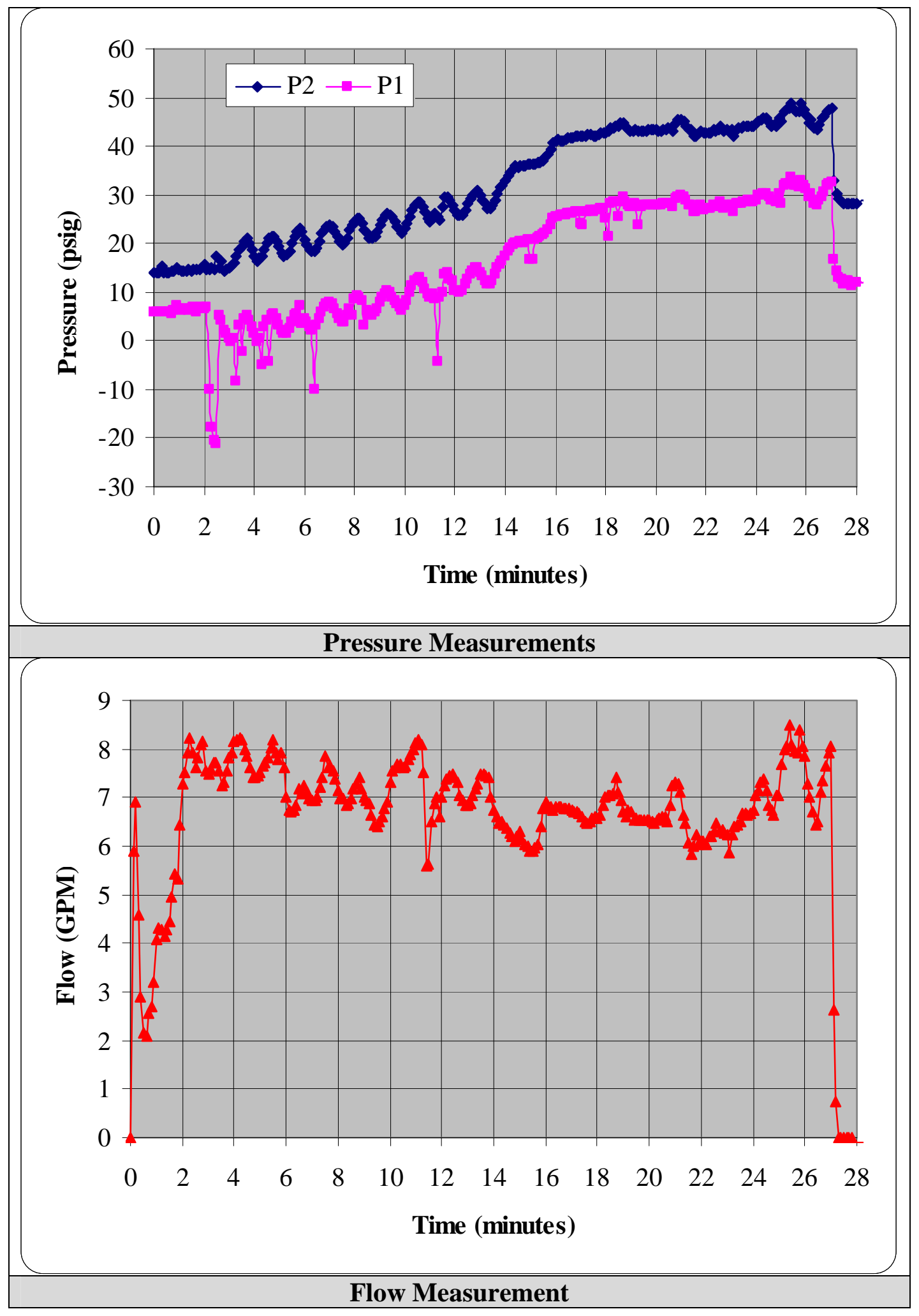

Figure 3-2 Vertical Cooling Coil Process Parameters 
Sampling of the discharge occurred over a period of twelve minutes and resulted in thirteen samples being pulled. The grout discharging the cooling coil assembly is shown in Figure 3-3, just before a sample is about to be taken. Visually, the grout looked very smooth upon discharge. The water content and density of the cured grout samples are provided in Figure 3-4. The first sample ( $\mathrm{t}=15.5$ minutes into the run) was not analyzed because it contained mostly water. The remaining discharge and baseline samples when cured did not have any bleed water. Based on the water content data, five minutes (total run time of 20.5 minutes) after the grout was first observed to be leaving the discharge of the assembly, the characteristics of the grout in the assembly matched those of the batched material. In essence, the mixing zone, given this pumping condition, required approximately 35 gallons of additional grout over that required to fill the cooling coil (cooling coil fill volume was approximately 125 gallons). This data compares well to that of the pressure data. The grout density data from bench scale testing is $2.07 \mathrm{~g} / \mathrm{ml}$ [5]. The density data indicates that the samples, as well as the bench scale are similar, but all the discharge samples were lower in value than the baseline and bench samples, indicating that the discharge samples had slightly more entrained air or voids.

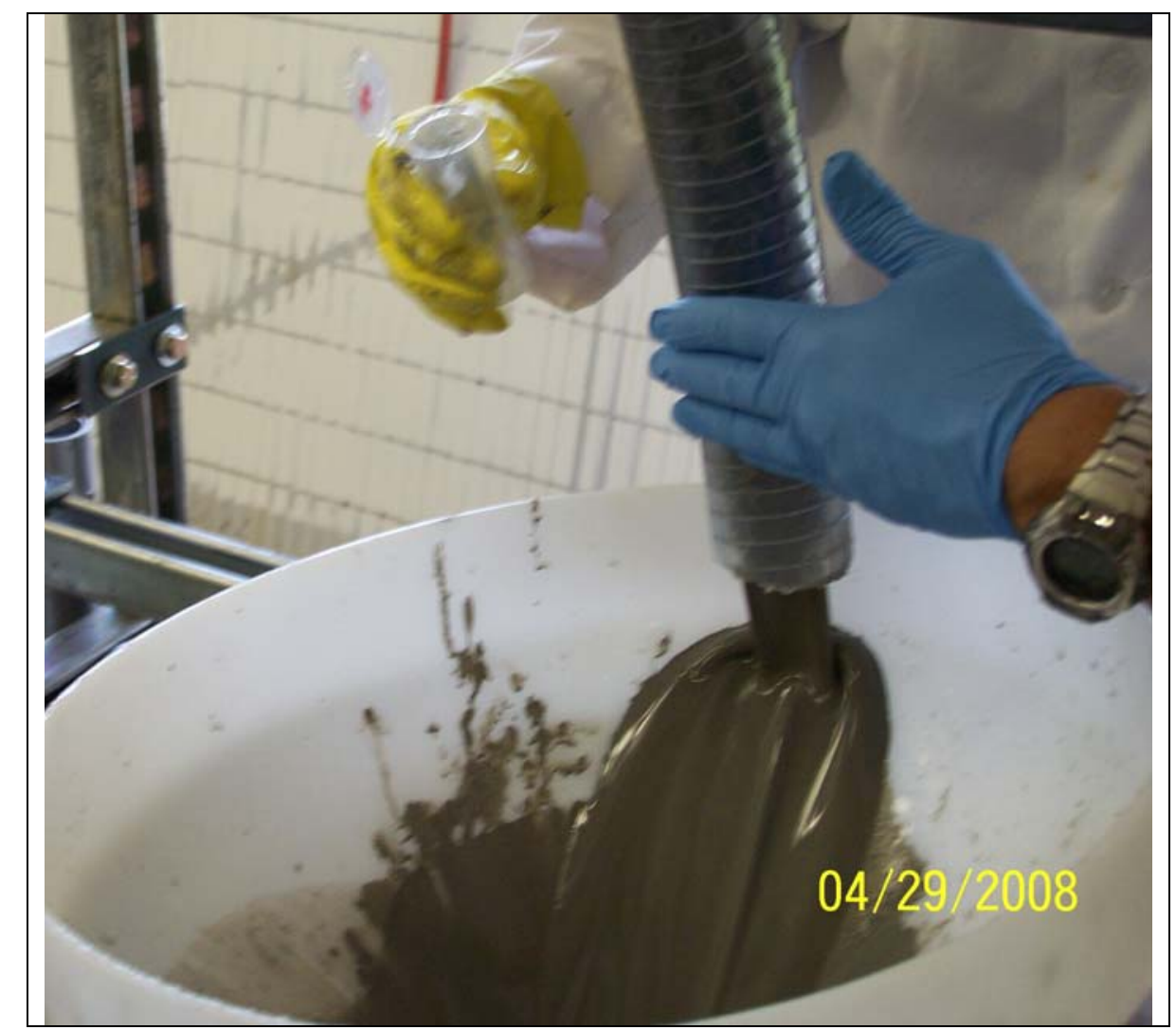

Figure 3-3 Typical Grout Discharging the Vertical Cooling Coil Assembly - Sampling 


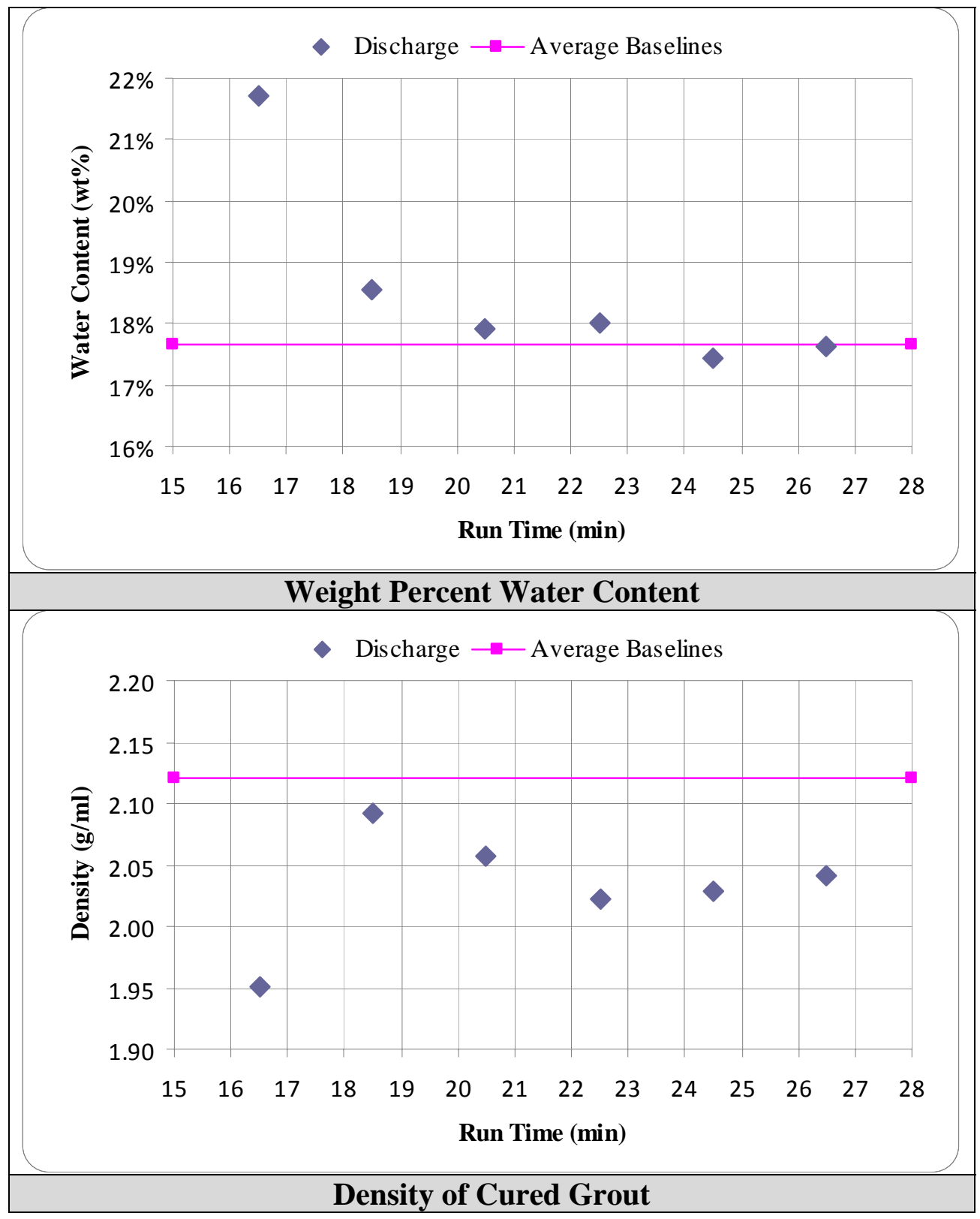

Figure 3-4 Physical Properties of Discharged Grout for the Vertical Cooling Coil Assembly

The temperatures of the curing grout, for the insulated piping sections are shown in Figure 3-5 and Figure 3-6 and the un-insulated piping sections are shown in Figure 3-7. These figures clearly show that if the piping is insulated (such as having cured grout around the pipe, although the heat transfer characteristics of the insulation is most likely not the same as the tank grout fill), then the heat of hydration will cause the temperature of the curing grout to be greater than that of an un-insulated pipe. The insulated pipe reached a maximum temperature of $65^{\circ} \mathrm{C}$ as compared to $35^{\circ} \mathrm{C}$ for the un-insulated pipe. The thermal properties of the curing grout, piping and final heat sink (grout or air) will determine the actual temperature increase. The maximum temperature for all conditions peaks around 9.5 hours after the cooling coil assembly was filled. This data compared well to the peak observed in the normalized heat flow [5]. At approximately 
seventeen hours into the curing cycle, the ambient temperature dropped due to the opening of the high bay doors in the morning. There is active air motion in the location where the vertical cooling coil assembly was located. The ventilation system of the building maintains a fairly constant temperature at this location if the high bay doors are maintained closed.

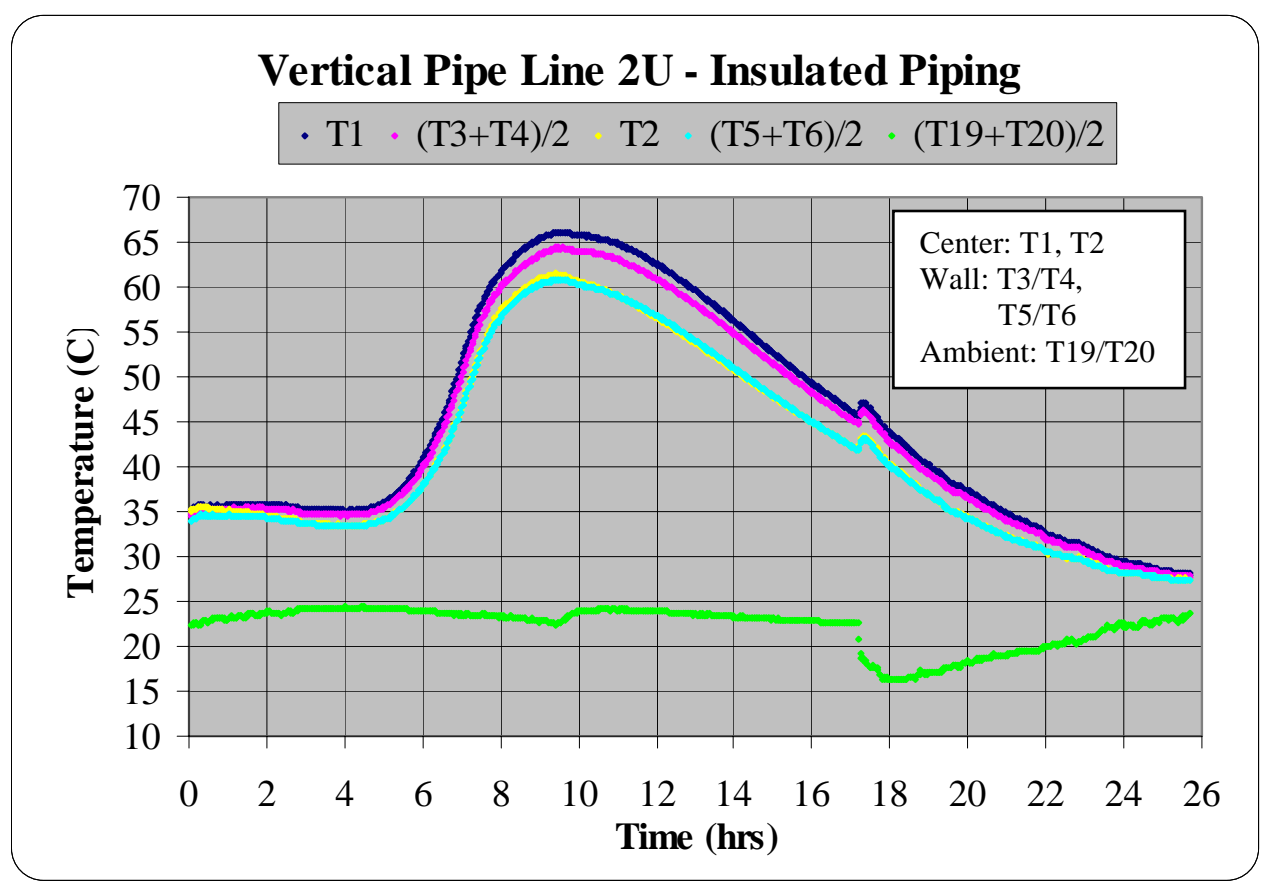

Figure 3-5 Temperature Measurements of Insulated Pipe 2U

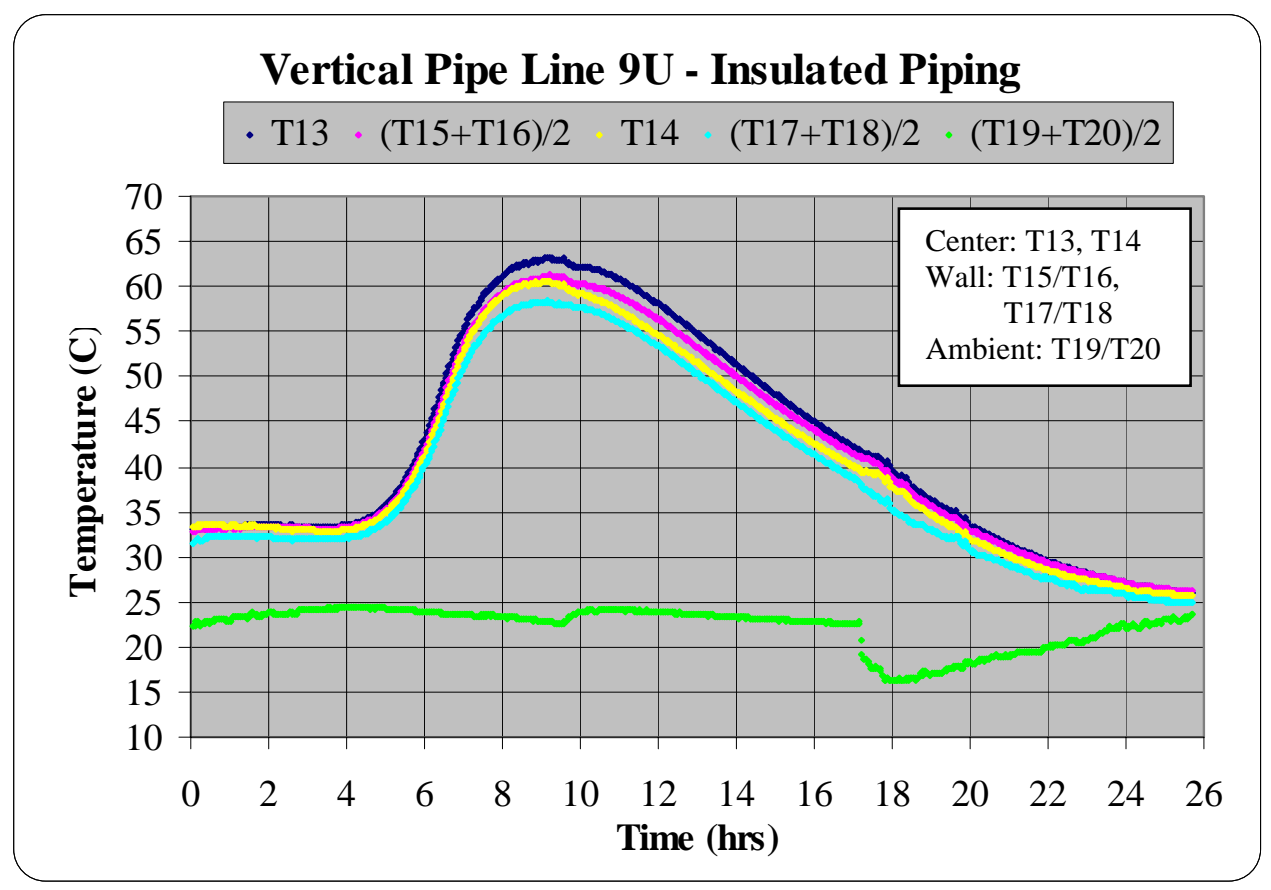

Figure 3-6 Temperature Measurements of Insulated Pipe 9U 
Rev. 0

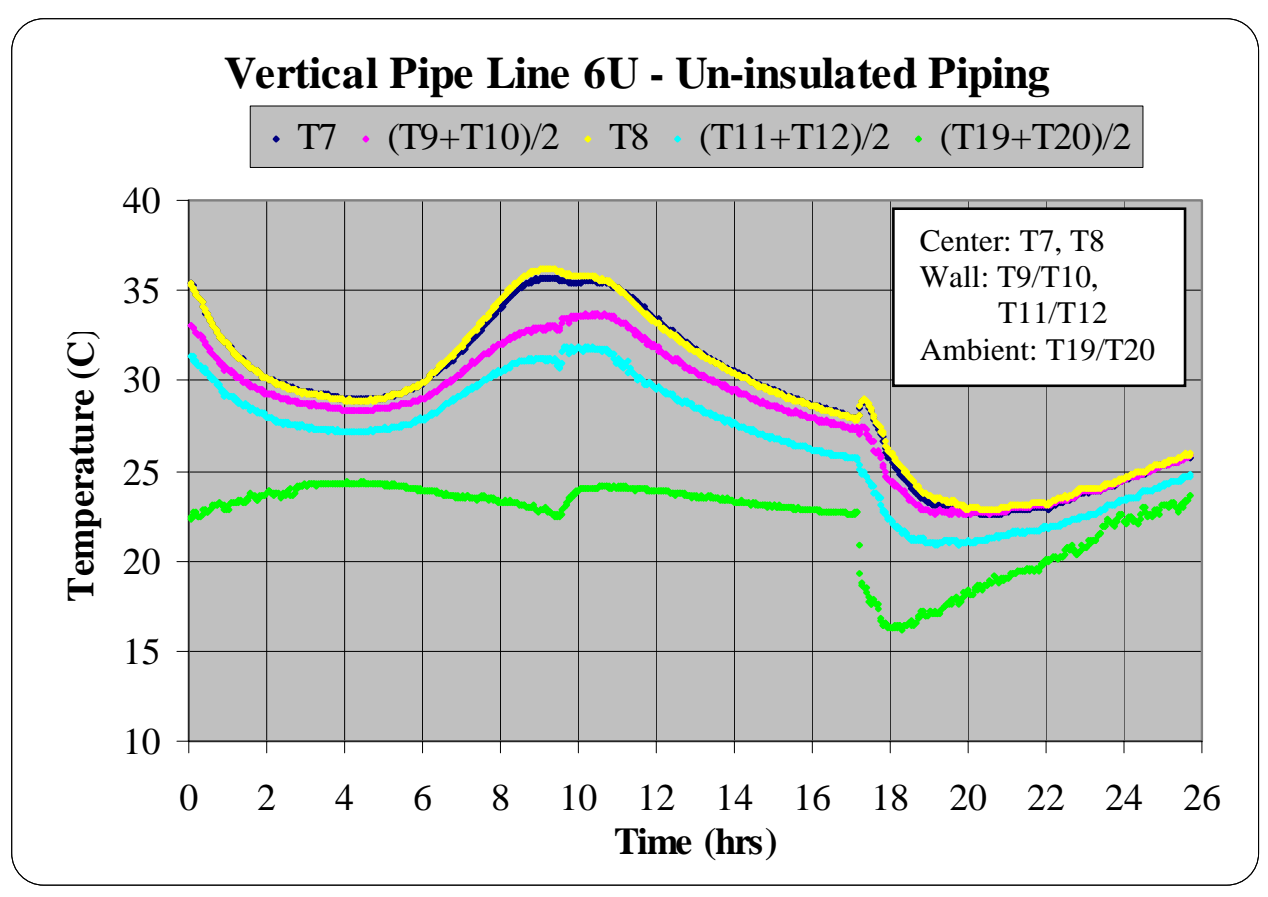

Figure 3-7 Temperature Measurements of Un-insulated Pipe 6U

Examples of sectioned vertical piping of the cured grout are shown in Figure 3-8 and Figure 3-9. Reference 10 contains additional pictures of the cured grout for the vertical cooling coil assembly. Visual examination of all of the vertical sections of piping showed that they were filled with grout and none of them visually had four volume percent void (see Figure 2-18 for what constitutes four volume percent). Very small voids were observed in some of the cuts. There were no continuous voids in any vertical sections. Radiographs of some of the vertical sections are provided in Reference 11 and they do not show voids greater than four volume percent, nor are they continuous. There are no radiographs of the grout made from the bench scale testing [5] for comparison. 


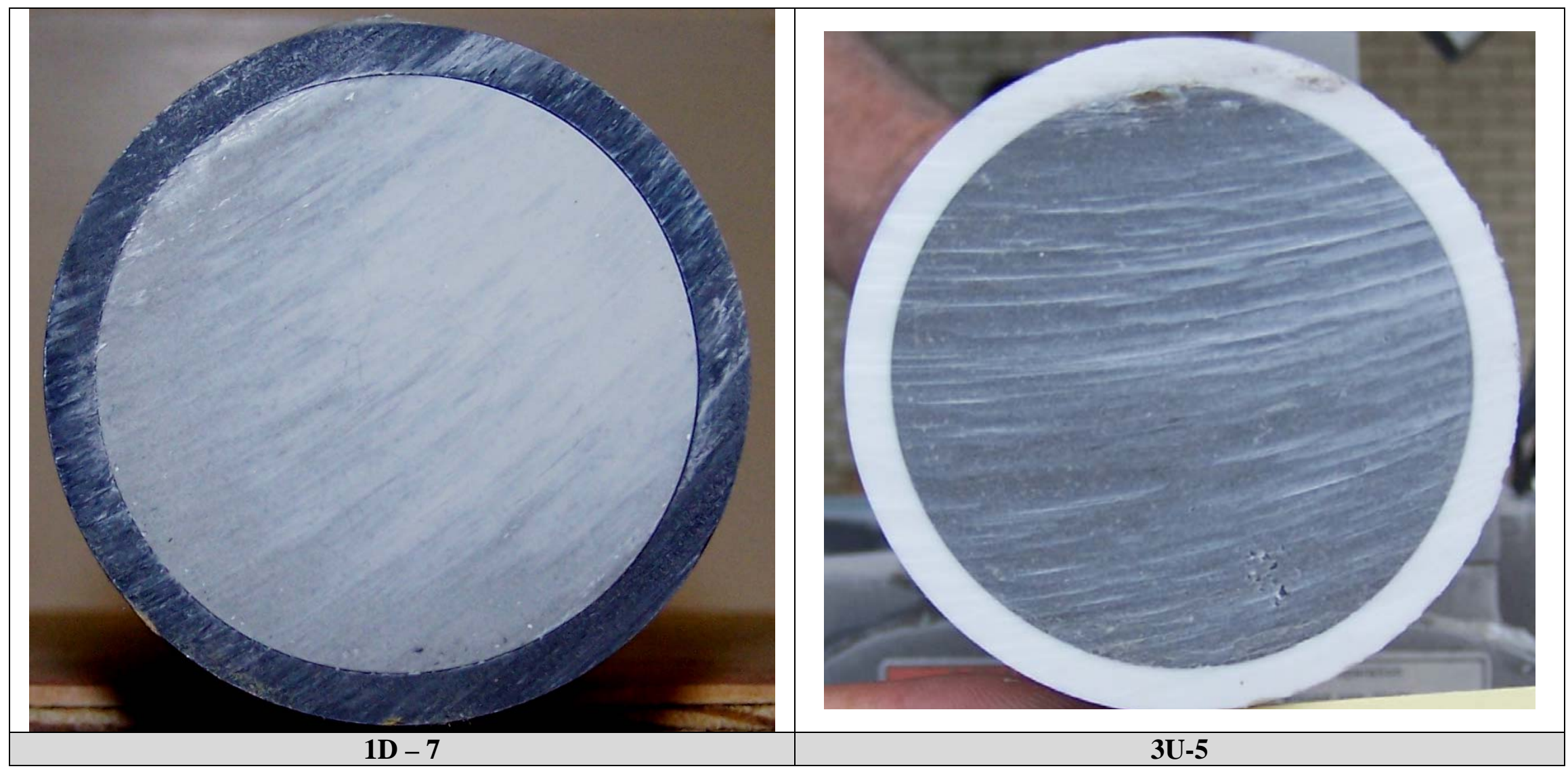

Figure 3-8 Sectioned Vertical Piping 1D and 3U from the Vertical Cooling Coil Assembly 


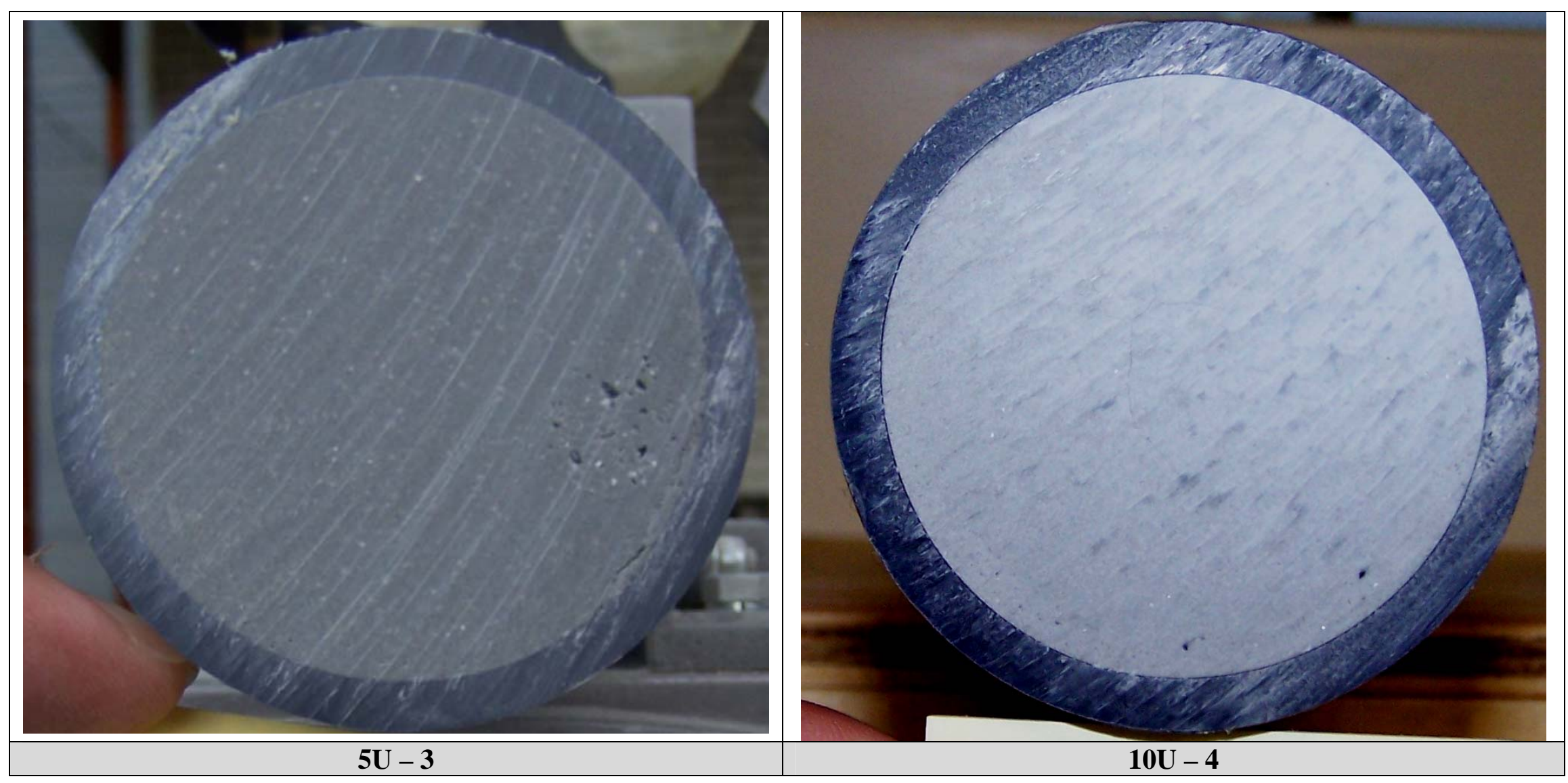

Figure 3-9 Sectioned Vertical Piping $5 \mathrm{U}$ and $10 \mathrm{U}$ from the Vertical Cooling Coil Assembly 
Air voids were present in all horizontal sections of piping. The voids were close to or exceeded the four volume percent in the horizontal supply line, see Figure 3-11. Voids were also present in the return headers and the $180^{\circ} 2$-foot radius bends at the top part of the cooling coils, see Figure 3-10 and Figure 3-11. In Figure 3-10 the $180^{\circ}$ 2-foot radius bend is marked, showing a section where air bubbles were present, but the actual voided bubble length is approximately two to four inches of piping for this loop. The supply header seemed to contain a much larger upper void as compared to the other horizontal piping. The reason for this air is due to the mixing/pumping process employed and the supply header is the first section of horizontal piping, where large voids would displace themselves. The paths for air entrainment in this process (see Figure 3-12) are from air associated with the dry solids being mixed into a slurry, vigorous mixing in the mixing tank, discharging the grout onto the meshed grate at the hopper inlet, and the recirculation line returning a large fraction of the flow onto the meshed grate of the hopper inlet. Based on the experiences with the vertical cooling coil fill, the mixing/pumping process for the horizontal cooling coil assembly was changed to further minimize air entrainment. Additional pictures of the sectioned horizontal piping and $180^{\circ} 2$-foot radius bends for the vertical cooling coil assembly are provided in References 15 and 18. 


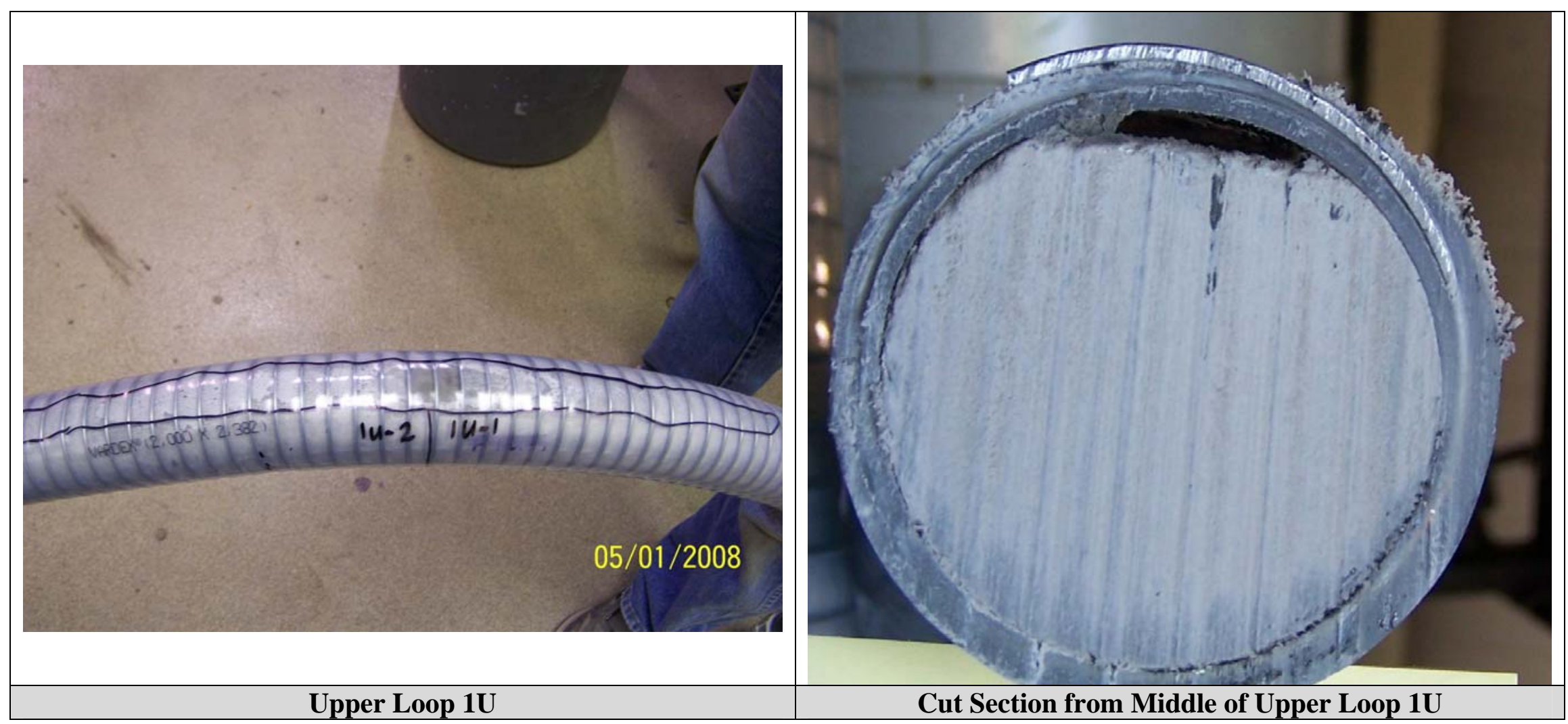

Figure 3-10 Voids in the Upper Loops in the Vertical Cooling Coil Assembly 


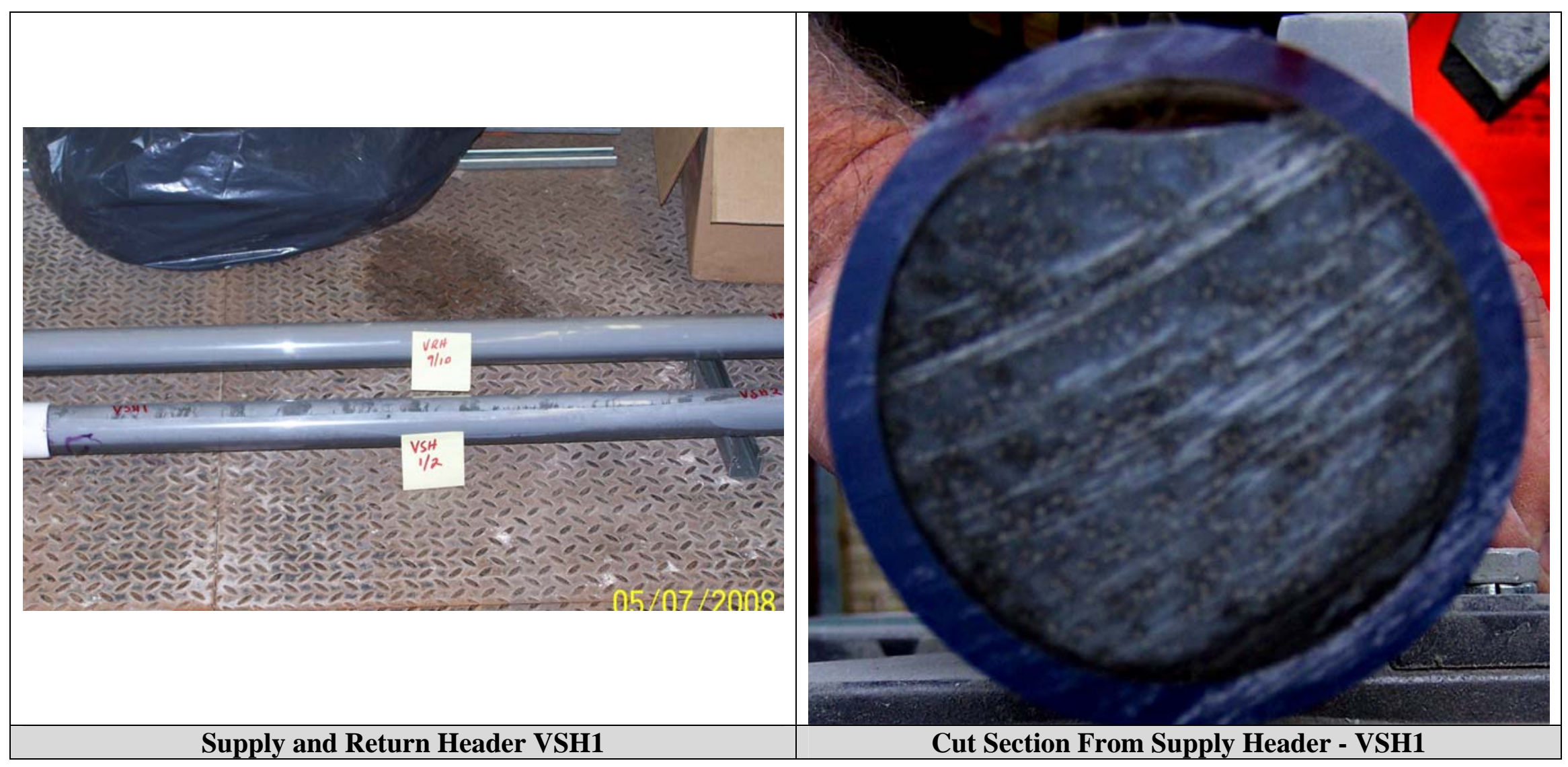

Figure 3-11 Voids in Horizontal Piping VSH1 in the Vertical Cooling Coil Assembly 


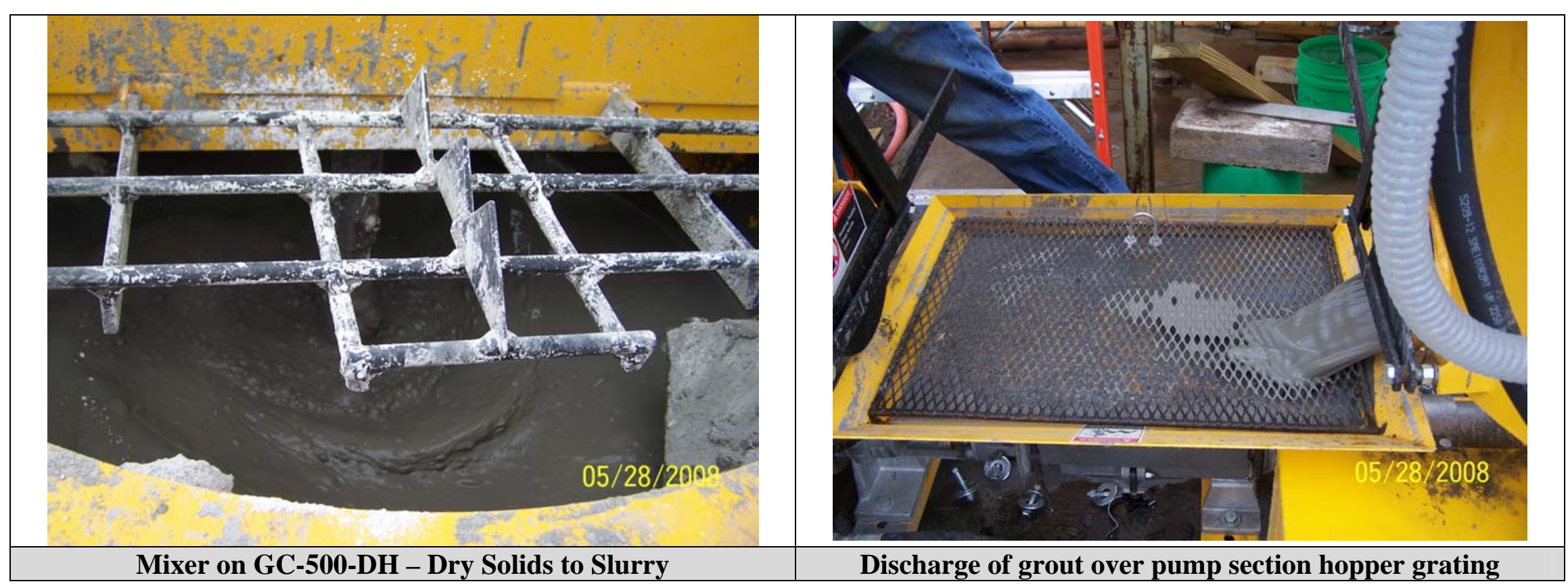

Figure 3-12 Process Locations that Lead to Air Entrainment 


\subsection{Horizontal Cooling Coil Assembly}

The controlled operation of making each 38 gallon batch and then pumping the grout to the 500 gallon mixing tank was very successful and minimized the stress on the operating crew. Operation of the 500 gallon mixing tank containing nine 38 gallon batches showed that this grout composition can be mixed for at least an hour and fifteen minutes without any concern of physical property changes that would impact mixing or transport. Miscellaneous pictures taken before, during and after the horizontal cooling coil assembly run are provided in Reference 16.

The operational data, pressure and flow, during the filling of the assembly are shown in Figure 3-13. The flow rate was initially targeted for $20 \mathrm{gpm}$, but the operator ran the process at higher rate of approximately 26 gpm. A review of the pressure data indicates that it started to stabilize at between nine to eleven minutes into the run, indicating that the cooling coils were filled with the batched grout. The maximum pressure at the cooling coil assembly located outside was approximately 120 psig, which was below the design pressure of the Type I SRS cooling coils. The pump discharge pressure gage reached a maximum of 168 psig at approximately the same time the 120 psig was observed in the cooling coil assembly. The temperature of the grout being pumped into the assembly was $38^{\circ} \mathrm{C}$. The flow measurement was taken seven minutes after the contents in the 500 gallon tank began to be pumped out and the flow time was 24 seconds, which was within the acceptable flow time for this grout. 
Rev. 0

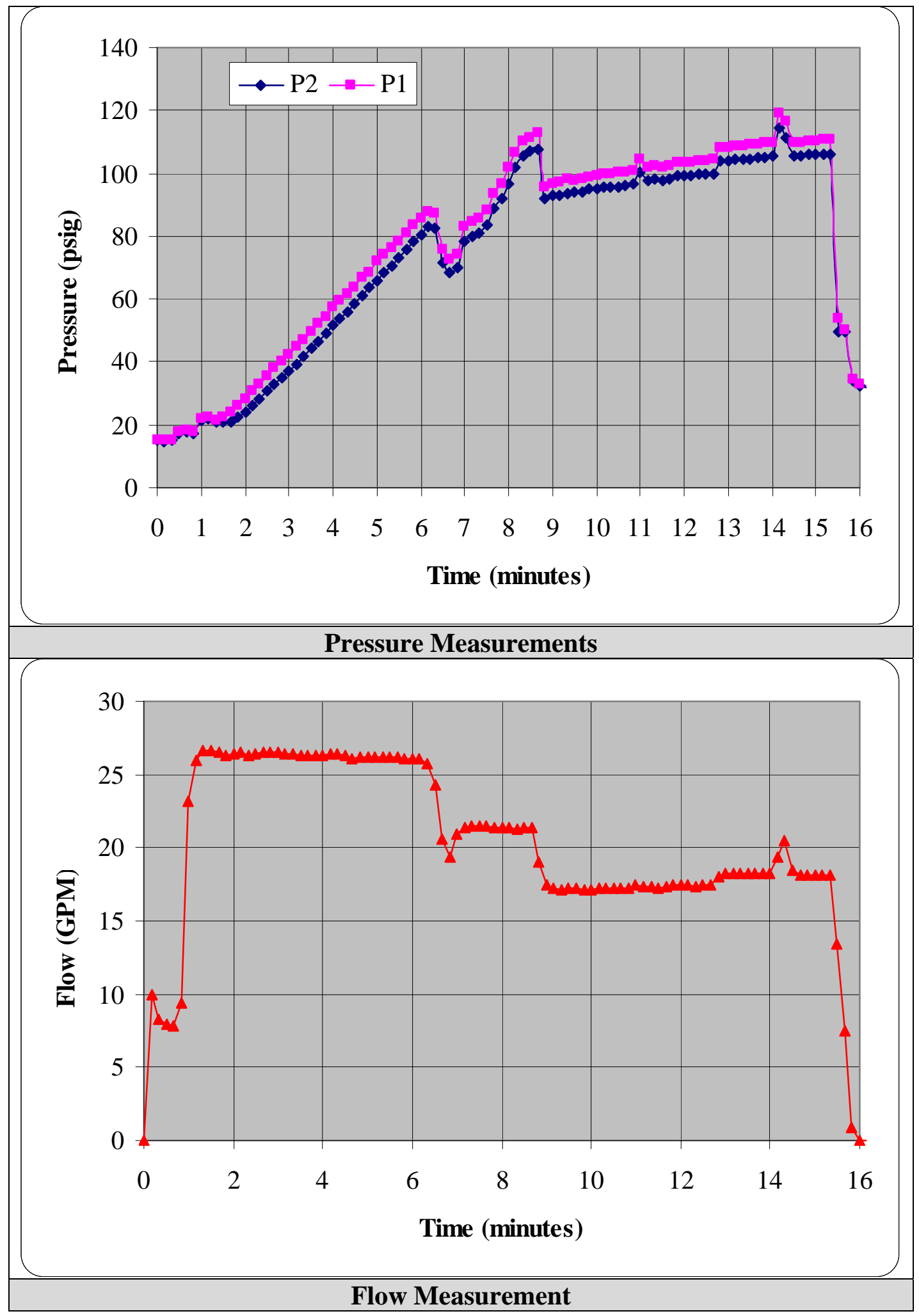

Figure 3-13 Horizontal Cooling Coil Assembly Process Parameters 
Sampling of the discharge occurred over a period of 7.5 minutes, resulting in sixteen samples. The grout discharging the cooling coil assembly is shown in Figure 3-14. Visually, the grout looked very smooth and consistent throughout the run, after the first sample had been pulled. The water content and density of the cured grout are provided in Figure 3-15. The first sample ( $\mathrm{t}$ = nine minutes into the run) was not analyzed because it contained mostly water. The remaining discharged and baseline samples when cured did not have any bleed water. Based on the water content data, 1.5 minutes (total run time of 10.5 minutes) after the grout was first observed to be leaving the discharge of the assembly, the grout in the assembly contained that of the batched material. In essence, the mixing zone, given this pumping condition, coincidently required approximately 35 gallons of additional grout over that of the grout required to fill the cooling coil assembly (total assembly volume was approximately 200 gallons). This quantity of grout compares exactly to the vertical cooling coil assembly, though the flow rates and piping configurations are very different. The actual mixing zone for the horizontal cooling coil assembly is smaller than that of the vertical cooling coil assembly, since the volume of grout in the horizontal cooling assembly is much greater than that of the vertical cooling coil assembly. The velocity of the grout most likely had an influence on the mixing zone, but is not quantified in this report. All of the discharge sample densities, except for the last sample, were greater than the baseline density. All of the grout densities, except the last discharge sample, from this test exceeded the bench scale test density of $2.07 \mathrm{~g} / \mathrm{ml}$ [5], which indicates that the discharge samples contained less air than either the bench scale or baseline densities.

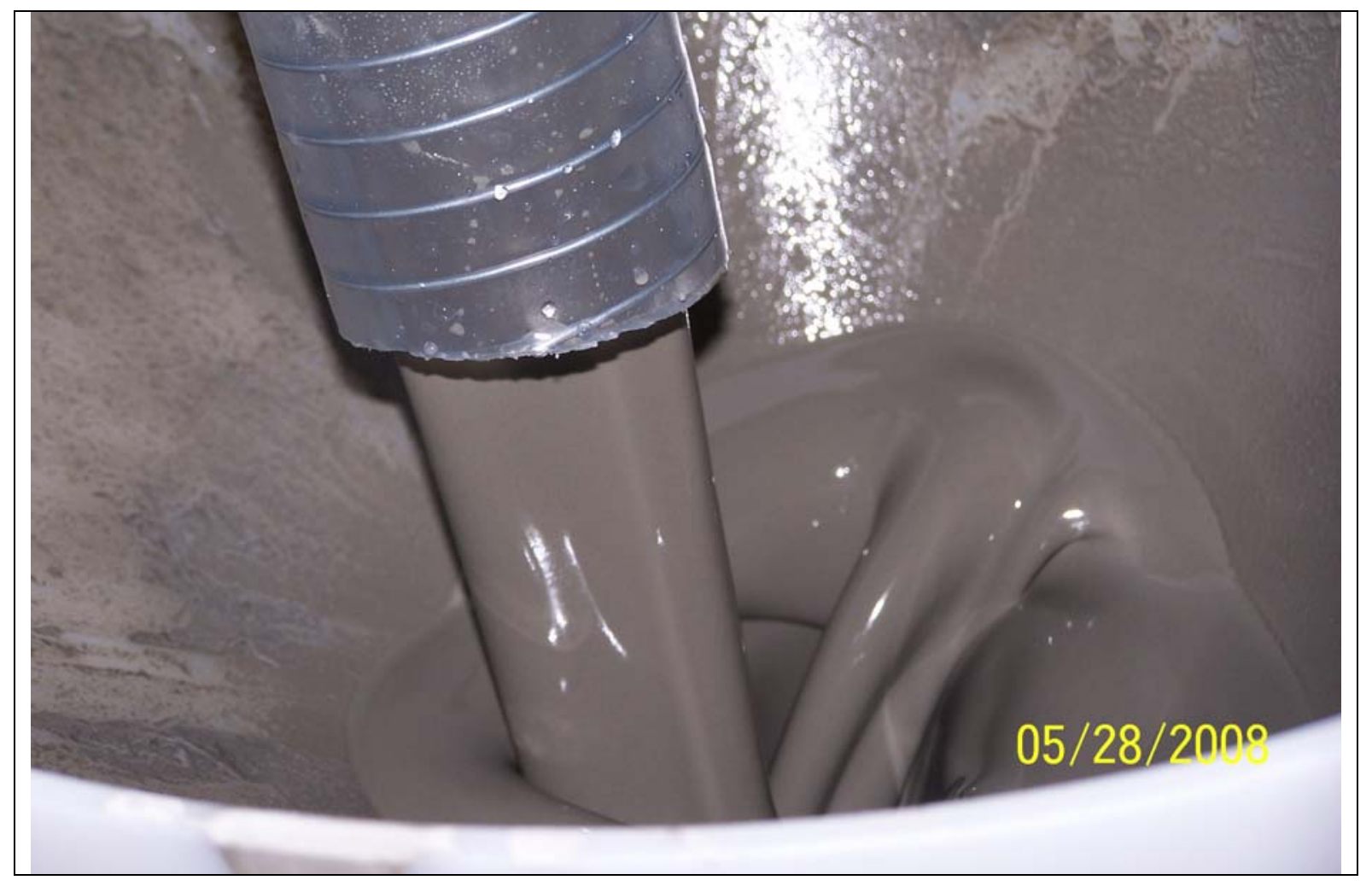

Figure 3-14 Typical Grout Discharging the Horizontal Cooling Coil Assembly 


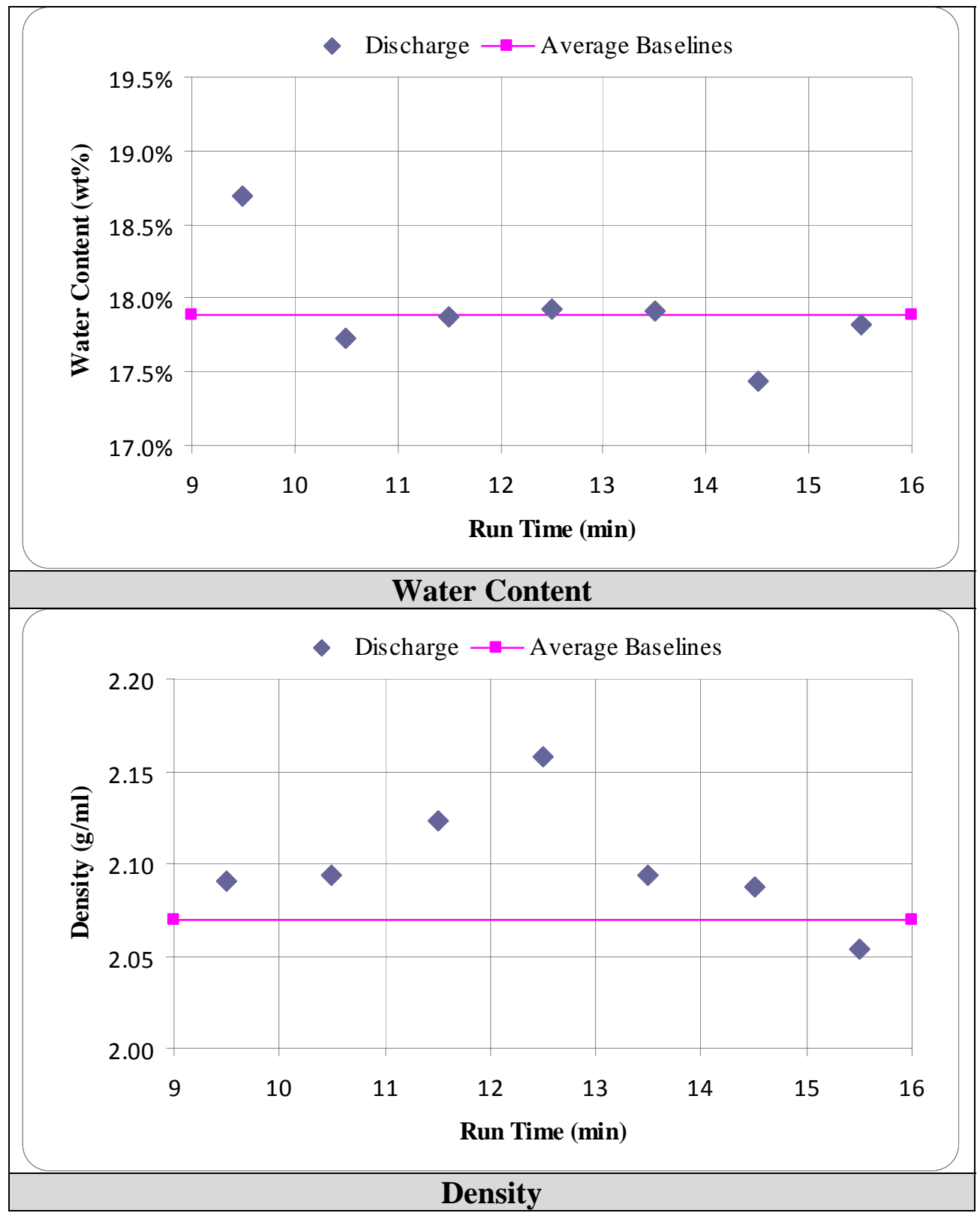

Figure 3-15 Physical Properties of Discharged Grout for the Horizontal Cooling Coil Assembly

Sectioning of various locations in the vertical runs showed them to be filled completely with grout and with hardly any noticeable air voids. Examples of these vertical sections are shown in Figure 3-16 and Figure 3-17. Upon filling of the horizontal sections of piping, visual observations were made using the sections of transparent piping and there were no observable air voids on top of the lines. Visual observations were made the next morning and they showed that the air in the grout had traveled to the tops of the horizontal piping. The ability for the air to move upward leads one to conclude that this grout did not set immediately. For the horizontal runs in the outside assembly, over 99\% of the sectioned locations were observed to be solid in nature, as shown in Figure 3-18 and Figure 3-19. Upon closer inspection, one can see a very 
small rough area, much less than four volume percent in each of these photographs. The rough areas are located on the outer diameter and on the top of the pipe. Figure 3-20 is a piece of cured grout that was extruded from the pipe to expose the top surface of the grout and a cross section was cut to examine the rough area. This piece of grout also contained a visible void, that if cut, would have looked like what is in Figure 3-21. Figure 3-20 is typical of how the top surface of the grout looked in the horizontal sections of piping and is fairly uniform. In Figure 3-21, there is a large and small void. A walk down of the 380 feet of transparent piping yielded four large type voids approximately 1.25 inches long and 28 small voids 0.25 to 0.5 inches long. Assuming the voids have the longest lengths for their size, the length of the voids add up to 19 inches, which is less than $0.5 \%$ of the length of transparent piping. Additional photographs of the sectioned cured grout in the horizontal cooling coil assembly can be found in Reference 11. 


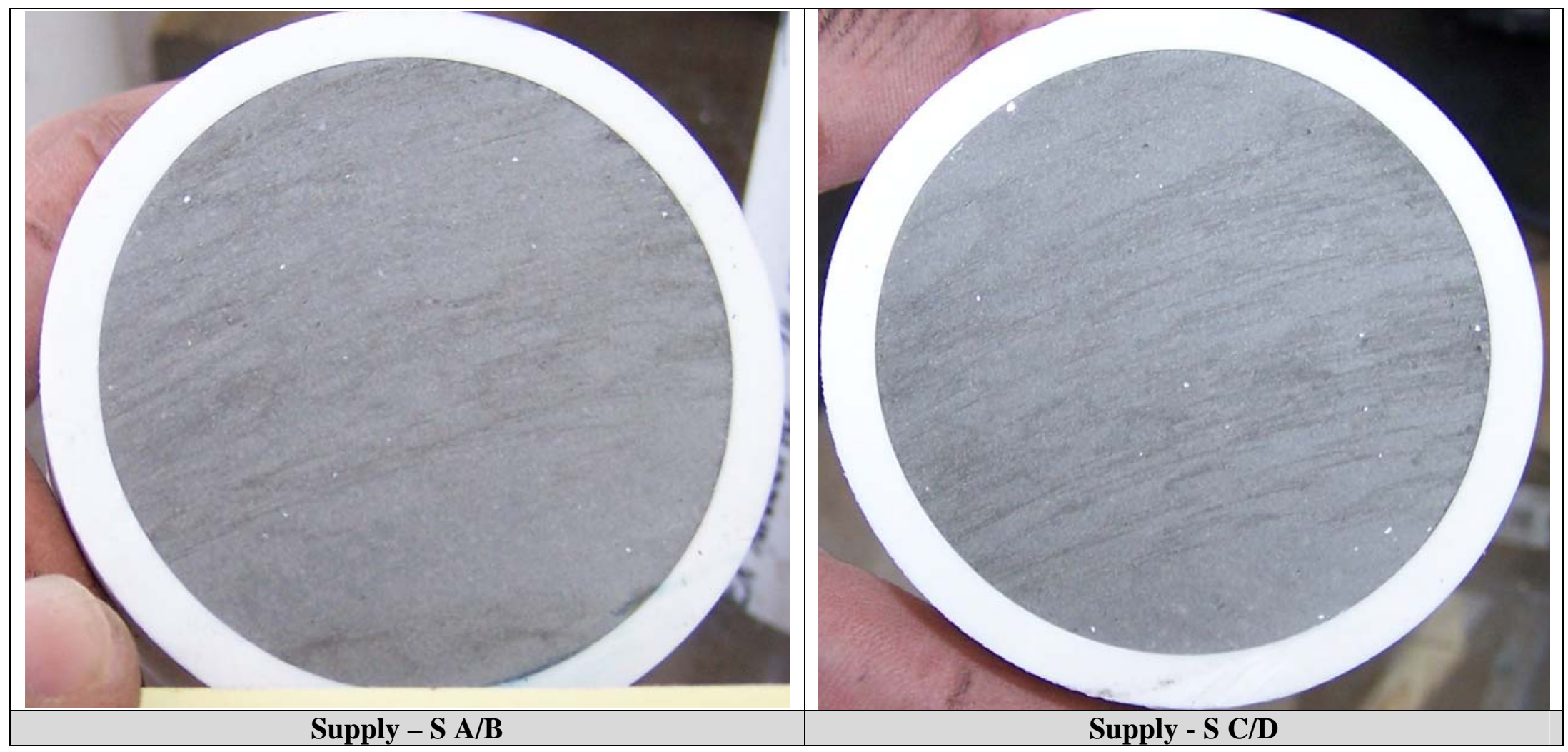

Figure 3-16 Sectioned Vertical Supply Piping - Horizontal Cooling Coil Assembly 


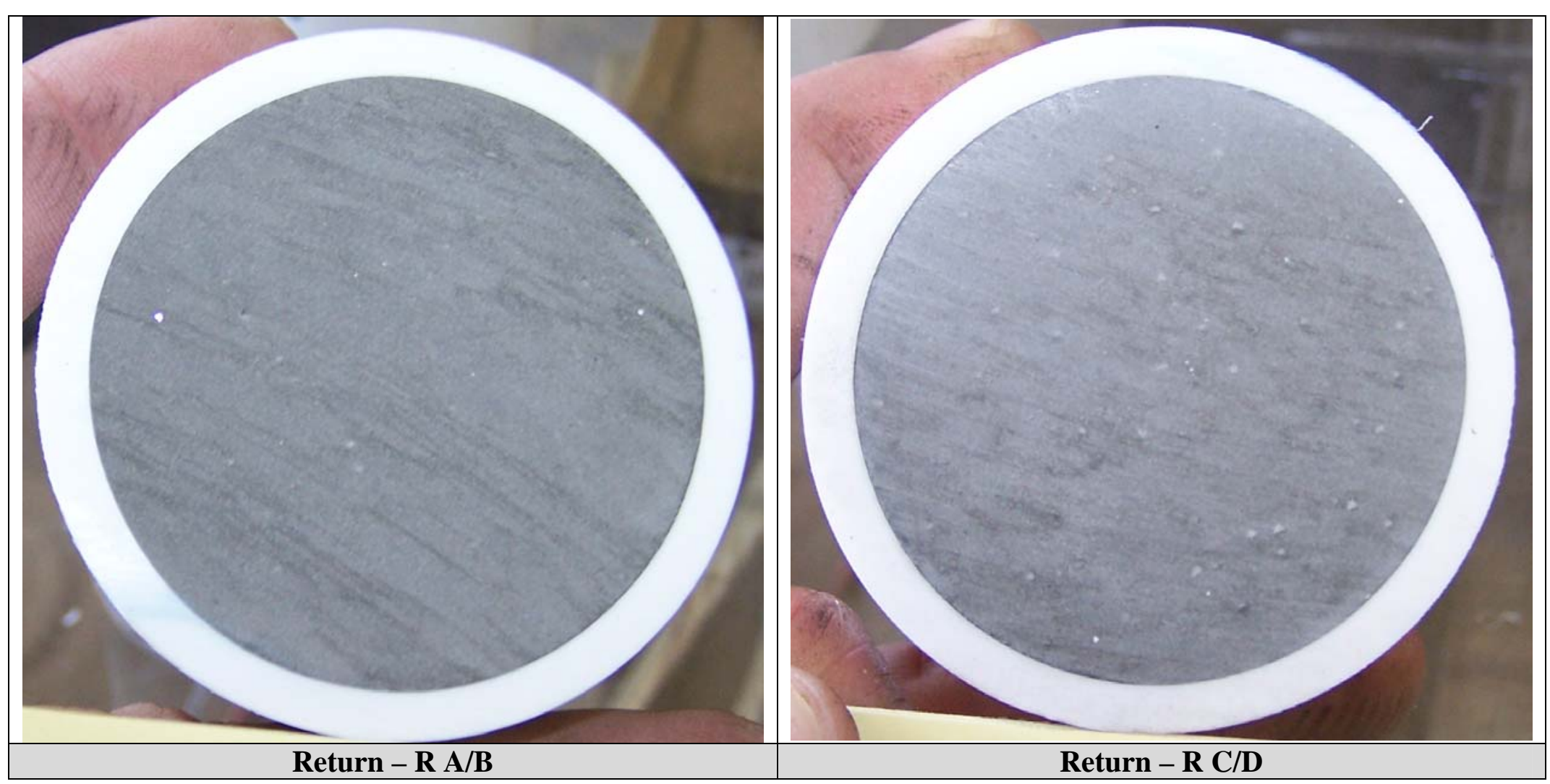

Figure 3-17 Sectioned Vertical Return Piping - Horizontal Cooling Coil Assembly 


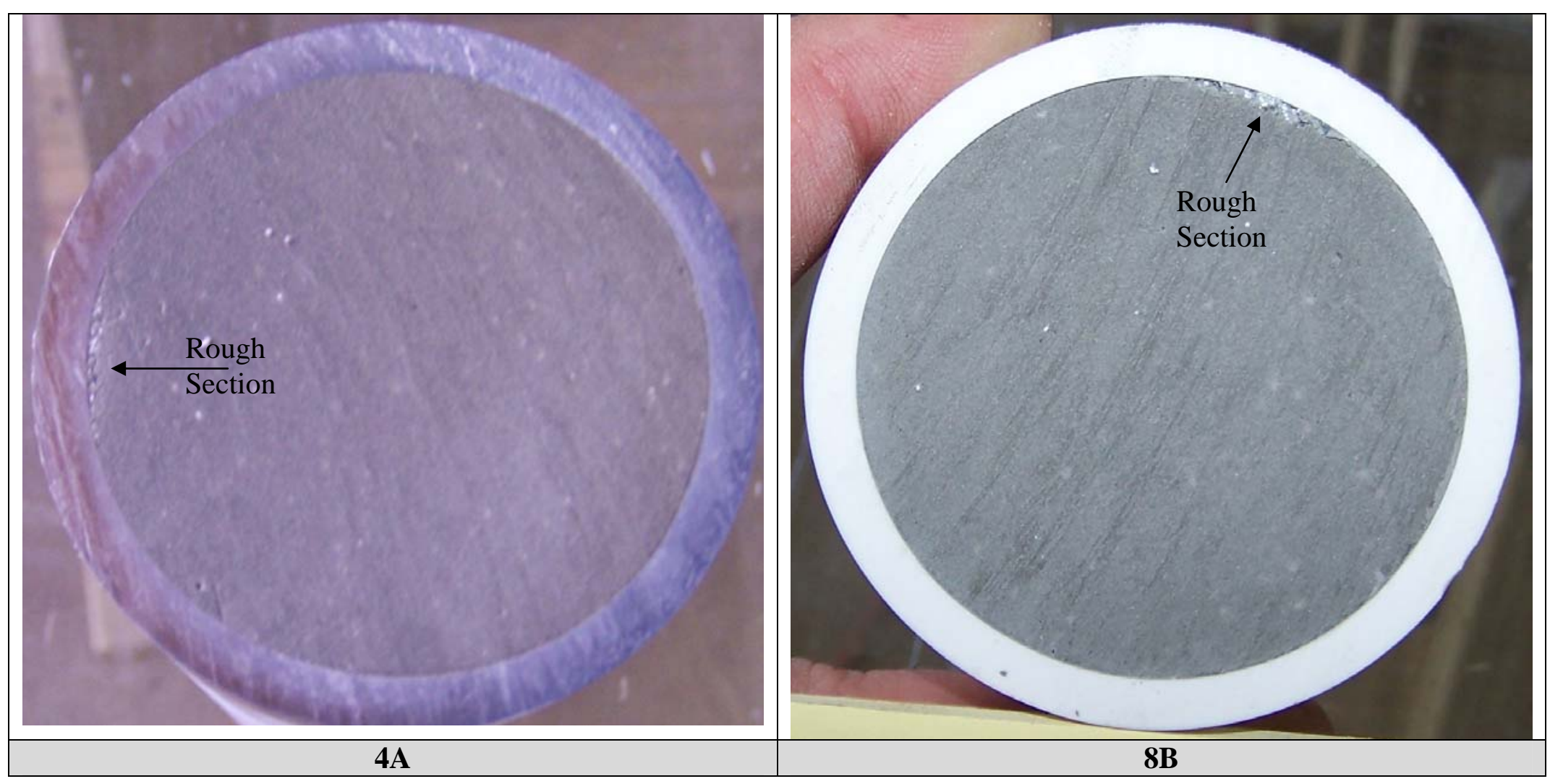

Figure 3-18 Sectioned 4A and 8B Horizontal Piping - Horizontal Cooling Coil Assembly 


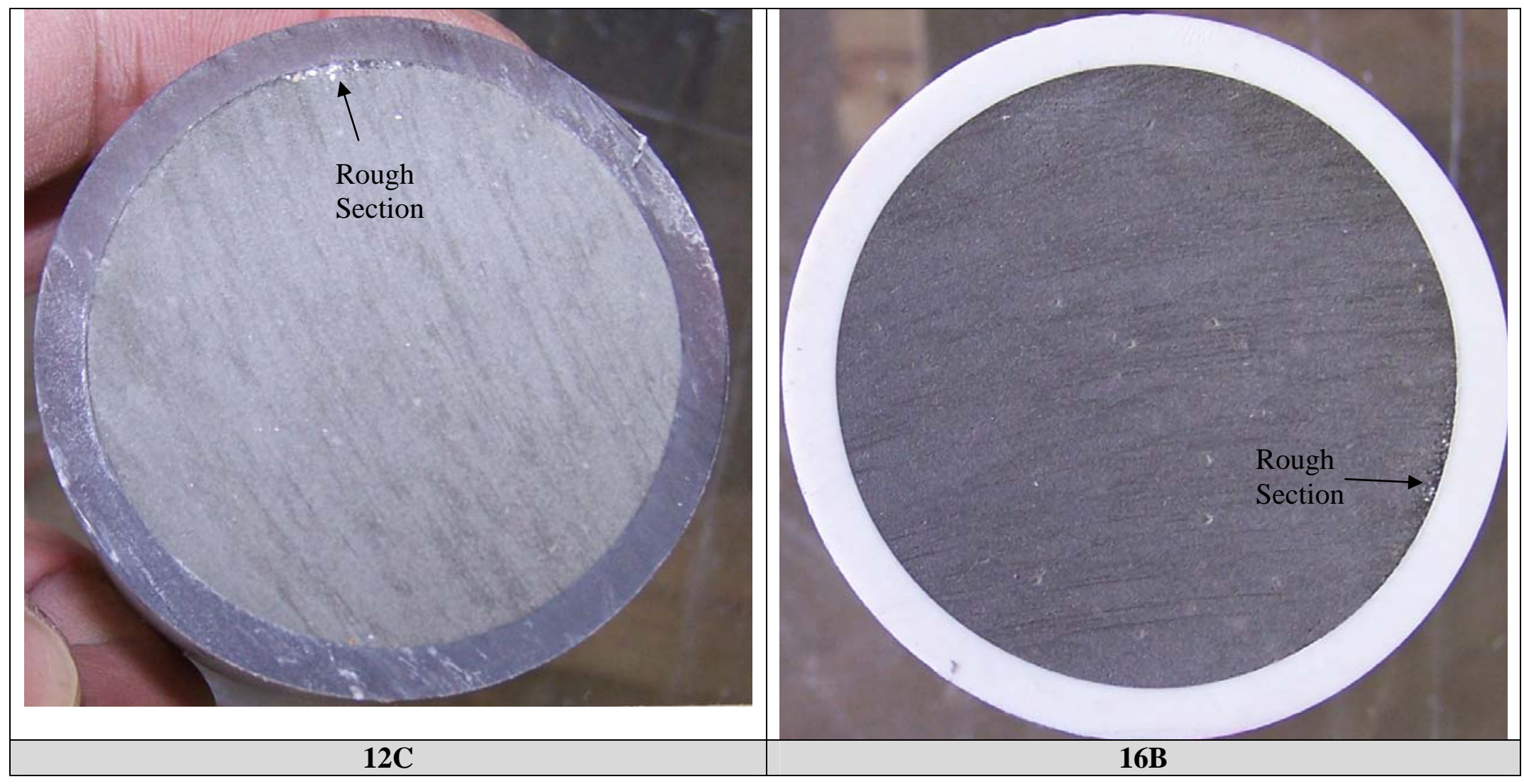

Figure 3-19 Sectioned 12C and 16B Horizontal Piping - Horizontal Cooling Coil Assembly 
WSRC-STI-2008-00298

Rev. 0

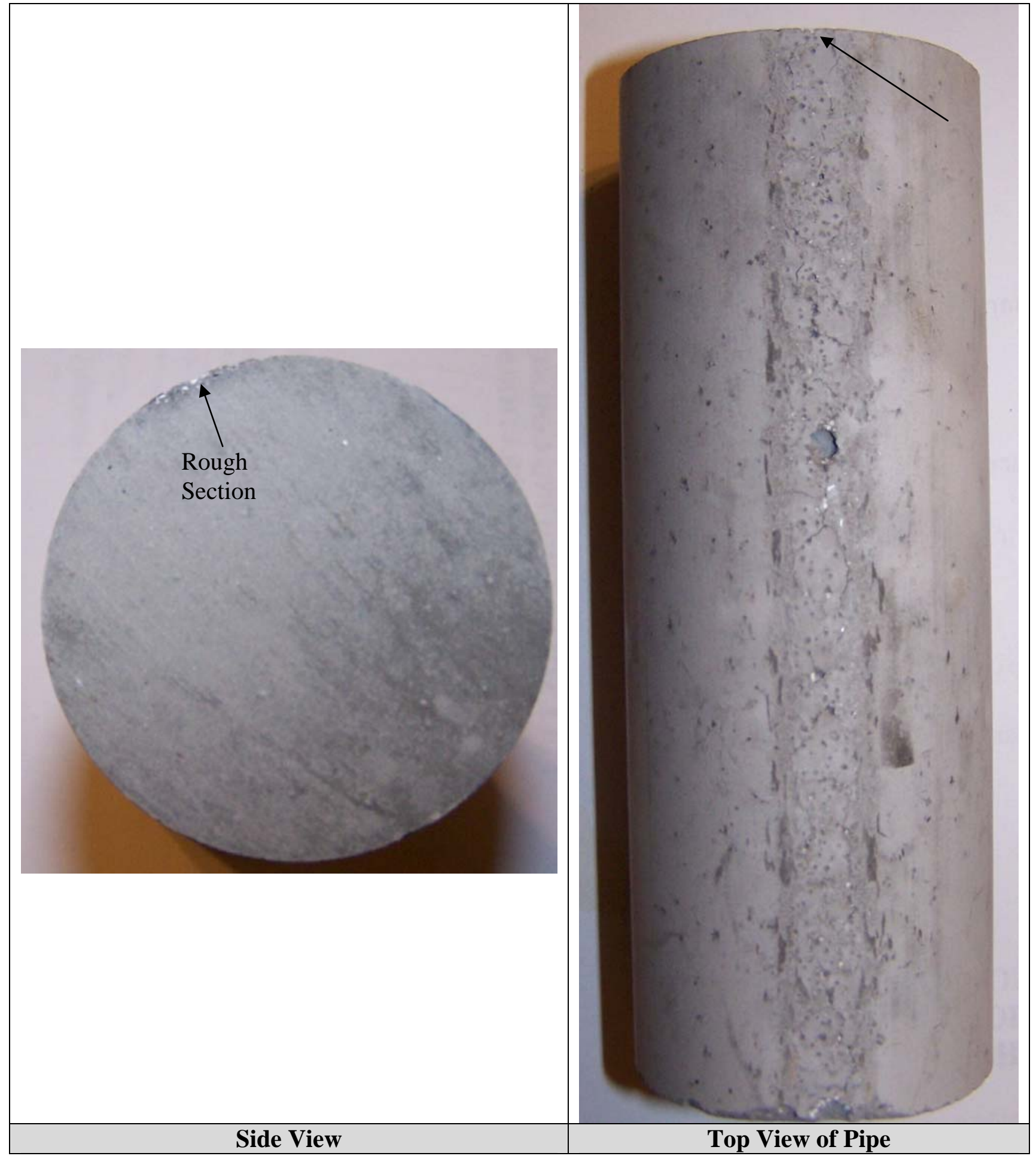

Figure 3-20 Horizontal Section 8B - Horizontal Cooling Coil Assembly 


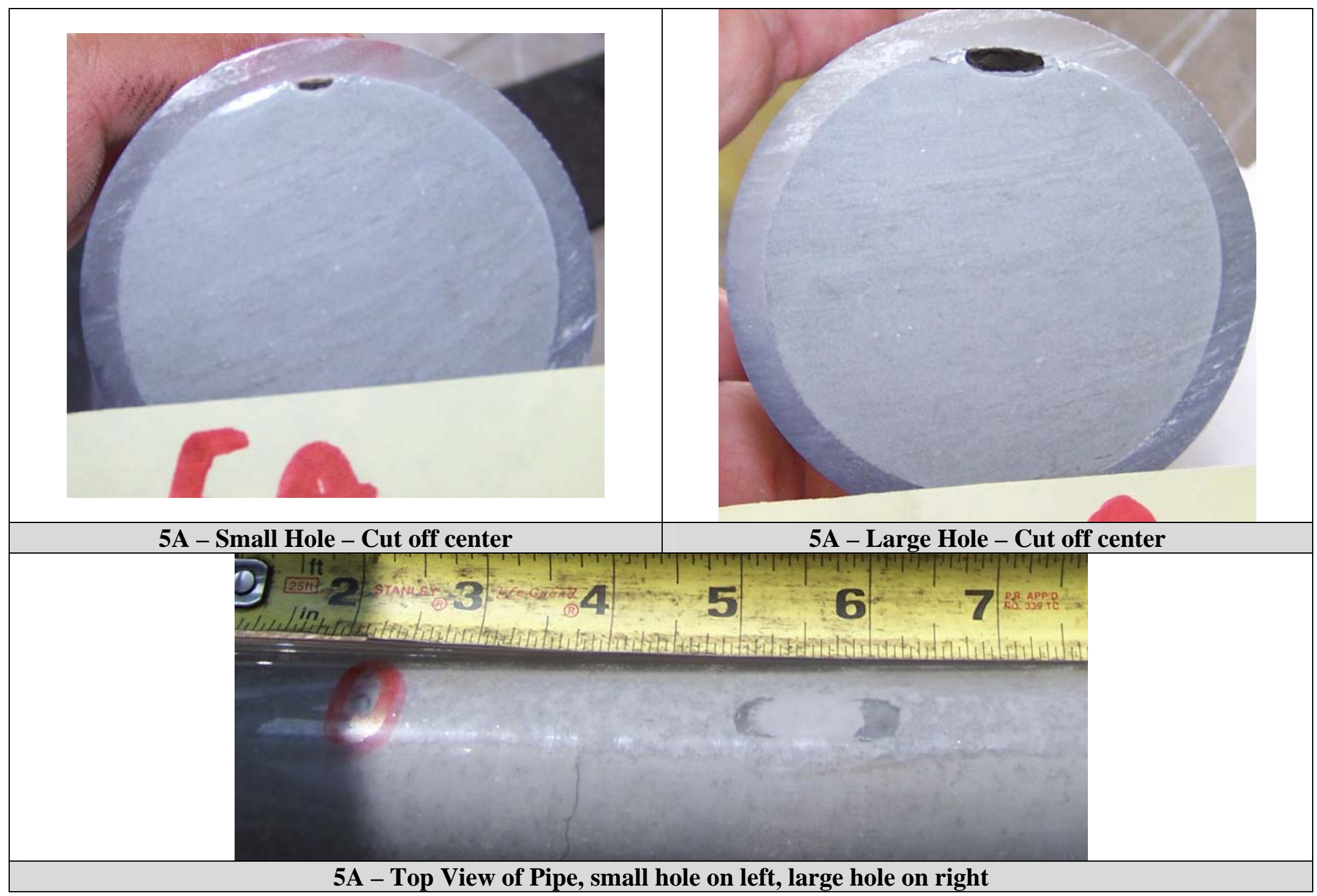

Figure 3-21 Sectioned 5A Horizontal Piping - Horizontal Cooling Coil Assembly 


\subsection{CONCLUSIONS}

The results of the full scale cooling coil operations to support final closure of the HLW tanks at the Savannah River Site are provided below:

- The first task objective was fulfilled. Different types of simulated field conditions, using commercially available equipment, were employed successfully in filling the full scale cooling coils assemblies.

- The second task objective was fulfilled. Placement flow cone measurements were made and the batched grouts satisfied the flow requirements. Water content and density of cured grout samples were also measured and they provided insight on when the grout in the cooling coil assembly was full of the batched grout. Process measurements, flow and pressure were also obtained. The combination of these two measurements can also be used to determine when the grout in the cooling coil assembly is full of the batched grout.

- The horizontal cooling coil assembly is hydraulically conservative to any of the Type I tank cooling coil assemblies. The length of piping in the horizontal cooling coil assembly was approximately 1100 feet of two inch schedule 40 piping. The maximum pressure in the assembly did not exceed the plant design pressure of 150 psig at $20 \mathrm{gpm}$.

- The mixing equipment used in this task easily incorporated the dry materials into a slurry.

- A vigorous mixing time of at least six minutes is recommended for this grout in order to provide a flowable grout that satisfies the flow cone requirements. Note that the flow cone measurements were performed at 35 to $38{ }^{\circ} \mathrm{C}$, which were the process temperatures and not the recommended temperature of the vendor, which was between 21 to $25^{\circ} \mathrm{C}$.

- The working time of this grout was tested at 1.25 hours and there were no observable changes in the flowability of this grout. It is believed that this working time is longer.

- If the SRS HLW cooling coil assemblies are void of liquid, it is recommended that the cooling coils be filled with water prior to filling with grout, to help ensure that a liquid to liquid interface will be maintained during the grout fill. This is based on visual observations while water was being used to remove the air from the cooling coils. The interaction between the air and water at lower flow rates resulted in trapped air in the upper $180^{\circ} 2$-foot radius bends. Testing would be required to determine the impact of void-grout processing, because the void-grout interface and quantity of trapped air is unknown. At least two cooling coil assembly volumes of water and a flow rate of at least 28 gpm are recommended to make the cooling coil assembly full of water.

- A vent line was installed to remove the air between the grout hose and assemblies. This results in a grout-liquid interface and is recommended.

- The grout flow rate for the vertical and horizontal cooling coil assemblies was approximately six and twenty gpm, respectively. In both cases, the mixing zone of the water/grout interface was approximately 35 gallons. This means that an additional 35 gallons over that required to fill the cooling coil assembly is required for the grout contents in the cooling coil assembly to be the same as that of the batched grout. It is recommended that the higher flow rate be used to fill all of the cooling coil assemblies because the higher flow rate should provide a shorter mixing zone between the grout and water. 
- The volume percent of air in the vertical sections for both the vertical and horizontally cooling coil assemblies was much less than four volume percent, based on visual observations.

- Air entrainment into the grout occurred at the following processing steps: (1) during mixing the dry solids into a slurry, (2) during vigorous mixing, (3) during discharge of the grout out of the mixing tank and into the hopper inlet, and (4) during pumping where a fraction of the flow was recirculated back to the inlet of the hopper.

o Filling of the vertical cooling coil assembly had all four of the air entrainment processing steps described above and this mode of operation is not recommended. Air gaps existed in the horizontally sections of piping that may have exceed four volume percent.

o During the filling of the horizontal cooling coil assembly steps (3) and (4) were removed. Slight agitation in the 500 gallon mixing tank helped to remove some of the entrained air. The grout was pumped directly to the assembly, without any recirculation flow. Horizontal piping did not exceed the four volume percent of void.

- Entrainment of air can be reduced by using a large batch tank to hold enough grout to completely fill a cooling coil assembly and by enclosing the pump suction.

- After filling the horizontal cooling coil assembly, there were no observable air voids in the horizontal sections of piping. Observations of the horizontal lines the day after filling showed air in the top sections of the horizontal piping, which indicated that the grout does not cure quickly during field conditions.

- The maximum temperature of the curing grout peaked around 9.5 hours after the cooling coil assembly was filled. This data compared well to the peak observed in the normalized heat flow [5].

- The insulated pipe showed a much larger maximum temperature than an un-insulated pipe.

- The positive progress cavity pump provided excellent pumping operations throughout the testing.

- There was no feedback loop to control flow to the assemblies. Rather, this was manually controlled for both tests. 


\subsection{RECOMMENDATIONS}

Recommendations from this test are as follows:

- Perform bench scale vane tests to determine the maximum working time of the grout and to quantify temperature effects on the flow cone results.

- Perform ASTM C 9393 flow method to verify flowability of grout during actual placement.

- Install water flush lines, but the urgency to immediately flush the line may not be required, due to the working time of this grout. Vane method under quasi-static conditions should be performed on the bench scale to determine how the shear stress changes with time. This data could potentially be used to determine when flushing will be required or when pumping is still achievable.

- If tank grout is used to support the cooling coils, there could be an issue with the maximum temperature that would be observed in the curing of this grout. Calculations may be required to determine if boiling will occur. If so, grout formulation or additional testing of filling of the cooling coils as supported in the facility may be required.

- The methodology of filling the cooling coil assemblies may require additional studies to determine the maximum number of cooling coils that can be filled at any one time due to heat generation and/or for the requirements for active ventilation to remove heat.

- This grout can be used to fill broken cooling coil assemblies that are still attached to the supply/return header. If such operations occur, it is recommended that a ball valve or blank be used to isolate the line after the fill is complete.

- Cooling coil assemblies should be full of water prior to grout placement. If cooling coil assemblies are void of water, then fill the coils using at least twice the volume of the cooling coils and a flow rate of at least $28 \mathrm{gpm}$. A vent line should be attached to the supply line to vent out the air in the grout hose during grout placement.

- Use flow and pressure measurements during grout operations. A grout flowrate of 20 gpm or higher is recommended. The higher flow rate will reduce the mixing zone. If the excess grout is pumped back into the tank, this will help reduce the heat load. Stable pressure readings for a constant flow rate will indicate a cooling coil is full of the batched grout.

- A mixing system that can blend and process the quantity of material required to fill at least one or more assemblies should be considered. The mixing system should be designed to blend in the solids and to minimize air entrainment. To further remove entrained air in the grout, the tank could be placed under a vacuum. This would require additional testing to determine operating parameters. A minimum of six minutes of vigorous mixing is recommended for this grout to become flowable, after all the solids have been added. During pump down of this grout, recommend that the agitator be deenergized. If necessary, the tank could also be used to control the temperature of the batch.

- The use of a positive progress pump for pumping the grout and water into the cooling coils is recommended. Pump speed should be controlled via a flow meter.

- A water system must be installed for cleaning the mixing/pumping system. This waste water can easily be managed by separating out the solids and $\mathrm{pH}$ correcting the solution. 


\subsection{REFERENCES}

1 Adkins, B. J., 2007. "Develop Cooling Coil Closure Technology Grout Formulations," Technical Task Request, HLE-TTR-2007-007, May 1, 2007, Washington Savannah River Company, Aiken SC 29808.

2 Harbour, J. R. and E. K. Hansen, "Task Technical and QA Plan: Cooling Coil Grout and Technology Development” WSRC-RP-2007-00384, Rev. 2, March 2008.

3 Martin, B. A., 2007. "Defining Attributes Leading to Successful Closure of Tank Cooling Coils,” LWO-PIT-2007-00021, Washington Savannah River Company, Aiken SC 29808.

4 Adkins, B. J., 2007. "Calculation of Permissible Rheology Range for Cooling Coil Grout,” April 9, 2007, G-CLC-G-00111, Revision 0, Washington Savannah River Company, Aiken SC 29808.

5 Harbour, J. R., V. J. Williams, and E. K. Hansen, “Closure of HLW Tanks - Formulation for a Cooling Coil Grout”, WSRC-STI-2008-00172, Rev. 0, April 2008.

6 Hansen, E. K., "Statement of Work for Design and Construction of Cooling Coils", PR\#7P1998, 3/21/2008.

7 ASTM C939-02, "Standard Test Method for Flow of Grout for Preplacement-Aggregate Concrete (Flow Cone Method)".

8 Hansen, E. K. and Harden, J., "Run Plan for Vertical Cooling Coils”, SRNL-PSE-200800078, Rev. 0, 4/29/2008.

9 Hansen, E. K. and Harden, J. "Run Plan for Horizontal Cooling Coils”, SRNL-PSE-200800096, Rev. 0, 5/28/2008.

10 Hansen, E. K., "Pictures of Vertical Cut Sections From the Vertical Cooling Coil Test at CETL, 2008”, SRNL-PSE-2008-00121, Rev. 0, 6/11/2008.

11 Hansen, E. K., "Pictures of Cut Sections From the Horizontal Cooling Coil Test at CETL 2008”, SRNL-PSE-2008-00122, Rev. 0, 6/11/2008.

12 Hansen, E. K., "Digital Radiographs of Grout - Vertical Fill at CETL", SRNL-PSE-200800120, Rev. 0, 6/11/2008.

13 D115048, "Savannah River Plant 200 Area BLDG. 241 F\&H Vertical Cooling Coils For Waste Storage Tank", latest revision.

14 D116001, "Savannah River Plant 200 Area BLDG. 241 F\&H Horizontal Cooling Coil For Waste Storage Tank", latest revision.

15 Hansen, E. K., "Miscellaneous Pictures From the Horizontal Cooling Coil Test at CETL, 2008”, SRNL-PSE-2008-00128, Rev. 0, 6/11/2008.

16 Hansen, E. K., "Miscellaneous Pictures From the Horizontal Cooling Coil Test at CETL, 2008”, SRNL-PSE-2008-00129, Rev. 0, 6/11/2008.

17 Hansen, E. K.,"Miscellaneous Pictures From the Vertical Cooling Coil Test at CETL, 2008”, SRNL-PSE-2008-00130, Rev. 0, 6/11/2008.

18 Hansen, E. K., "Pictures of Looped Cut Sections From the Vertical Cooling Coil Test at CETL, 2008”, SRNL-PSE-2008-00131, Rev. 0, 6/11/2008.

19 Hansen, E. K., "Pictures of the Horizontal Sectioned Cuts from the Vertical Cooling Coil Test at CETL, 2008”, SRNL-PSE-2008-00132, Rev. 0, 6/11/2008. 


\section{Distribution:}

B. J. Adkins, 766-H

A. B. Barnes, 999-W

R. L. Boisvert, 704-26F

A. D. Cozzi, 999-W

D. A. Crowley, 999-W

N. R. Davis, 766-H

R. D. Deshpande, 766-H

A. P. Fellinger, 723-A

A. Ganguly, 730-4B

B. J. Giddings, 786-5A

J. C. Griffin, 773A

E. K. Hansen, 999-W

J. R. Harbour, 999-W

C. C. Herman, 999-W

W. L. Isom, 704-26F

R. C. Jolly, 704-70F

C. A. Langton, 773-43A

D. B. Little, 766-H

M. J. Mahoney, 766-H

J. E. Marra, 773A

S. L. Marra, 773A

B. A. Martin, 766-H

T. C. Robinson, 766-H 